\title{
Particulate Organic Matter Distributions in the Water Column of the Chukchi Sea During Late Summer
}

\author{
Miguel A. Goni \\ Lauren W. Juranek \\ Rachel E. Sipler \\ Virginia Institute of Marine Science \\ Kylie A. Welch
}

Follow this and additional works at: https://scholarworks.wm.edu/vimsarticles

Part of the Oceanography Commons

\section{Recommended Citation}

Goni, Miguel A.; Juranek, Lauren W.; Sipler, Rachel E.; and Welch, Kylie A., Particulate Organic Matter Distributions in the Water Column of the Chukchi Sea During Late Summer (2021). JGR Oceans, 126(e2021JC017664). doi: 10.1029/2021JC017664

This Article is brought to you for free and open access by the Virginia Institute of Marine Science at W\&M ScholarWorks. It has been accepted for inclusion in VIMS Articles by an authorized administrator of W\&M ScholarWorks. For more information, please contact scholarworks@wm.edu. 


\section{JGR Oceans}

\section{RESEARCH ARTICLE \\ 10.1029/2021JC017664}

Special Section:

Uncovering the hidden links between dynamics, chemical, biogeochemical and biological processes under the changing Arctic

Key Points:

- There are marked contrasts in particulate organic matter (POM) distributions and compositions associated with distinct water masses on the northeast Chukchi Shelf

- Despite high stratification, wind events elicit increases of planktonderived POM in subsurface regions of the water column

- Turbid bottom waters display elevated concentrations of mineralrich particles enriched in altered POM likely resuspended from the seabed

Supporting Information: Supporting Information may be found in the online version of this article.

Correspondence to:

M. A. Goni,

miguel.goni@oregonstate.edu

Citation:

Goñi, M. A., Juranek, L. W., Sipler, R. E., \& Welch, K. A. (2021). Particulate organic matter distributions in the water column of the Chukchi Sea during late summer. Journal of Geophysical Research: Oceans, 126, e2021JC017664. https://doi. org/10.1029/2021JC017664

Received 11 JUN 2021 Accepted 16 AUG 2021

\section{Particulate Organic Matter Distributions in the Water Column of the Chukchi Sea During Late Summer}

\author{
Miguel A. Goñi ${ }^{1} \mathbb{E}^{\text {, Lauren W. Juranek }}{ }^{1} \mathbb{C}^{\mathbb{D}}$, Rachel E. Sipler ${ }^{2,3}$, and Kylie A. Welch ${ }^{1}$ \\ ${ }^{1}$ College of Earth, Ocean, and Atmospheric Sciences, Oregon State University, Corvallis, OR, USA, ${ }^{2}$ Virginia Institute of \\ Marine Sciences, College of William \& Mary, Williamsburg, VA, USA, ${ }^{3}$ Now at Bigelow Laboratory for Ocean Sciences, \\ East Boothbay, ME, USA
}

\begin{abstract}
Two oceanographic cruises were completed in September 2016 and August 2017 to investigate the distribution of particulate organic matter (POM) across the northeast Chukchi Shelf. Both periods were characterized by highly stratified conditions, with major contrasts in the distribution of regional water masses that impacted POM distributions. Overall, surface waters were characterized by low chlorophyll fluorescence $\left(\mathrm{Chl} \mathrm{Fl}<0.8 \mathrm{mg} \mathrm{m}^{-3}\right)$ and particle beam attenuation $\left(c_{\mathrm{p}}<0.3 \mathrm{~m}^{-1}\right)$ values, and low concentrations of particulate organic carbon ( $\mathrm{POC}<8 \mathrm{mmol} \mathrm{m}^{-3}$ ), chlorophyll and pheophytin $\left(\mathrm{Chl}+\right.$ Pheo $\left.<0.8 \mathrm{mg} \mathrm{m}^{-3}\right)$, and suspended particulate matter $\left(\mathrm{SPM} \sim 2 \mathrm{~g} \mathrm{~m}^{-3}\right)$. Elevated $\mathrm{Chl} \mathrm{Fl}$ and $\mathrm{Chl}+\mathrm{Pheo}\left(\sim 2 \mathrm{mg} \mathrm{m}^{-3}\right)$ values measured at mid-depths below the pycnocline defined the subsurface chlorophyll maxima (SCM), which exhibited moderate POC $\left(\sim 10 \mathrm{mmol} \mathrm{m}^{-3}\right), c_{\mathrm{p}}\left(\sim 0.4 \mathrm{~m}^{-1}\right)$ and SPM $\left(\sim 3 \mathrm{~g} \mathrm{~m}^{-3}\right)$. In contrast, deeper waters below the pycnocline were characterized by low $\mathrm{Chl} \mathrm{Fl}$ and $\mathrm{Chl}+$ Pheo $\left(\sim 0.7 \mathrm{mg} \mathrm{m}^{-3}\right)$, high $c_{\mathrm{p}}\left(>1.5 \mathrm{~m}^{-1}\right)$ and SPM $\left(>8 \mathrm{~g} \mathrm{~m}^{-3}\right)$ and elevated POC $\left(>10 \mathrm{mmol} \mathrm{m}^{-3}\right)$. POM compositions from surface and SCM regions of the water column were consistent with contributions from active phytoplankton sources whereas samples from bottom waters were characterized by high Pheo/ $(\mathrm{Chl}+\mathrm{Pheo})$ ratios $(>0.4)$ indicative of altered phytoplankton detritus. Marked contrasts in POM were observed in both surface and middepth waters during both cruises. Increases in chlorophyll and POC consistent with enhanced productivity were measured in middepth waters during the September 2016 cruise following a period of downwelling-favorable winds, and in surface waters during the August 2017 cruise following a period of upwelling-favorable winds.
\end{abstract}

Plain Language Summary We investigated the distribution and composition of particulate organic matter in waters from the northeast Chukchi Sea during two late summer periods (September 2016 and August 2017). During both cruises we measured a variety of properties (salinity, temperature, density, chlorophyll fluorescence and particle beam attenuation). We also collected individual water samples from specific depths and measured the concentrations of suspended particulate matter, particulate organic carbon and nitrogen, chlorophyll-a and pheophytin (a chlorophyll degradation product). These measurements revealed highly stratified conditions throughout the study area, with surface waters exhibiting relatively low particle and biomass concentrations, middepth waters with well-defined subsurface chlorophyll maxima and moderate biomass, and turbid bottom waters with intermediate concentrations of particulate organic carbon and elevated levels of pheophytin. Large contrasts in the composition of particulate materials in both cruises were related to the distribution of different regional water masses. In addition, we observed increases in biogeochemical tracers of phytoplankton production in response to downwelling- and upwelling-favorable wind events. Overall, our work suggests that under the right conditions, phytoplankton production may occur under highly stratified conditions both in surface and sub-surface waters, extending the productive season along Arctic marginal seas.

\section{Introduction}

Surface warming associated with increased atmospheric $\mathrm{CO}_{2}$ concentrations is occurring in the Arctic at a pace roughly double the global average (e.g., Allen et al., 2018), leading to significant decreases in sea ice extent and thickness, and changes in the timing of seasonal melt and refreeze throughout the Arctic Ocean (e.g., Fetterer et al., 2017; Stroeve \& Notz, 2018; Wood et al., 2015). The expansion of the seasonal ice zone and lengthening of the meltwater season have profound implications for the productivity and ecology of

\footnotetext{
This is an open access article under the terms of the Creative Commons Attribution License, which permits use, distribution and reproduction in any medium, provided the original work is properly cited.
} 
the Arctic Ocean (e.g., Ardyna \& Arrigo, 2020; Grebmeier et al., 2015; Huntington et al., 2020). Earlier sea ice melt and a longer open-water period can have positive feedbacks on water column conditions that can extend the growing season and result in marked increases in phytoplankton productivity if both nutrients and light are available (e.g., Ardyna et al., 2020; Arrigo et al., 2012; McLaughlin \& Carmack, 2010; Zhang et al., 2010).

Remote-sensing based observations indicate increases in the extent and duration of the open water season over the past two decades have contributed to the enhancement in net primary production along Arctic marginal seas over this period (Arrigo \& van Dijken, 2015; Lewis et al., 2020). Analyses by these authors suggest that the observed increases in net primary production over the past 10 years are driven by enhanced phytoplankton biomass, indicating that increases in nutrient supply are required to support the observed productivity increases. In inflow shelves, such as the Chukchi Shelf, advection of nutrients from the Pacific may contribute to these trends. Work by Woodgate (2018) based on mooring data from the Bering Strait indicated an increase in the Pacific inflow to the Arctic Ocean, which could represent a source for enhanced nutrient input. However, more recent studies suggest there is significant interannual variability in the northward transport across Bering Strait (e.g., Nguyen et al., 2020) and no clear long-term trends in the supply of nutrients from the Pacific (e.g., S. Danielson et al., 2021).

Enhancement in the vertical mixing of nutrients into the euphotic zone is another mechanism that can explain increases in net primary productivity, especially in the shallow Arctic shelves and marginal seas (see review by Ardyna \& Arrigo, 2020). In terms of predicting the effects of climate change on Arctic Ocean ecosystems, it important to understand how physical drivers (e.g., stratification and mixing) control key biogeochemical processes (e.g., dissolved nutrient supply) that impact primary productivity (e.g., Slagstad et al., 2015). For example, at an Arctic-wide scale, increased warming and greater inputs of melt water and river runoff are likely to enhance stratification in the euphotic zone, which can result in nutrient depletion in the late season and potentially decreased overall productivity despite increases in light availability (e.g., Jackson et al., 2011; Yamamoto-Kawai et al., 2009). On the other hand, longer periods of open water over Arctic marginal seas may enhance current- and wind-driven mixing (e.g., S. L. Danielson et al., 2014, 2017; Foukal et al., 2019; Lin et al., 2019; Pickart et al., 2013, 2019) that can inject nutrients into the euphotic zone. Recent studies indicate that episodic mixing and inputs of nutrients along geographic and bathymetric features such as capes, canyons and shelf margins can drive phytoplankton productivity and increases in biomass within surface waters during the open water season (e.g., Goñi et al., 2019; Juranek et al., 2019). Additionally, the prolonged ice-free conditions in late summer and fall can lead to enhanced wave resuspension and coastal erosion, which mobilize reactive materials from the nearshore that can fuel secondary production and nutrient cycling (e.g., Bröder et al., 2019; Vonk et al., 2015).

In this study, we present hydrographic properties and particulate organic matter (POM) distributions in waters along the northeast region of the Chukchi Sea shelf during two late summer-early fall cruises in 2016 and 2017. We investigate the role that stratification and bathymetric features have on influencing POM concentrations and compositions, and examine the impacts of both downwelling- and upwelling-favorable wind events along different regions of the Chukchi Shelf, including areas around Hannah Shoal and Barrow Canyon. We focus specifically on subsurface distributions that were not evident from our previous studies of surface trends (e.g., Goñi et al., 2019; Juranek et al., 2019). Our efforts contribute to an increased understanding of mechanisms of enhanced productivity during the open-water season and provide additional insights into potential biogeochemical impacts of increased and prolonged sea ice loss in marginal Arctic seas.

\section{Background and Methods}

\subsection{Study Area}

The Chukchi Sea is located directly north of the Bering Sea and constitutes the gateway between the Pacific and Arctic Oceans (Figure 1a). Several regional water masses, including Anadyr Water, Bering Shelf Water, and Alaska Coastal Water, enter the Chukchi Shelf through Bering Strait, with their inflow being regulated by sea level differences between the Pacific and Arctic and regional wind forcings (e.g., Coachman et al., 1975; S. L. Danielson et al., 2014, 2017; Weingartner et al., 2005; Woodgate et al., 2015; and references therein). While the mean flow is from the Pacific to the Arctic, once inside the Chukchi Sea circulation is 
a)

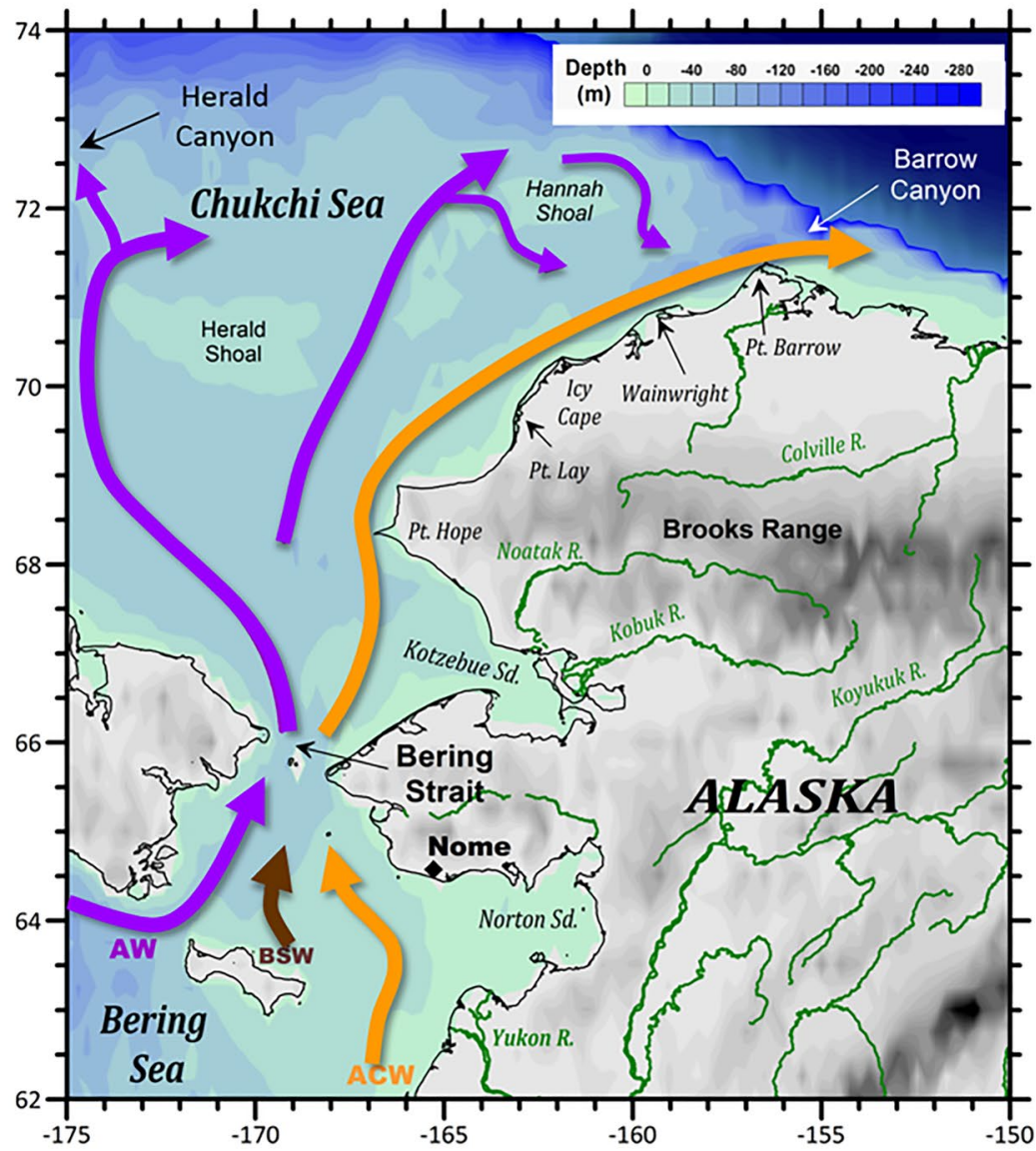

b)

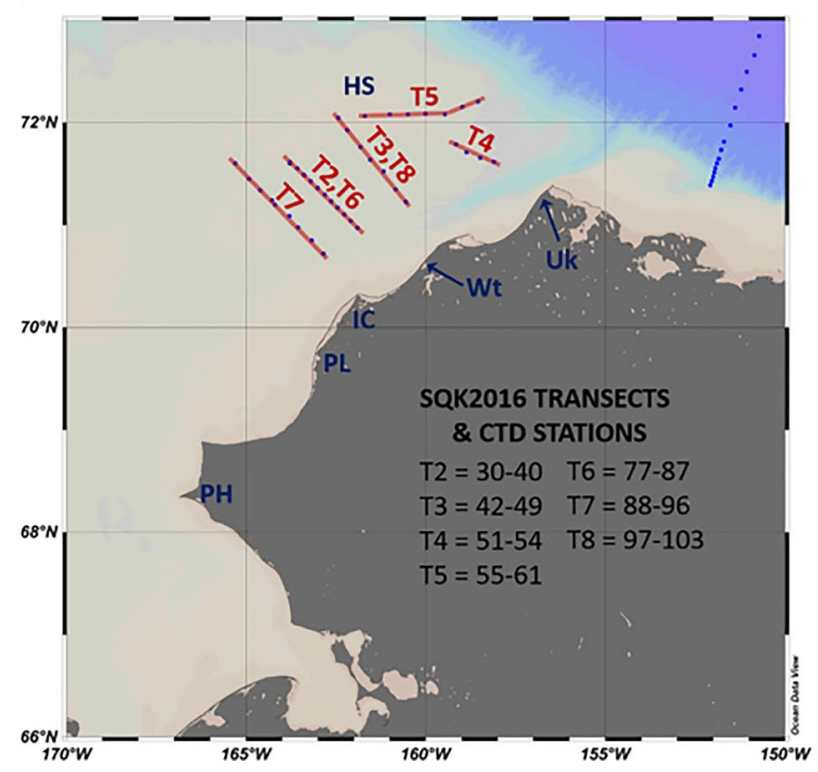

c)

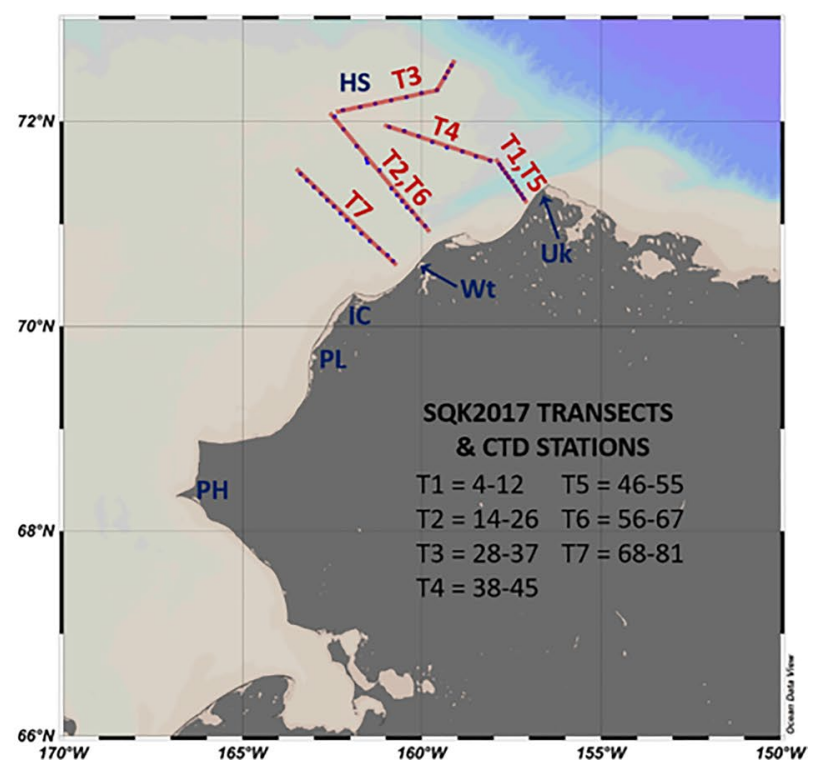

Figure 1. 
largely topographically steered along three primary pathways: a western branch through Herald Canyon; a Central Channel pathway between Herald and Hannah Shoals; and an eastern branch along the Alaskan coast (e.g., S. L. Danielson et al., 2017). This latter coastal pathway is typically the fastest to transport materials to the Beaufort Sea, whereas the other two pathways are significantly slower and can take several months to traverse the Chukchi Shelf (e.g., Shroyer \& Pickart, 2019). Significant physical and biogeochemical modifications of these inflow waters occur during their transit to the Beaufort Sea, fundamentally impacting the biogeochemistry and ecology of this inflow shelf (e.g., Arrigo et al., 2014; Grebmeier et al., 2015).

The major water masses entering the Chukchi Sea have distinct characteristics, with Anadyr Water having significantly higher dissolved nutrients than Bering Shelf Water and Alaska Coastal Water (ACW), the latter of which also tends to be fresher (e.g., Arrigo et al., 2014; Coachman et al., 1975). During winter, waters in the northern Bering and Chukchi Sea can undergo complete mixing due to sea ice formation and brine rejection, resulting in cold $\left(T<0^{\circ} \mathrm{C}\right)$, salty $(S>30-33.5)$, dense and nutrient-rich waters that are identified as Bering-Chukchi Winter Water (BCWW; S. L. Danielson et al., 2017). These winter waters can be further differentiated based on temperature (e.g., Pacini et al., 2019) into colder, newly ventilated winter water $\left(<-1.6^{\circ} \mathrm{C}\right)$ and warmer $\left(>-1.6^{\circ} \mathrm{C}\right)$ remnant winter water. In the spring and early summer, water column stratification due to warming, sea ice melt and river discharge (e.g., Weingartner et al., 2017), facilitates phytoplankton growth and drawdown of dissolved nutrients within the euphotic zone (e.g., Arrigo et al., 2014; Brown et al., 2015). The warming throughout the summer season over the Pacific Arctic region results in relatively warm $\left(T>0^{\circ} \mathrm{C}\right)$ waters that can be classified as Bering-Chukchi Summer Water (BCSW; S. L. Danielson et al., 2017). Other water masses observed along the Chukchi Sea during the spring and summer seasons include Melt Water (MW), which describes lower salinity $(S<30)$, high-buoyancy waters directly influenced by seasonal sea ice melt,as well as the warmer $\left(T>7^{\circ} \mathrm{C}\right) \mathrm{ACW}$, which because of its circulation path can remain as a discernible water mass along the Alaskan coastline (e.g., S. L. Danielson et al., 2017).

The strongly advective regime that characterizes the Chukchi Shelf is influenced by seasonal processes that affect light and nutrient availability and impact overall productivity (e.g., see review by Ardyna \& Arrigo, 2020 and references therein). Thus, the Chukchi Sea exhibits a strong seasonal cycle of productivity that starts in the spring (May and June) with ice-algae and under-ice plankton blooms and develops into a two-layer open water system with strong nutrient depletion that limits surface productivity later in the summer (July-September). Our study is designed to investigate the distribution of POM in the northeastern Chukchi shelf during this latter period and evaluate the role of physical forcings in its production and fate.

\subsection{Oceanographic Cruises}

In September of 2016, we sailed aboard the R/V Sikuliaq from Nome, AK, to the northeast Chukchi Sea and carried out oceanographic measurements and sampling along several cross-shelf transects (Figure 1b). During this period (September 3-25, 2016), we were able to occupy repeated transects along the established (e.g., Grebmeier et al., 2019) DBO4 line (transects 2 and 6) and off Wainwright (transects 3 and 8). This cruise (SKQ201612S) took place during a period of critical subsistence hunting of marine mammals by several coastal communities along Alaska's North Slope. To avoid interference with these activities and following best practice guidelines (e.g., Konar et al., 2017), the ship was kept $>30$ nautical miles offshore from established hunting grounds. In 2017, we conducted a second cruise (SKQ201712S) aboard the R/V Sikuliaq and occupied several transects along our study area from August 7-21, 2017 (Figure 1c). During this campaign, we were able to carry out repeated occupations along two transects, one offshore from Pt. Barrow (Transects 1 and 5), which coincided with the location of the DBO5 line, and one offshore from Wainwright (Transects 2 and 6). Because this cruise did not interfere with subsistence hunting efforts, we were able to extend the 2017 transects much closer to shore, including transect 7 , which coincided with the location of the DBO4 line. As we discuss below, the differences in spatial coverage during the two cruises

Figure 1. Maps of the study area highlighting (a) regional circulation and bathymetry; (b) CTD stations and transects occupied SKQ201612S and (c) CTD stations occupied during SKQ201712S. Transect and station numbers for both cruises are listed. Note that based on the location of the Distributed Biological Observatory array (e.g., Grebmeier et al., 2019), transects 2 and 6 in SKQ201612S coincided with the DBO4 line, whereas in SKQ201712S, transects 1 and 5 coincided with the DBO5 line and transect 7 coincided the DBO4 line. Highlighted in panel (a) are different regional water masses including Anadyr Water (AW), Bering Shelf Water (BSW), and Alaska Coastal Water (ACW). 
impacted the water masses and hydrographic features we observed in each campaign. During both cruises, spaced hydrographic stations were occupied along each transect. At each station, the ship's CTD-rosette system was deployed to conduct a variety of sensor-based measurements during the down cast and to collect water samples at selected depths during the up cast.

\subsection{Ancillary Data}

Wind and atmospheric pressure data were downloaded from NOAA's Barrow Meteorological station (https://www.esrl.noaa.gov/gmd/obop/brw/) for the periods around each cruise. We used wind magnitude and direction to calculate the east-west $\left(U_{\text {wind }}\right)$ component of the wind speed, which reflects upwelling-favorable (easterly winds) and downwelling-favorable (westerly winds) conditions along Alaska's north slope margin (e.g., Foukal et al., 2019; Pickart et al., 2019; Pisareva et al., 2019).

\subsection{Methods}

\subsubsection{CTD and Optical Sensor Data}

Temperature $\left({ }^{\circ} \mathrm{C}\right)$ and conductivity measurements were collected using a Sea-Bird 911 CTD instrument package and used to calculate salinity and density $\left(\sigma_{\mathrm{t}}, \mathrm{kg} \mathrm{m}^{-3}\right)$. Measurements of photosynthetically active radiation (PAR; $\mu$ Ein $\mathrm{cm}^{-2} \mathrm{~s}^{-1}$ ), chlorophyll fluorescence $\left(\mathrm{Chl} \mathrm{Fl;} \mathrm{mg} \mathrm{m}^{-3}\right.$ ) and particle beam attenuation $\left(c_{\mathrm{p}} ; \mathrm{m}^{-1}\right)$ were obtained using sensors mounted on the CTD rosette (Biospherical QSP-240, Wet Labs ECO FL Fluorometer, and Wet Labs C-Star 25-cm transmissometer, respectively). All sensors were calibrated prior to each cruise, and cleaned and rinsed with distilled water after each cast. All sensor-based measurements were conducted during both the down- and up-cast at each station. Down-cast data were binned at $1 \mathrm{~m}$ intervals to produce water column profiles at each station, which were then gridded and interpolated by kriging techniques using the software package Surfer (Golden Software). To account for the spatial scale differences of the data sets (i.e., depth in meters vs. distance along transect in kilometers), the gridding was conducted using a 3:1 anisotropy ratio to construct the contoured transects presented below. Up-cast data were averaged for each Niskin bottle deployment and were used to calculate temperature, salinity, $\sigma_{\mathrm{t}}$, PAR, $\mathrm{Chl} \mathrm{Fl,} \mathrm{and} c_{\mathrm{p}}$ values for each of the water samples that were collected using the CTD rosette.

\subsubsection{Collection and Analyses of Individual Water Samples}

Water samples were collected from specific depths using Niskin bottles mounted on the CTD rosette. For the most part, we collected samples from the surface, mid- and bottom sections of the water column, often targeting features in $\mathrm{Chl} \mathrm{Fl}$ and $c_{\mathrm{p}}$ to capture particle variability throughout the water column. Niskin bottles were sampled immediately after the CTD package was brought up on deck and variable volumes of water vacuum were filtered onto different-diameter glass fiber GF/F filters (nominal pore size of $0.7 \mu \mathrm{m}$ ) to isolate suspended particles using established procedures (e.g., Chaves et al., 2021). In order to collect large amounts of particles, we filtered between 2 and 4 liters of individual water samples through precombusted, preweighed 47-mm diameter GF/F filters. For particulate organic carbon and nitrogen analyses, 200-500 ml of water were filtered through precombusted 13-mm diameter GF/F filters, whereas for pigment analyses, we used precombusted $25-\mathrm{mm}$ diameter GF/F filters. Water samples that had undergone filtration through $\mathrm{GF} / \mathrm{F}$ filters were filtered again on a periodic basis and these samples used to estimate the mass of salt in the filter as well as carbon and nitrogen blanks associated with sorption of dissolved organic matter (e.g., Chaves et al., 2021; Goñi et al., 2019). All filter samples were kept frozen $\left(-80^{\circ} \mathrm{C}\right)$ until analyses.

The dry mass concentration of suspended particulate matter (SPM; $\mathrm{g} \mathrm{m}^{-3}$ ) in each 47-mm filter sample was determined by weighing the dry filter, subtracting the original mass of the filter, applying a mass correction, and dividing by the volume filtered. We note that because of concerns associated with rupturing cell membranes and potentially losing materials from the filters, we did not include a deionized water rinse step to remove salt (e.g., Stramski et al., 2007). Instead, we used the SPM-particle beam attenuation relationships observed (Figure S1) to determine background mass gain following filtration, which is primarily due to the presence of residual salt (e.g., Stavn et al., 2009). The magnitude of the $c_{p}$-based correction was comparable to SPM determinations from the filtration of selected prefiltered samples. While we recognize the challenges of determining the mass of total suspended solids in salt water samples (e.g., Stavn et al., 2009), the SPM 
data presented here provide insight into the distribution of suspended particulate materials in the study area.

Particulate organic carbon (POC) and particulate nitrogen (PN) concentrations $\left(\mathrm{mmol} \mathrm{m}^{-3}\right)$ in water samples were measured by analyzing 13-mm GF/F filter samples according to established techniques (see Goñi et al., 2019; Chaves et al., 2021). Briefly, the procedure involves exposing filter samples placed in silver boats to hydrochloric acid fumes over $24 \mathrm{~h}$ to remove inorganic carbon, drying the samples for another 24-h period and then wrapping the silver boats into tin boats for $\mathrm{CN}$ analyses by high temperature combustion. Samples and blanks associated with dissolved organic matter (DOM) sorption were analyzed in the same manner and the average carbon and nitrogen contents of the DOM blanks used to correct the measured values for POM samples. During each cruise, DOM-associated blanks were collected at surface, mid- and near-bottom depths of the water column and the averages applied to correct samples from each respective depth. POC and PN concentrations were calculated by dividing the blank-corrected carbon and nitrogen contents of each filter by the total volume of water filtered.

Chlorophyll (Chl) and pheophytin (Pheo) concentrations $\left(\mathrm{mg} \mathrm{m}^{-3}\right)$ were analyzed by extracting the filters in $8 \mathrm{~mL}$ of a $90 \%$ acetone solution at $4^{\circ} \mathrm{C}$ overnight. The samples were then measured using a Turner Design Model 10-AU fluorometer according to the acid addition method (Arar \& Collins,, 1997; Parsons et al., 1984) with a detection limit of $0.025 \mathrm{mg} \mathrm{m}^{-3}$.

\section{Results}

\subsection{Sea Ice and Atmospheric Conditions}

During SKQ201612S, we encountered significant amounts of sea ice above latitudes of $72^{\circ}$ north, which limited our operations in the area north and east of Hannah Shoal. In contrast, during SKQ201712S, the sea ice edge was well to the east and north of our study area and thus we had no limitations in operations.

Measurements from the meteorological station at Pt. Barrow provide a regional context to the atmospheric conditions during each cruise (Figure 2). For example, SKQ201612S took place during a period in September characterized by highly variable, moderate winds (5-20 knots) that included short periods of easterlies (upwelling-favorable) and westerlies (downwelling-favorable) (Figure 2a). A period of high (peak winds $>20$ knots) downwelling-favorable winds occurred between September 17 and 20, which provided a chance to compare conditions before and after the wind event by reoccupying transects along the DBO4 line and off Wainwright (Transects 2 and 6 and Transects 3 and 8, respectively; Figure 1b). Conditions during SKQ201712S were characterized by markedly lower wind speeds, which rarely exceeded 15 knots (Figure 2b). A switch from downwelling-favorable winds (positive $U_{\text {wind }}$ speeds) to upwelling favorable winds (negative $U_{\text {wind }}$ speeds) occurred around August 12 and lasted several days, which allowed us to compare conditions under contrasting wind forcings by evaluating distributions across Barrow Canyon (DBO5 line) and off Wainwright (Transects 1 vs. 5 and Transects 2 vs. 6, respectively; Figure 1c).

\subsection{Hydrographic Properties and Particle Distributions}

The hydrographic CTD surveys during the two cruises focused on the eastern Chukchi Shelf. Chlorophyll fluorescence $(\mathrm{Chl} \mathrm{Fl})$ and particle beam attenuation $\left(c_{\mathrm{p}}\right)$ measurements from sensors mounted on the CTD package, combined with measured concentrations of particulate organic carbon (POC), suspended particulate matter (SPM), and the photosynthetic pigments chlorophyll and pheophytin (Chl and Pheo, respectively), allowed us to explore particulate material distributions throughout the water column under different conditions. Here, we present contoured hydrographic (temperature, salinity and density) and Chl $\mathrm{Fl}$ and $c_{\mathrm{p}}$ sensor data along with superimposed POC, Chl + Pheo, and SPM concentrations from individual bottle samples to illustrate trends in POM distributions during both late-season cruises. Table 1 provides a summary of the bottle data from both SKQ201612S and SKQ201712S individual water samples from the three depth intervals routinely sampled. Distributions of PN concentrations showed similar trends to those of POC and are presented in the Supporting Information S1 (Goni, 2021). PAR profiles are shown for selected CTD stations occupied during daylight hours to document light availability throughout the water column during both cruises. 
a)

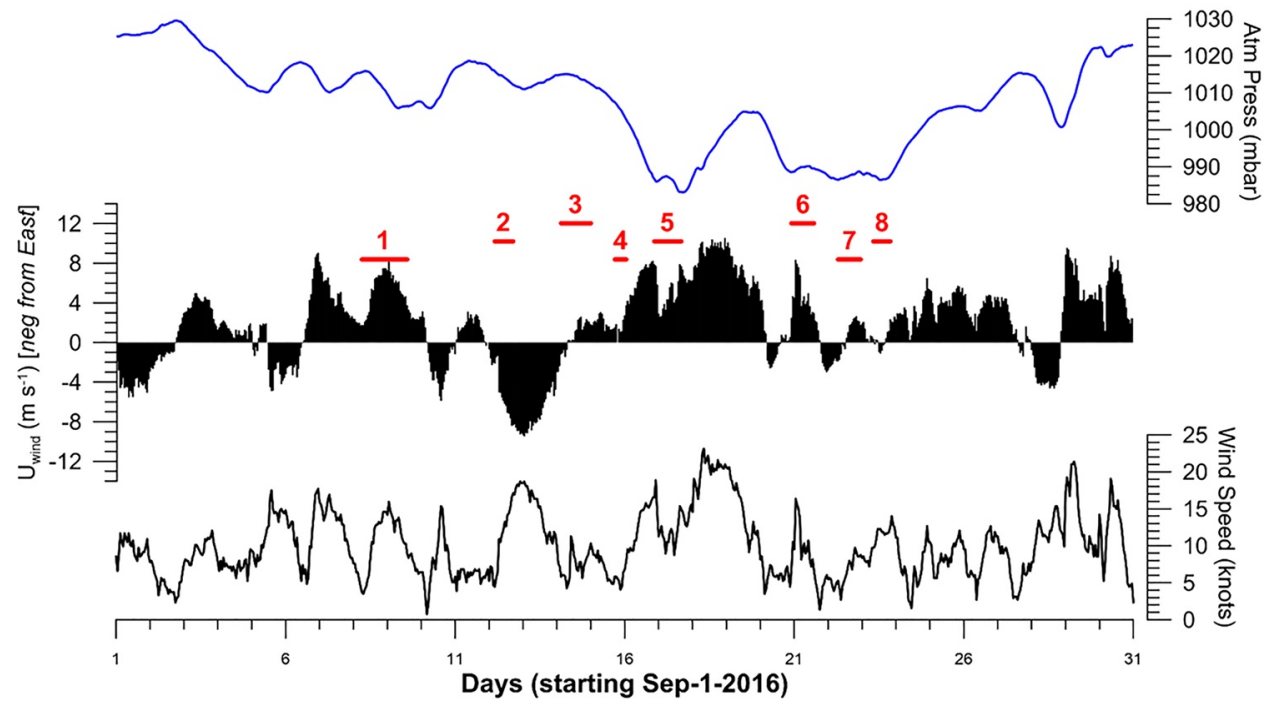

b)

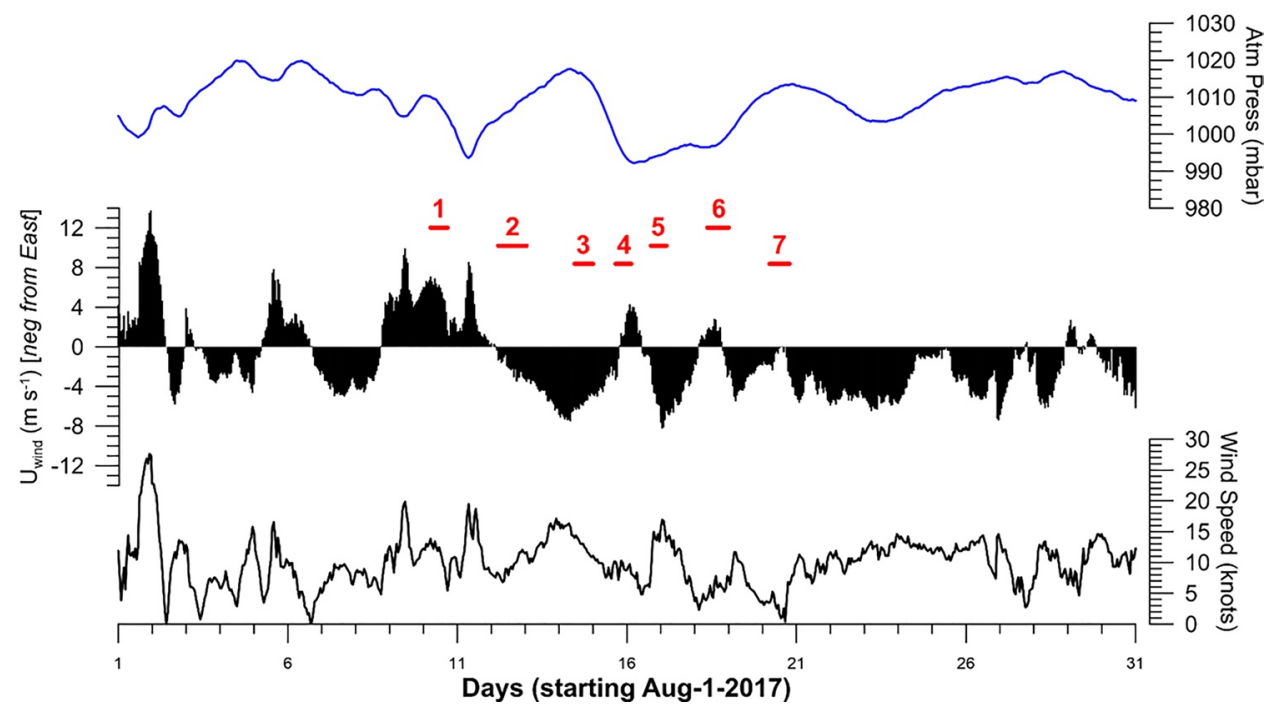

Figure 2. Atmospheric measurements from Pt. Barrow Meteorological station during (a) SKQ201612S and (b) SKQ201712S cruise periods. The data plotted include overall wind speed (knots), east-west wind speed ( $\mathrm{m} \mathrm{s}^{-1}$ ), and atmospheric pressure (mbar). The timing and duration of CTD transects (see Figures $1 \mathrm{~b}$ and $1 \mathrm{c}$ ) are shown to provide context to oceanographic observations. All NOAA met data are available at https://www.esrl.noaa.gov/gmd/obop/brw/.

\subsubsection{SKQ201612S (September 12-23, 2016) Transects}

The salinity and temperature distributions along the seven transects completed during the 2016 cruise are presented in Figure 3. As it is evident from these plots, the water column in the study area was highly stratified, primarily due to the large contrasts in salinity, with the top 10-20 $\mathrm{m}$ of the water column displaying low to intermediate salinities of (26-28), whereas the deeper sections were characterized by higher values (28-33). The temperature signatures displayed much less vertical variability with surface waters $(0-20 \mathrm{~m})$ exhibiting temperature ranges $\left(-1^{\circ} \mathrm{C}-2^{\circ} \mathrm{C}\right)$ that were comparable to those in deeper waters (Figure 3$)$. There were several noticeable spatial and temporal trends. For example, cold, fresher surface waters were most predominant in the transects from the northeast region of the study area (e.g., transects 4 and 5) whereas 
Table 1

Summary of Bottle Data From Samples Collected at Different Depths Along CTD Transects During SKQ201612S and SKQ201712S Cruises

\begin{tabular}{|c|c|c|c|c|c|c|c|c|}
\hline Sample water depth & Temperature $\left({ }^{\circ} \mathrm{C}\right)$ & Salinity & $\begin{array}{c}\text { Density } \\
\left(\sigma_{\mathrm{t}} ; \mathrm{kg} \mathrm{m}^{-3}\right)\end{array}$ & $\begin{array}{c}\mathrm{Chl} \mathrm{Fl} \\
\left(\mathrm{mg} \mathrm{m}^{-3}\right)\end{array}$ & $c_{\mathrm{p}}\left(\mathrm{m}^{-1}\right)$ & $\begin{array}{c}\text { POC } \\
\left(\mathrm{mmol} \mathrm{m}^{-3}\right)\end{array}$ & $\begin{array}{l}\text { Chl + Pheo } \\
\left(\mathrm{mg} \mathrm{m}^{-3}\right)\end{array}$ & $\begin{array}{c}\text { SPM } \\
\left(\mathrm{g} \mathrm{m}^{-3}\right)\end{array}$ \\
\hline \multicolumn{9}{|c|}{ SKQ2016 Cruise Transects (September 12-23, 2016) } \\
\hline \multicolumn{9}{|l|}{ Surface } \\
\hline Avg. +/- St.Dev. & $0.72 \pm 1.43$ & $28.12 \pm 0.67$ & $22.51 \pm 0.48$ & $0.59 \pm 0.21$ & $0.21 \pm 0.09$ & $7.22 \pm 3.32$ & $0.69 \pm 1.76$ & $2.30 \pm 0.72$ \\
\hline $\operatorname{Min} / \mathrm{Max}$ & $-1.25 / 4.09$ & $27.21 / 30.12$ & $21.82 / 23.92$ & $0.21 / 1.15$ & $0.06 / 0.68$ & $2.76 / 19.86$ & $0.21 / 9.82$ & $0.65 / 4.44$ \\
\hline Median & 0.50 & 27.88 & 22.36 & 0.56 & 0.20 & 6.35 & 0.37 & 2.19 \\
\hline \multicolumn{9}{|l|}{ Middepth } \\
\hline Avg. +/- St.Dev. & $0.69 \pm 1.67$ & $31.15 \pm 0.93$ & $24.95 \pm 0.76$ & $1.65 \pm 1.44$ & $0.26 \pm 0.22$ & $7.62 \pm 4.98$ & $1.34 \pm 2.37$ & $2.76 \pm 1.41$ \\
\hline Min/Max & $-1.42 / 4.98$ & $27.82 / 32.20$ & $22.32 / 25.87$ & $0.18 / 9.20$ & $0.06 / 1.35$ & $3.12 / 34.55$ & $0.32 / 13.25$ & $0.44 / 8.62$ \\
\hline Median & 0.45 & 31.36 & 25.18 & 1.22 & 0.20 & 6.38 & 0.71 & 2.36 \\
\hline \multicolumn{9}{|l|}{ Bottom } \\
\hline Avg. +/- St.Dev. & $-0.14 \pm 0.57$ & $32.26 \pm 0.09$ & $25.90 \pm 0.08$ & $0.55 \pm 0.19$ & $1.64 \pm 0.49$ & $9.89 \pm 2.09$ & $0.72 \pm 0.12$ & $7.65 \pm 2.63$ \\
\hline Min/Max & $-1.53 / 1.38$ & $32.05 / 32.48$ & $25.74 / 26.12$ & $0.12 / 1.14$ & $0.80 / 3.07$ & $5.35 / 14.12$ & $0.52 / 0.82$ & $3.37 / 13.06$ \\
\hline Median & -0.06 & 32.28 & 25.90 & 0.55 & 1.60 & 10.03 & 0.74 & 7.15 \\
\hline \multicolumn{9}{|c|}{ SKQ2017 Cruise Transects (August 10-20, 2017) } \\
\hline \multicolumn{9}{|l|}{ Surface } \\
\hline Avg. +/- St.Dev. & $5.24 \pm 1.41$ & $30.60 \pm 0.87$ & $24.15 \pm 0.64$ & $0.44 \pm 0.56$ & $0.30 \pm 0.29$ & $7.60 \pm 6.07$ & $0.78 \pm 0.51$ & $2.67 \pm 1.69$ \\
\hline Min/Max & $2.06 / 8.23$ & $28.41 / 33.19$ & $22.47 / 26.52$ & $0.00 / 3.32$ & $0.11 / 1.76$ & $0.60 / 31.65$ & $0.23 / 1.52$ & $0.24 / 13.28$ \\
\hline Median & 4.96 & 30.88 & 24.27 & 0.25 & 0.18 & 5.70 & 0.54 & 2.39 \\
\hline \multicolumn{9}{|l|}{ Middepth } \\
\hline Avg. +/- St.Dev. & $2.02 \pm 2.63$ & $31.72 \pm 0.36$ & $25.30 \pm 0.39$ & $2.73 \pm 2.66$ & $0.57 \pm 0.50$ & $10.71 \pm 6.88$ & $1.97 \pm 0.88$ & $4.15 \pm 2.38$ \\
\hline $\operatorname{Min} / \operatorname{Max}$ & $-1.61 / 7.78$ & $30.29 / 32.32$ & $24.04 / 25.87$ & $0.14 / 15.04$ & $0.09 / 2.74$ & $0.38 / 39.37$ & $0.19 / 3.83$ & $0.81 / 14.65$ \\
\hline Median & 0.97 & 31.79 & 25.41 & 1.71 & 0.39 & 9.49 & 2.03 & 3.45 \\
\hline \multicolumn{9}{|l|}{ Bottom } \\
\hline Avg. +/- St.Dev. & $1.05 \pm 1.94$ & $32.28 \pm 0.62$ & $25.83 \pm 0.54$ & $0.89 \pm 1.07$ & $1.72 \pm 0.91$ & $11.50 \pm 8.10$ & $0.75 \pm 0.34$ & $8.19 \pm 3.67$ \\
\hline Min/Max & $-1.60 / 7.64$ & $31.01 / 34.58$ & $24.61 / 27.75$ & $0.09 / 7.80$ & $0.43 / 7.38$ & $0.25 / 69.14$ & $0.16 / 1.59$ & $1.95 / 26.68$ \\
\hline Median & 0.38 & 32.17 & 25.80 & 0.52 & 1.58 & 10.08 & 0.68 & 7.56 \\
\hline
\end{tabular}

Note. Avg., average; St.Dev., standard deviation; Min, minimum; Max, maximum; Chl Fl, chlorophyll fluorescence; $c_{\mathrm{p}}$, particle beam attenuation; POC, particulate organic carbon; Chl + Pheo, combined pigments chlorophyll and pheophytin; SPM, suspended particulate matter.

the inshore sections of transects in the southwestern section were characterized by higher salinities $(\sim 29)$ and temperatures $\left(3^{\circ} \mathrm{C}-4^{\circ} \mathrm{C}\right)$.

There was some variability in hydrographic distributions between transects occupied prior and following the downwelling-favorable wind event (September 17-20, 2016). For example, minimal changes in temperature and salinity were detected along transects 3 and 8 , which were located within the central part of the study area. However, we measured slight increases in both variables over the top $20 \mathrm{~m}$ of water column at the $50 \mathrm{~km}$ CTD station along transect 8 (Figure 3). Further to the west, transect 6 showed markedly elevated temperatures and salinities in surface waters following the wind event relative to values measured along transect 2 that covered the same geographical locations prior to the wind event. Transect 7, which was located in the western-most section of the study area and was occupied following the downwelling-favorable wind event, displayed markedly higher salinities and temperatures in surface waters throughout the transect. Overall, while these contrasts reflect spatial variability in surface water masses along this highly advective region of the Pacific Arctic, it is likely the wind event of September 17-20, 2016 led to advection and mixing of water masses that contributed to the trends observed. 


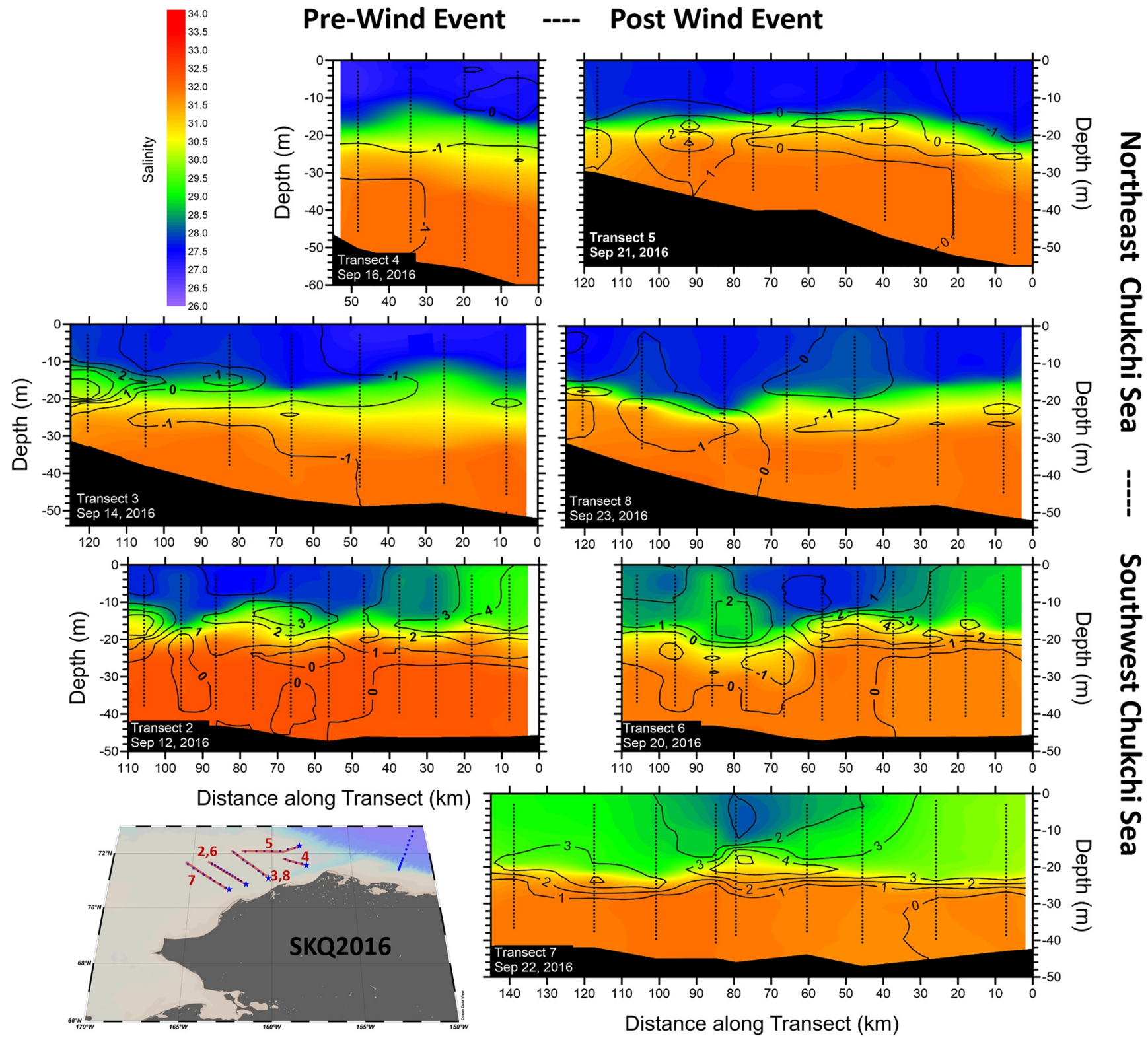

Figure 3. Distributions of salinity and temperature $\left({ }^{\circ} \mathrm{C}\right)$ throughout the water column across the seven hydrographic transects completed during SKQ201612S. Note that the start of each transect is identified by a blue star in the map insert. The cross-section contour plots are based on binned downcast data collected at each CTD station indicated by dotted lines in each transect.

The density distributions plotted in Figure 4 confirm the highly stratified conditions during SKQ201612S, especially along the northeast region of the study area (transects 4 and 5), where a very steep pycnocline was evident between 15 and $20 \mathrm{~m}$ water depth. Also evident in these plots were the contrasts in surface densities along transects occupied prior and following the wind event (e.g., transect 2 vs. 6, respectively) and the lack of major changes in density in the deeper regions of the water column below $\sim 20 \mathrm{~m}$. Data from individual water samples plotted in Figure 4 show POC concentrations ranged from 2 to $20 \mathrm{mmol} \mathrm{m}^{-3}$ throughout the water column of the seven transects occupied, with a high degree of variability in samples collected from surface and pycnocline depths. POC concentrations were quite low $\left(<5 \mathrm{mmol} \mathrm{m}^{-3}\right)$ in many of the surface samples, with higher $\left(10-20 \mathrm{mmol} \mathrm{m}^{-3}\right)$ values measured at locations that exhibited fronts associated with lateral density contrasts. Samples collected at depths near the pycnocline $\left(24<\sigma_{\mathrm{t}}<25.5 \mathrm{~kg} \mathrm{~m}^{-3}\right)$ also displayed significant variability, with most transects displaying intermediate POC values $\left(5-10 \mathrm{mmol} \mathrm{m}^{-3}\right)$. The DBO4 transects west of Wainwright (transects 2 and 6) included several samples displaying markedly 


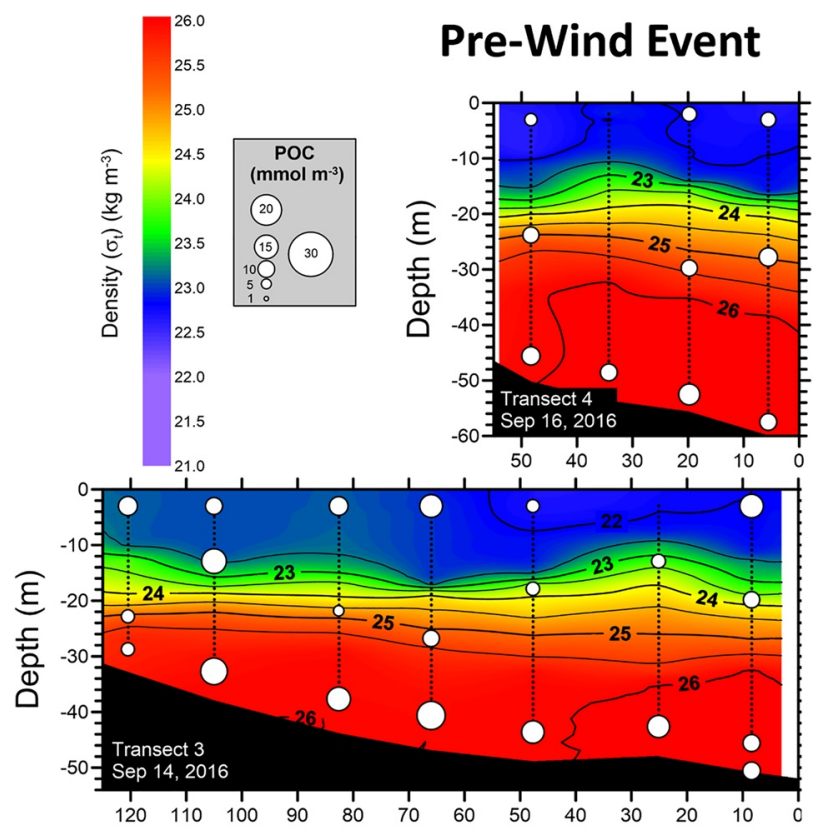

---- Post Wind Event
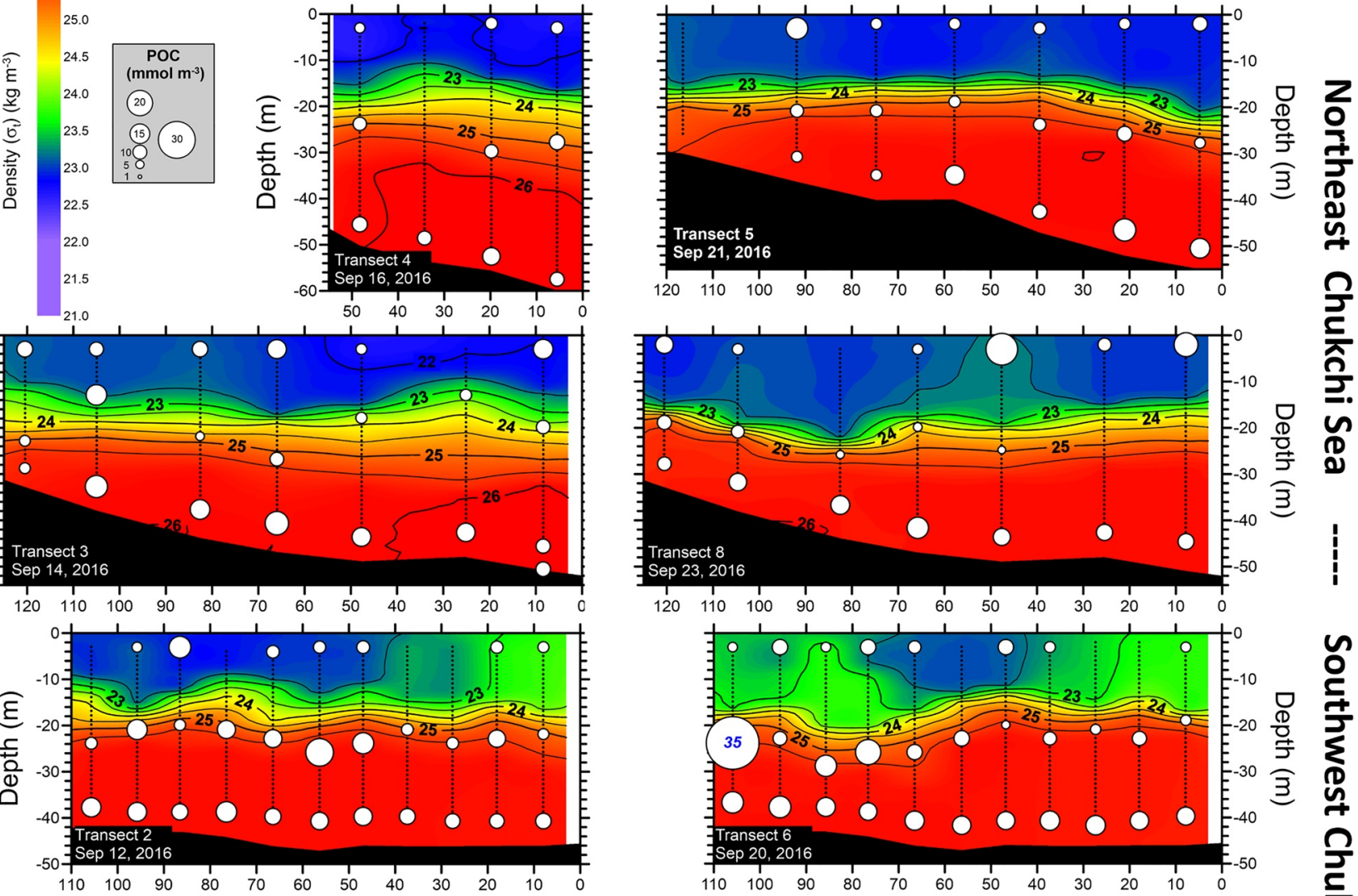

Distance along Transect (km)
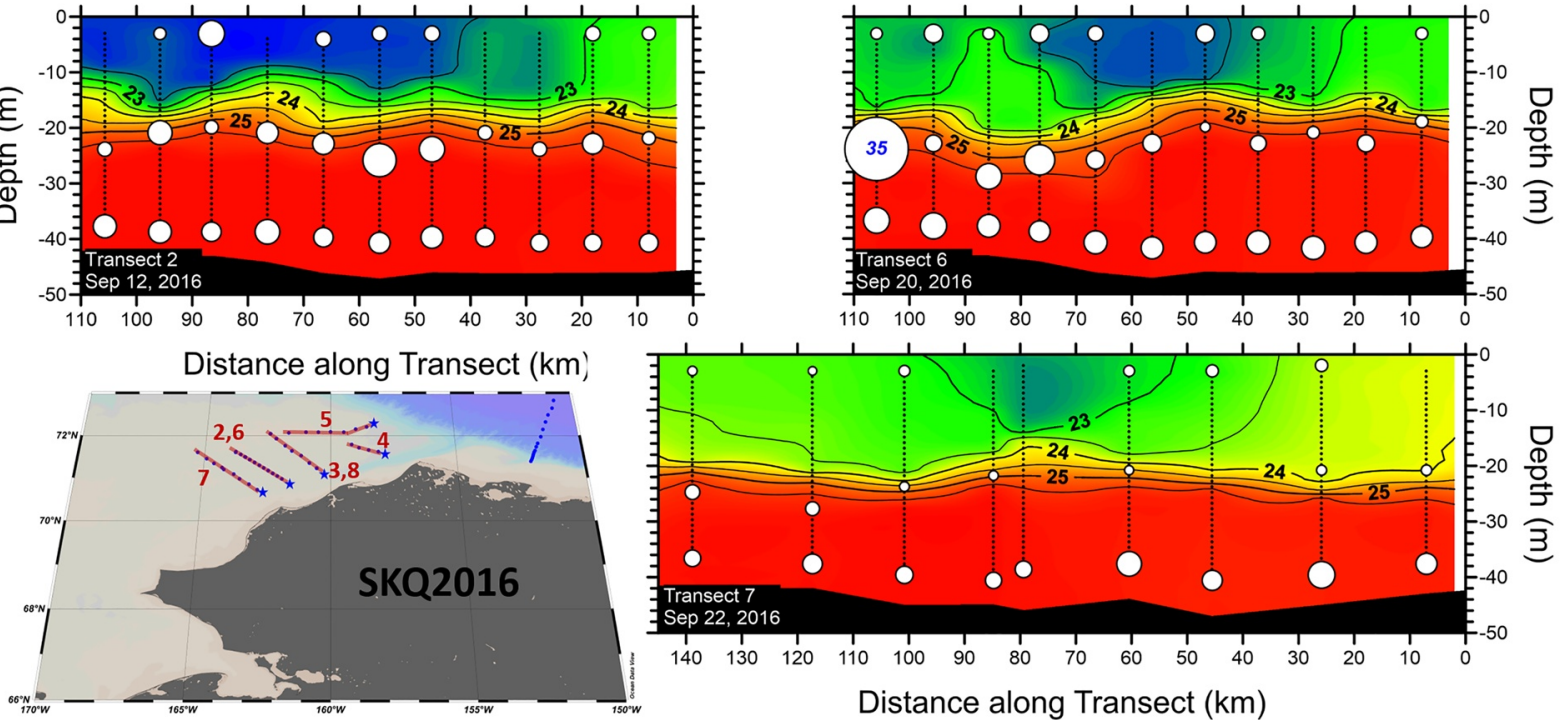

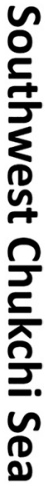

Figure 4. Distributions of density $\left(\sigma_{t} ; \mathrm{kg} \mathrm{m}^{-3}\right)$ throughout the water column and particulate organic carbon concentrations $\left(\mathrm{POC} ; \mathrm{mmol} \mathrm{m}^{-3}\right)$ from individual samples collected across the seven hydrographic transects completed during SKQ201612S. Note that the start of each transect is identified by a blue star in the map insert. The cross-section contour plots are based on binned downcast data collected at each CTD station indicated by dotted lines in each transect. The bubble plots showing POC concentrations are superimposed on the contour maps to identify the location of each individual sample.

higher POC concentrations $\left(10->30 \mathrm{mmol} \mathrm{m}^{-3}\right)$. In contrast, samples from the pycnocline along transects directly off Wainwright (transects 3,8$)$ were characterized by low POC values $\left(<5 \mathrm{mmol} \mathrm{m}^{-3}\right)$. The majority of samples collected from the higher-density waters $\left(\sigma_{\mathrm{t}}>25.5 \mathrm{~kg} \mathrm{~m}^{-3}\right)$ that occupied the deeper regions of the water column along all seven transects displayed moderately elevated POC concentrations (10-15 $\mathrm{mmol} \mathrm{m}^{-3}$ ), with the major exception being the samples from the shallower sections around Hannah Shoal, which displayed markedly lower $\left(>5 \mathrm{mmol} \mathrm{m}^{-3}\right)$ POC concentrations (Figure 4).

Contour plots of $\mathrm{Chl} \mathrm{Fl}$ along all seven transects are shown with the combined pigment (Chl $+\mathrm{Pheo})$ concentrations measured in individual water samples superimposed in each panel (Figure 5). As can be seen from these plots, all transects displayed relatively low Chl Fl signals $\left(<1.0 \mathrm{mg} \mathrm{m}^{-3}\right)$ throughout most of the water column except for the subsurface chlorophyll maxima (SCM) located between 20 and $30 \mathrm{~m}$ of water depth. The DBO4 transects west of Wainwright (transects 2 and 6) were characterized by the most intense 


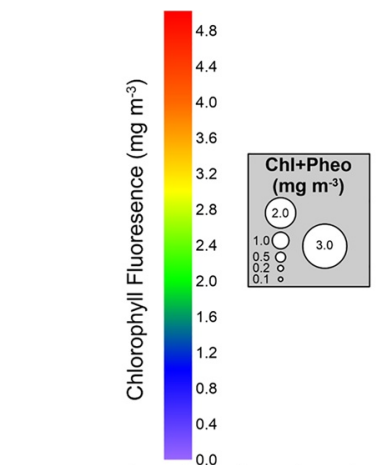

\section{Pre-Wind Event}
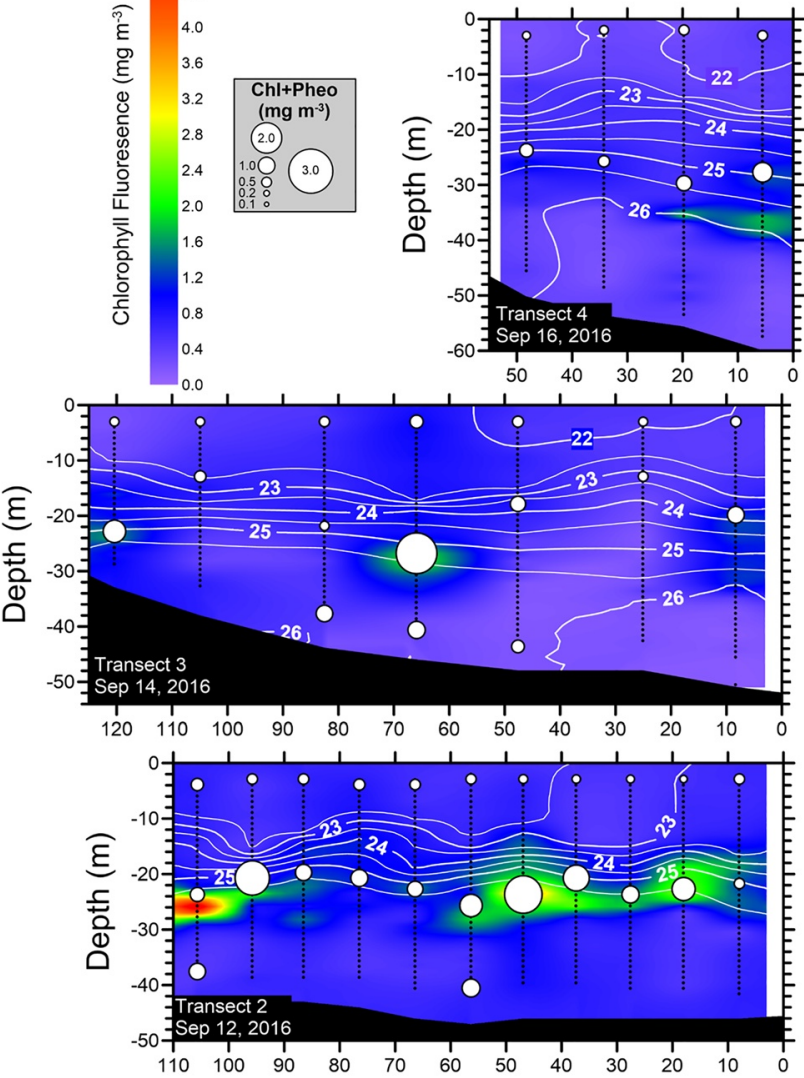

Distance along Transect $(\mathrm{km})$

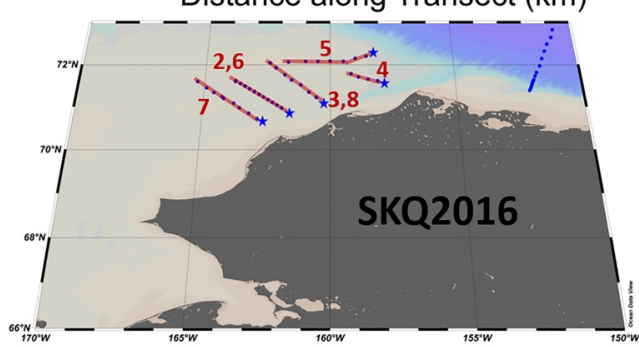

---- Post Wind Event
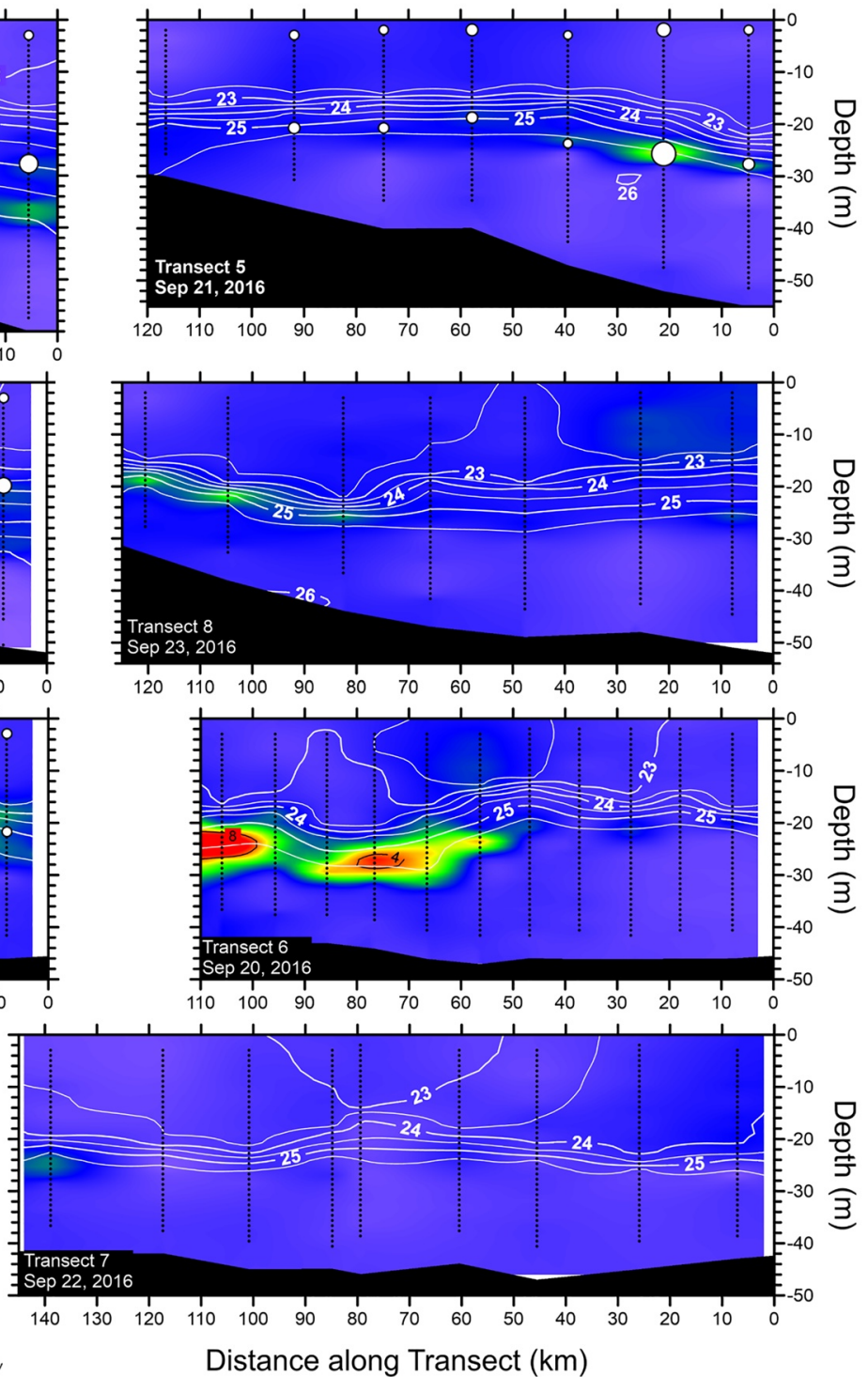

Distance along Transect $(\mathrm{km})$

Figure 5. Distributions of chlorophyll fluorescence sensor measurements ( $\mathrm{Chl} \mathrm{Fl;} \mathrm{mg} \mathrm{m}^{-3}$ ) throughout the water column and combined photosynthetic pigment concentrations, chlorophyll and pheophytin $\left(\mathrm{Chl}+\mathrm{Pheo} ; \mathrm{mg} \mathrm{m}^{-3}\right)$, from individual samples collected across the seven hydrographic transects completed during SKQ201612S. The white contour lines represent density distributions (see Figure 4). Note that the start of each transect is identified by a blue star in the map insert. The cross-section contour plots are based on binned downcast data collected at each CTD station indicated by dotted lines in each transect. The bubble plots showing $\mathrm{Chl}+$ Pheo concentrations are superimposed on the contour maps to identify the location of each individual sample.

$\mathrm{SCM}$, with peak fluorescence signals consistent with Chl concentrations $>3 \mathrm{mg} \mathrm{m}^{-3}$. In contrast, other transects, such as transects 4 and 7, were characterized by more muted SCM that did not extend along the whole transect distance. In all cases, SCM were located at depths directly below the pycnocline, typically within $\sigma_{\mathrm{t}}$ ranges between 24.5 and $25.5 \mathrm{~kg} \mathrm{~m}^{-3}$. The $\mathrm{Chl} \mathrm{Fl} \mathrm{signals} \mathrm{in} \mathrm{both} \mathrm{surface} \mathrm{and} \mathrm{deep} \mathrm{waters} \mathrm{ranged} \mathrm{from}$ $<0.4$ to moderate values around $1.5 \mathrm{mg} \mathrm{m}^{-3}$ and varied within and among transects. Combined pigment $(\mathrm{Chl}+\mathrm{Pheo})$ concentrations from individual water samples were conducted in selected transects (transects 2, 3, 4, and 5) and for the most part agreed well with the $\mathrm{Chl} \mathrm{Fl} \mathrm{patterns,} \mathrm{including} \mathrm{the} \mathrm{high} \mathrm{values} \mathrm{(}>2 \mathrm{mg}$ $\mathrm{m}^{-3}$ ) measured along specific locations of the SCM in transects 2 and 3.

Further insights into the distribution of suspended particles along the water column of the northeast Chukchi Shelf can be obtained from the contoured distributions of $c_{\mathrm{p}}$ signals along all seven transects (Figure 6). 


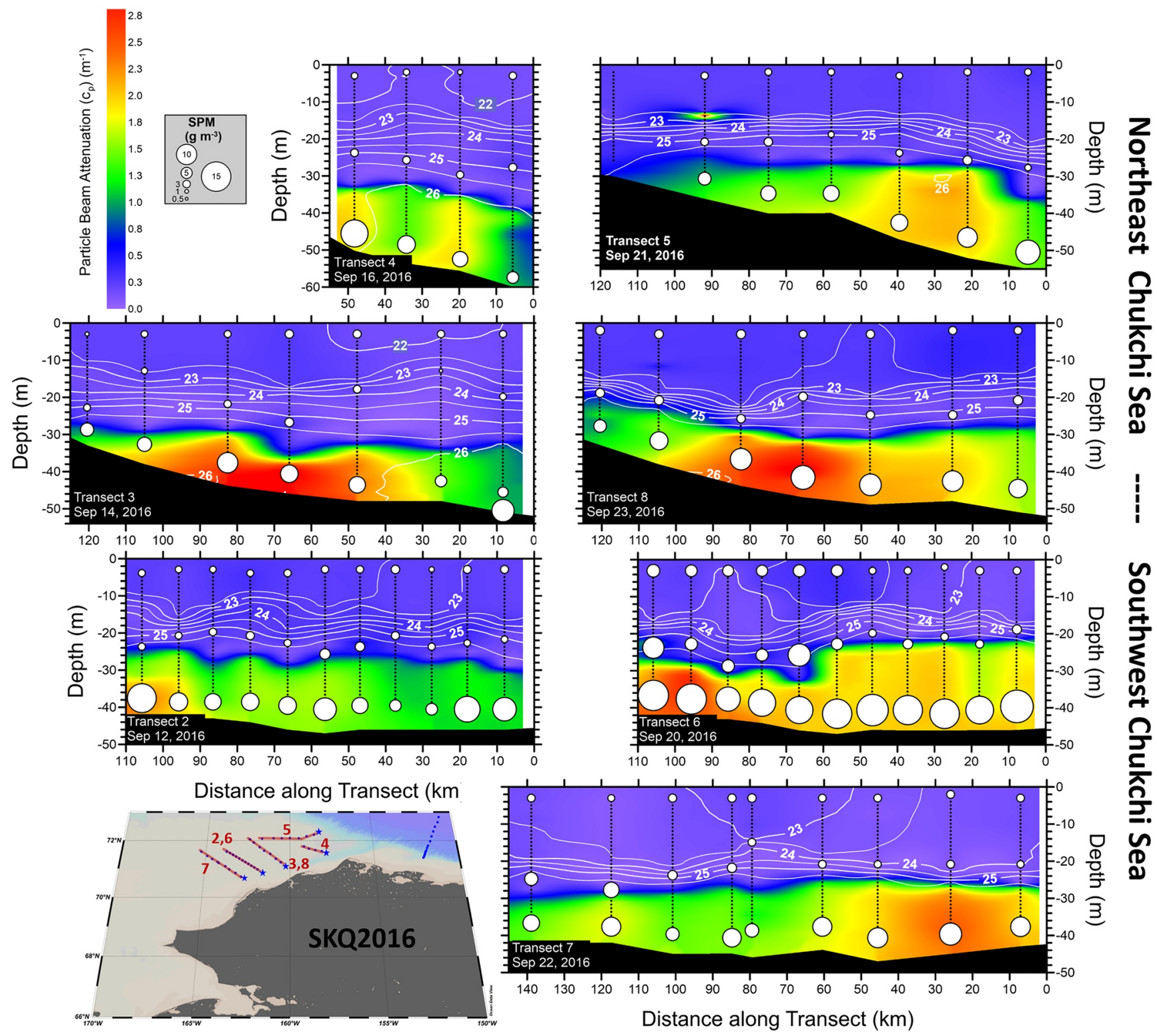

Figure 6. Distributions of particle beam attenuations sensor measurements $\left(c_{\mathrm{p}} ; \mathrm{m}^{-1}\right)$ throughout the water column and combined suspended particulate matter concentrations $\left(\mathrm{SPM} ; \mathrm{g} \mathrm{m}^{-3}\right.$ ) from individual samples collected across the seven hydrographic transects completed during SKQ201612S. The white contour lines represent density distributions (see Figure 4). Note that the start of each transect is identified by a blue star in the map insert. The cross-section contour plots are based on binned downcast data collected at each CTD station indicated by dotted lines in each transect. The bubble plots showing SPM concentrations are superimposed on the contour maps to identify the location of each individual sample.

In this figure, we also superimposed the SPM concentrations obtained from individual water samples collected using the CTD-rosette system. As is evident from these plots, the water column in this region of the Chukchi Sea during the cruise period exhibited marked contrasts in particle distributions and overall turbidity, with all surface waters at and above the pycnocline displaying $c_{\mathrm{p}}$ values of $<0.4 \mathrm{~m}^{-1}$, whereas bottom waters below the pycnocline were characterized by markedly elevated $c_{\mathrm{p}}$ values of $1-2.5 \mathrm{~m}^{-1}$. The stark contrasts in $c_{\mathrm{p}}$ were corroborated by the distributions of SPM concentrations from different depths, which showed low concentrations (SPM $<3 \mathrm{~g} \mathrm{~m}^{-3}$ ) in surface waters at and above the pycnocline and elevated concentrations $\left(5>\mathrm{SPM}>15 \mathrm{~g} \mathrm{~m}^{-3}\right)$ in bottom waters below the pycnocline. Based on $c_{\mathrm{p}}$ and SPM distributions before and after the period of downwelling-favorable winds (e.g., transects 2 vs. 6 and 3 vs. 8, respectively) there were changes in the overall turbidity of the water column that may have been related to this wind forcing. For example, there were increases in both $c_{\mathrm{p}}$ values and SPM concentrations in the regions of the water 


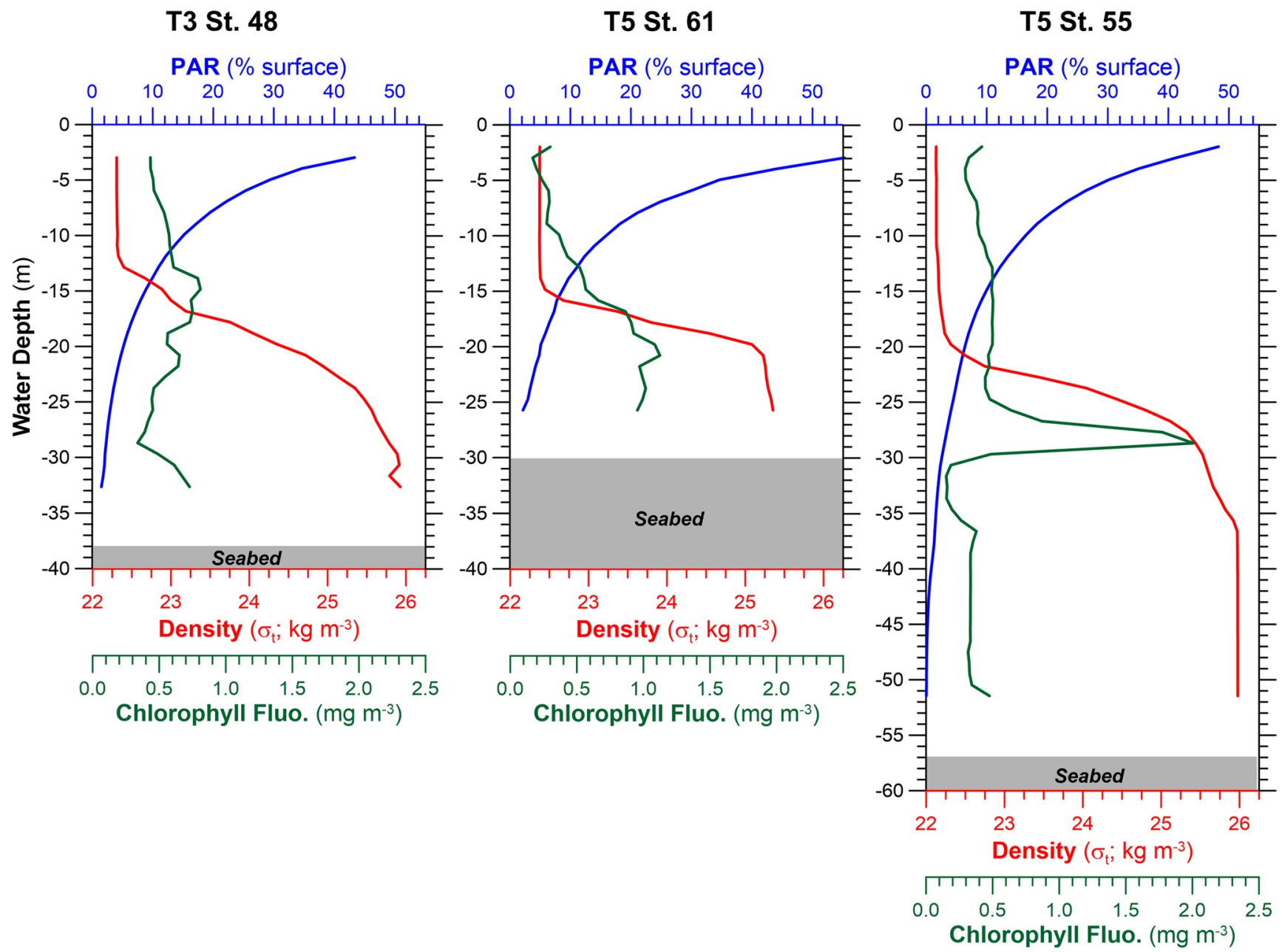

Figure 7. Profiles from selected hydrographic stations identified by transect (T\#) and CTD station (St.\#) numbers (see Figure 1) occupied near local mid-day during SKQ201612S. Local date/time occupation of these hydrographic stations is as follows: T3 St.48, September 14, 2016 at 12:30; T5 St.55, September 16, 2016 at 12:54; T5 St.61, September 17, 2016 at 12:21. The figures show depth profiles of density $\left(\sigma_{\mathrm{t}} ; \mathrm{kg} \mathrm{m}^{-3}\right)$, chlorophyll fluorescence $\left(\mathrm{mg} \mathrm{m} \mathrm{m}^{-3}\right)$ and photosynthetically active radiation (PAR; $\mu$ Ein $\mathrm{cm}^{-2} \mathrm{~s}^{-1}$ ) measurements calculated as a percent of surface PAR.

column below the pycnocline along transects 6 and 8 compared to transects 2 and 3, which were consistent with elevated particle concentrations following the September 17-20 wind event.

To illustrate the light conditions throughout the water column during the cruise, Figure 7 shows the profiles of PAR relative to surface values for three stations that were occupied around noon local time, when surface PAR was 550-570 $\mu$ Einsteins $\mathrm{cm}^{-2} \mathrm{~s}^{-1}$. Steep light attenuation characterized the water column along the Chukchi Shelf, with less than $10 \%$ of surface PAR reaching below $15 \mathrm{~m}$ of water depth. However, it is clear that at the height of daylight, more than $1 \%$ of surface PAR (often used to define the euphotic zone; e.g., Ardyna et al., 2013) penetrated below the pycnocline. Many of the CTD stations were occupied during nighttime operations, so we were not able to conduct a comprehensive survey of daily PAR profiles that would have allowed a full characterization of the light regime during the cruise.

\subsubsection{SKQ201712S (August 10-20, 2017) Transects}

The 2017 Sikuliaq cruise occupied similar locations to the 2016 cruise but, because it did not conflict with the subsistence harvest season, we were able to extend the transects closer to shore (Figure 1c). As was the case for the SKQ201612S, we illustrate water column distributions during SKQ201712S by showing contour plots for the different transects organized to show both spatial and temporal variability, the latter highlighting contrasts before and after the upwelling-favorable wind event during August 12-17, 2017 (Figure 2b). 


\section{Pre-Wind Event ---- Post Wind Event}
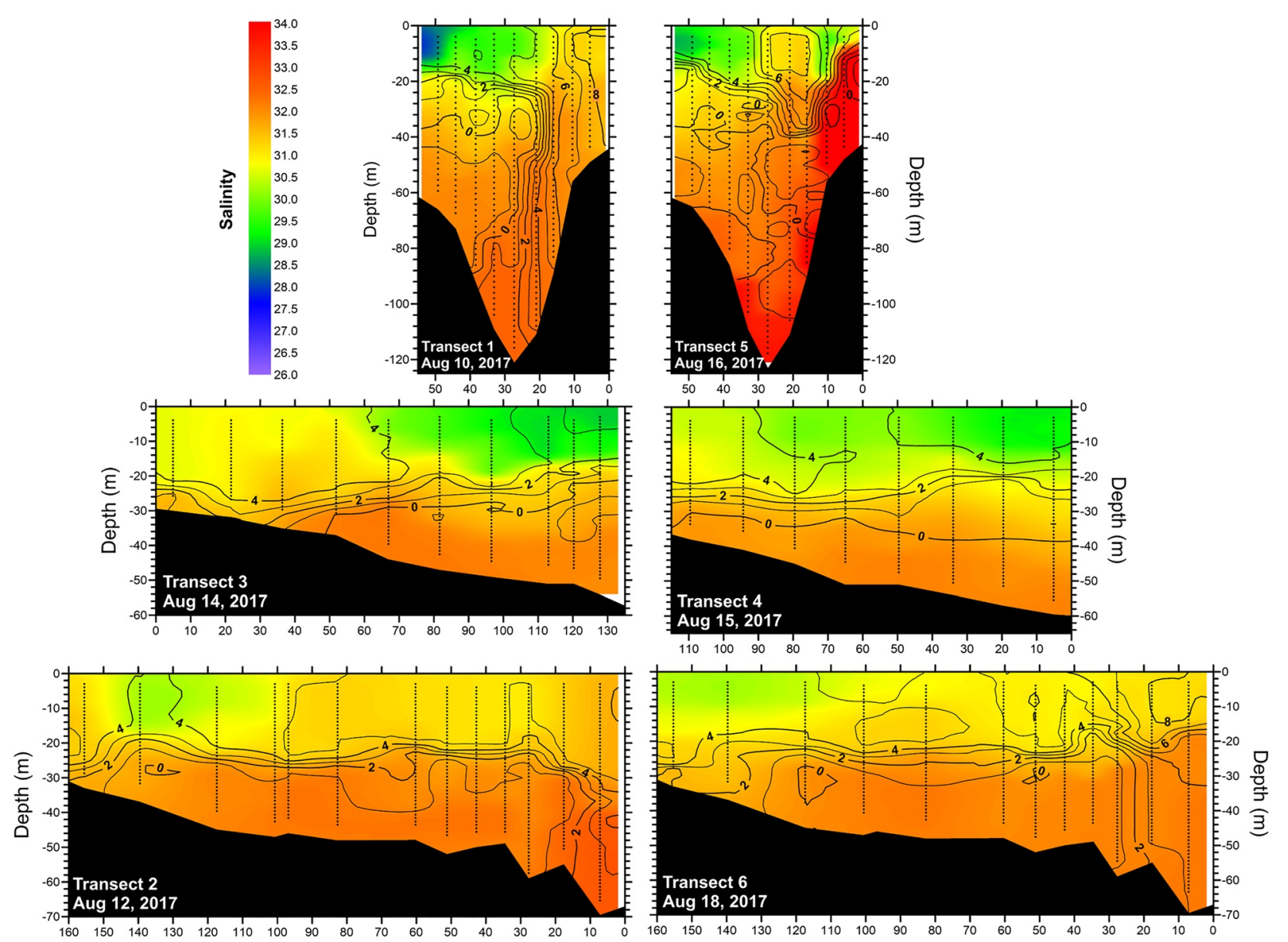

Distance along Transect $(\mathrm{km})$
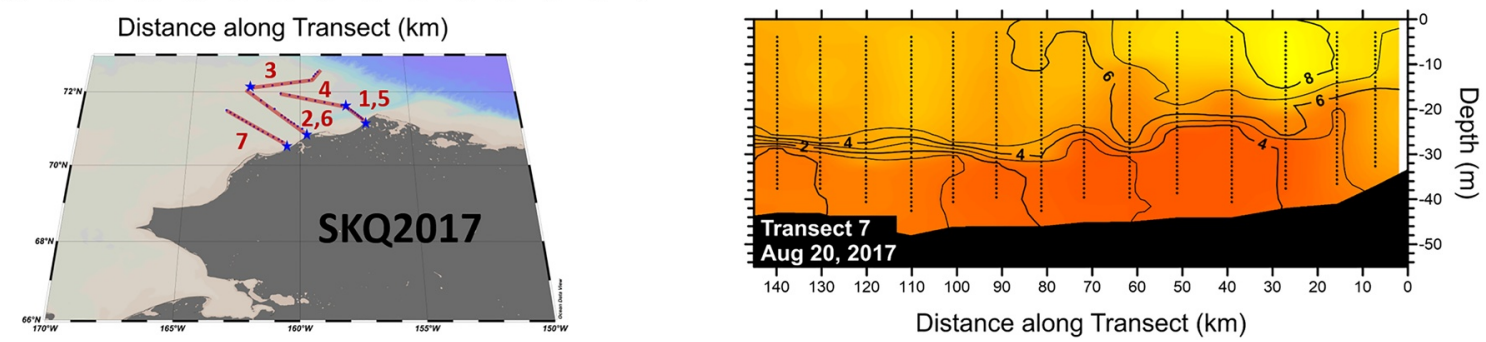

Figure 8. Distributions of salinity and temperature $\left({ }^{\circ} \mathrm{C}\right)$ throughout the water column across the seven hydrographic transects completed during SKQ201712S. Note that the start of each transect is identified by a blue star in the map insert. The cross-section contour plots are based on binned downcast data collected at each CTD station indicated by dotted lines in each transect.

Hydrographic data from all seven transects occupied during SKQ201712S (Figure 8) show that, in contrast to SKQ201612S, the water column of the northeast Chukchi Shelf in August of 2017 was characterized by relative uniform salinities and a larger range of temperatures. For example, SKQ201712S salinities varied between 29 and 34, with only surface waters from the most offshore station in transect 1 displaying salinities lower than 29. Temperature conditions through the water column of all seven transects showed a broad range in values from $-1^{\circ} \mathrm{C}$ to $8^{\circ} \mathrm{C}$. Surface waters were characterized by significantly warmer temperatures than deeper waters resulting in stratified conditions that, in contrast to SKQ201612S cruise, were much more temperature-controlled as opposed to salinity controlled. As can be seen in Table 1, the stark contrasts in salinity and temperature distributions between the two cruises was primarily caused by the diminished 


\section{Pre-Wind Event ---- Post Wind Event}
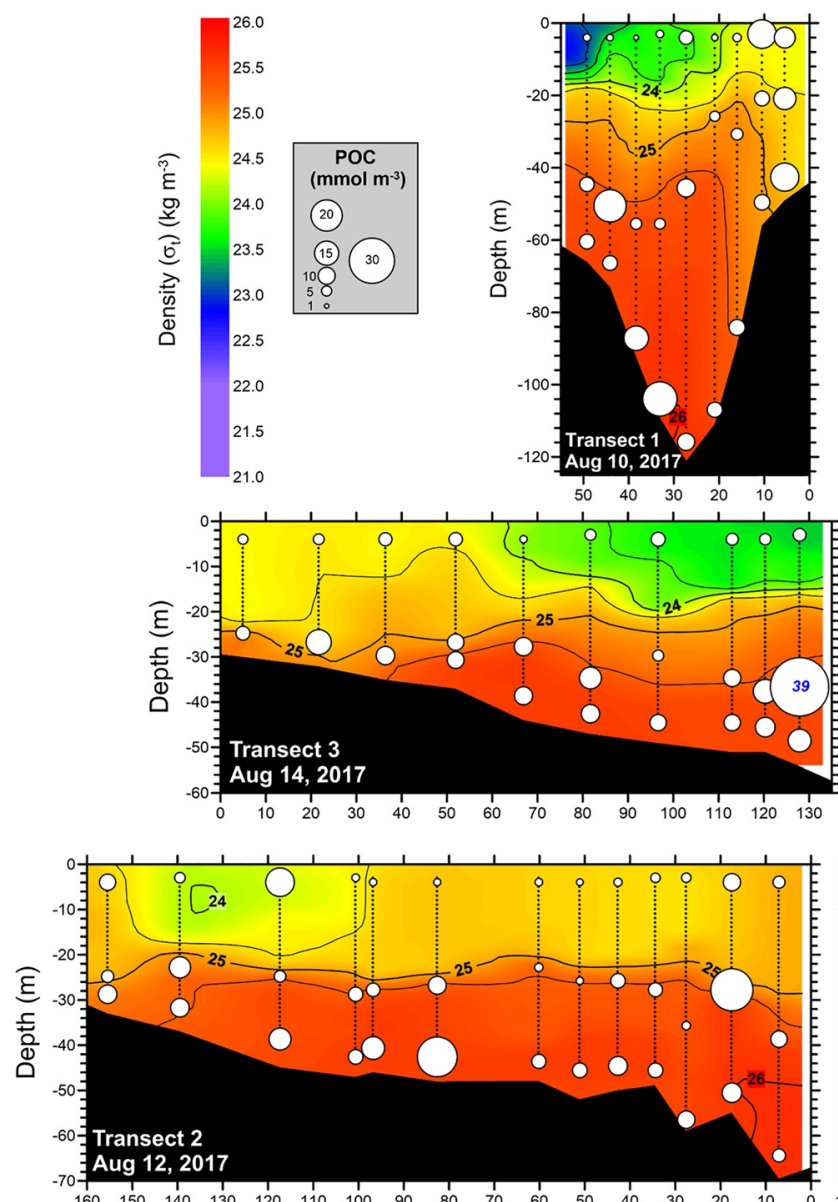

Distance along Transect $(\mathrm{km})$

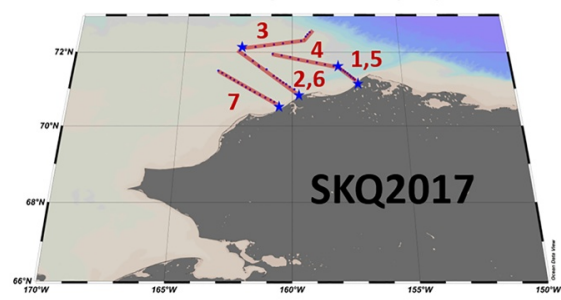

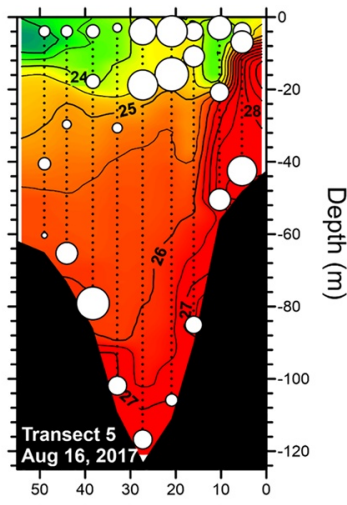
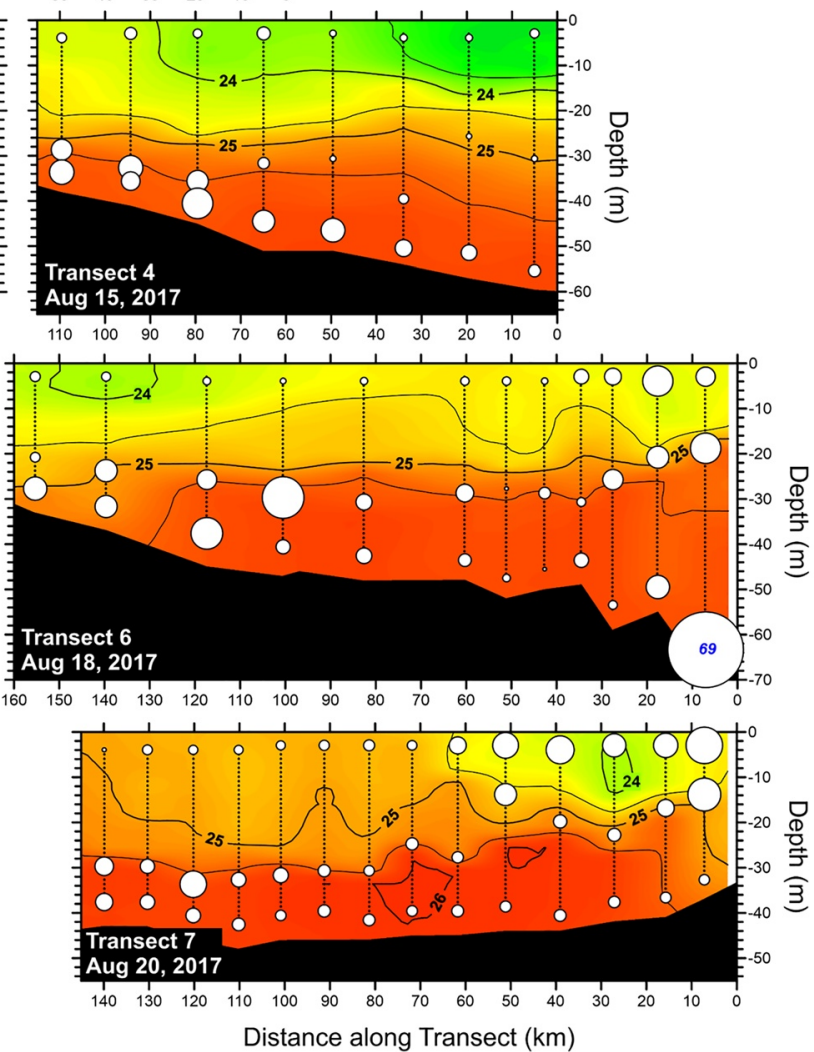

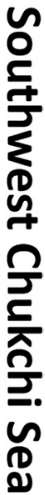

Figure 9. Distributions of density $\left(\sigma_{t} ; \mathrm{kg} \mathrm{m}^{-3}\right)$ throughout the water column and particulate organic carbon concentrations $\left(\mathrm{POC}\right.$; mmol $\left.\mathrm{m}^{-3}\right)$ from individual samples collected across the seven hydrographic transects completed during SKQ201712S. Note that the start of each transect is identified by a blue star in the map insert. The cross-section contour plots are based on binned downcast data collected at each CTD station indicated by dotted lines in each transect. The bubble plots showing POC concentrations are superimposed on the contour maps to identify the location of each individual sample.

presence of waters influenced by sea ice melt and the higher contributions from warmer waters during the 2017 cruise.

Despite the lower contributions from low-salinity melt waters, all seven transects during SKQ201712S still displayed stratified conditions (Figure 9). However, most profiles lacked the steep pycnoclines that characterized SKQ201612S and there were noticeable lateral differences in the distribution and spacing of isopycnals along the transects. Slightly more buoyant waters $\left(\sigma_{\mathrm{t}}<24 \mathrm{~kg} \mathrm{~m}^{-3}\right)$ characterized the offshore sections of several transects in the northeast region of the study area (transects $1,3,4,5)$ consistent with some influence from melt water. In transects from the southwestern region of the study area, especially transect 7 (DBO4 line) and to a lesser degree transect 6, low density surface waters coincided with near-shore 
locations. Virtually all deeper waters were characterized by $\sigma_{t}$ values between 25.5 and $26.0 \mathrm{~kg} \mathrm{~m}^{-3}$. The major exception was transect 5 across Barrow Canyon (DBO5 line), which was occupied following the period of upwelling-favorable winds and displayed high-density waters $\left(\sigma_{t}>26.0 \mathrm{~kg} \mathrm{~m}^{-3}\right)$ throughout the deeper sections of the water column and along the southern flank of the canyon. Following the period of easterly wind forcing between August 12 and 17, 2017, isopycnals along this section of the canyon shifted from a downward to upward-tilting direction. Furthermore, high-density waters reached the surface at the southernmost station of transect 5. Both of these observations are clear evidence of significant upwelling (Beaird et al., 2020; Pickart et al., 2019) after this wind event (Figure 2b). A more muted response to upwelling was evident when comparing density distributions off Wainwright before (transect 2) and after (transect 6) the wind event. In this case, the offshore extension of warmer temperatures in surface waters and the slight inshore shoaling of isopycnals along transect 6 compared to transect 2 were both consistent with the upwelling-favorable wind forcing. The difference in the magnitude of change between the two transects illustrate the sensitivity of Barrow Canyon to wind forcing relative to other inner shelf locations (e.g., Pickart et al., 2013, 2019). Overall, the densities of surface and middepth waters in SKQ201712S were greater than those in SKQ201612S, reflecting the importance of more buoyant waters derived from sea ice melt in September 2016 cruise (Table 1). Bottom waters showed comparable density averages during both cruises, but the higher variability in $\sigma_{\mathrm{t}}$ exhibited during SKQ201712S reflects the presence of multiple water masses in the deeper water column in this cruise relative to SKQ201612S.

POC distributions superimposed on the density profiles (Figure 9) showed for the most part low concentrations $\left(<5 \mathrm{mmol}^{\circ} \mathrm{m}^{-3}\right)$ in surface waters along the seven SKQ201712S transects. The major exceptions were inshore regions of transects occupied following the upwelling wind event (e.g., transects 5, 6, and 7). Samples from depths around the pycnocline $\left(24.5<\sigma_{\mathrm{t}}<25.5 \mathrm{~kg} \mathrm{~m}^{-3}\right)$ displayed intermediate POC values (5-10 $\left.\mathrm{mmol} \mathrm{m}^{-3}\right)$, with a few instances of higher concentrations approaching $20 \mathrm{mmol} \mathrm{m}^{-3}$. High-density $\left(\sigma_{\mathrm{t}}>25.5 \mathrm{~kg} \mathrm{~m}^{-3}\right)$ bottom waters generally displayed higher POC concentrations $\left(>10 \mathrm{mmol} \mathrm{m}^{-3}\right)$, although in some locations (e.g., transect 7) deep-water POC concentrations were significantly lower $\left(5 \mathrm{mmol} \mathrm{m}^{-3}\right)$. Comparison of POC distributions prior and following the wind event (i.e., transects 1 vs. 5 and 2 vs. 6) showed marked increases in POC concentrations at various depths and density ranges, but increases were most noticeable along the nearshore sections off Barrow Canyon and Wainwright. The buildup of POC in surface waters at these locations was consistent with enhanced biomass following the period of upwelling winds, especially along the southern flank of Barrow Canyon. In the case of transect 6, we also measured a major increase in POC directly above the seabed at the most inshore station. We note this sample also exhibited very high $c_{\mathrm{p}}$ values and SPM concentrations (see below), which indicate the elevated POC concentrations reflect high levels of POM in this highly turbid, particle rich section of transect 6 . Overall, despite the high variability, samples from the middepth and bottom regions of the water column during SKQ201712S displayed higher POC concentrations than those from SKQ201612S, highlighting contrasts in the overall abundance of POM during these two periods (Table 1).

Contour plots of Chl Fl signals along all seven transects revealed the presence of SCM that varied in intensity and location within and among transects (Figure 10). Elevated Chl Fl values $\left(>2 \mathrm{mg} \mathrm{m}^{-3}\right.$ ) were generally measured at mid-depths associated with the bottom of the pycnocline $\left(\sigma_{\mathrm{t}} \sim 25.5 \mathrm{~kg} \mathrm{~m}^{-3}\right)$ with a few locations displaying considerably higher values $\left(>4 \mathrm{mg} \mathrm{m}^{-3}\right)$. Overall, surface and deep waters consistently displayed low Chl Fl signals $\left(<0.5 \mathrm{mg} \mathrm{m}^{-3}\right)$ with a few exceptions. For example, surface inshore waters in transects 1 , and especially transects 5, 6 and 7, which were occupied following the upwelling wind event displayed elevated $\mathrm{Chl} \mathrm{Fl}$ values (1-3 $\mathrm{mg} \mathrm{m}^{-3}$ ). In addition, deep waters above the seabed displayed elevated $\mathrm{Chl} \mathrm{Fl}$ signals at a few locations, including the region around Hannah Shoal (start of transect 3) and the inshore regions along transect 6 , both of which also displayed moderate to very high POC concentrations. Combined pigment analyses $(\mathrm{Chl}+\mathrm{Pheo})$ from selected water samples displayed general agreement with the $\mathrm{Chl} \mathrm{Fl}$ signals and suggest that the trends in the latter reflected the distribution of photosynthetic biomass rather than interferences from other potential sources of fluorescence. Overall, as was the case for POC, the $\mathrm{Chl} \mathrm{Fl}$ values from samples collected during SKQ201712S from the middepth and bottom regions of the water column were somewhat higher than those collected from the same depth ranges during SKQ201612S (Table 1), likely reflecting differences in phytoplankton standing stocks in different water masses. 


\section{Pre-Wind Event $\quad$---- $\quad$ Post Wind Event}
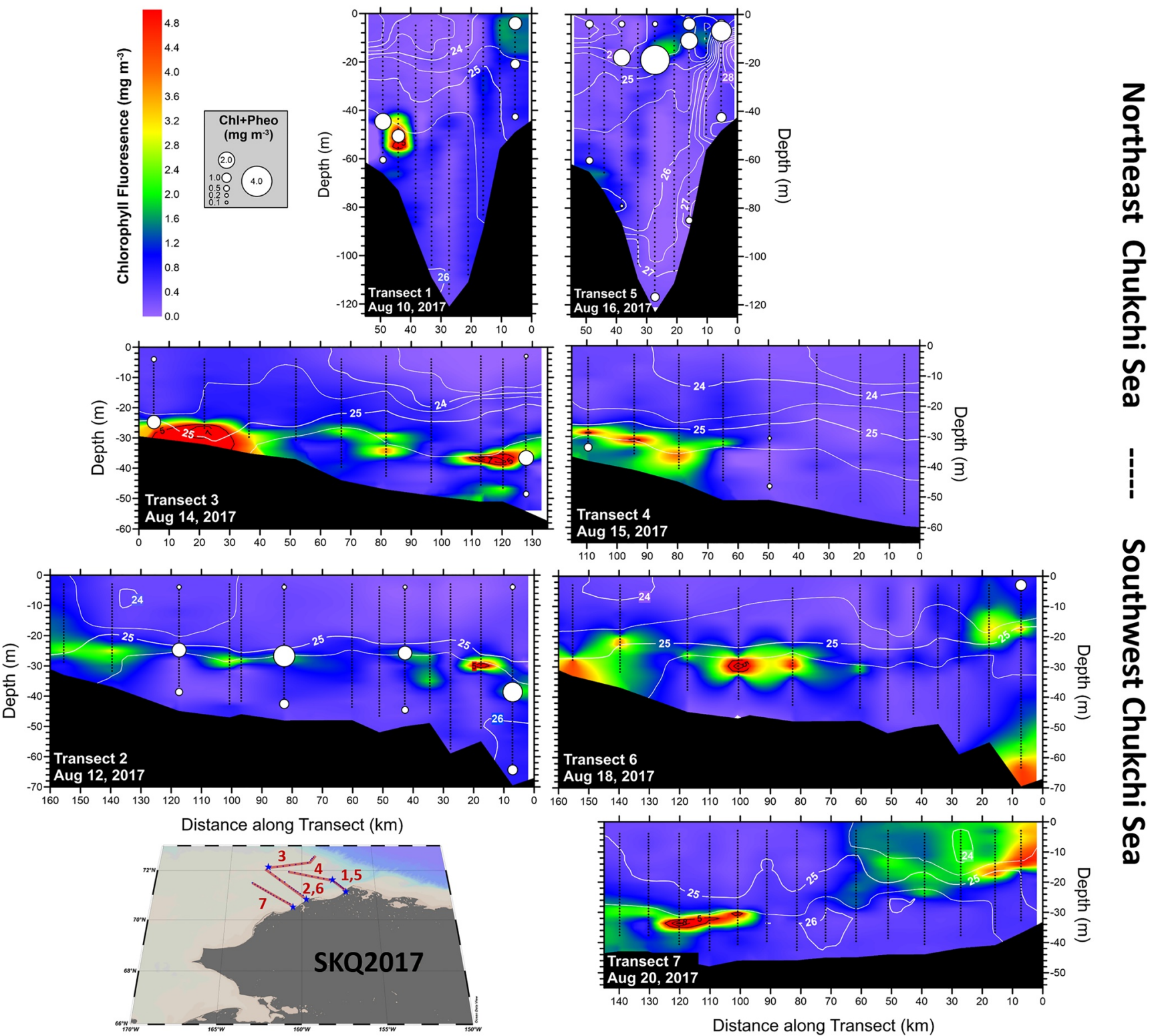

Figure 10. Distributions of chlorophyll fluorescence sensor measurements ( $\mathrm{Chl} \mathrm{Fl;} \mathrm{mg} \mathrm{m}^{-3}$ ) throughout the water column and combined photosynthetic pigment concentrations, chlorophyll and pheophytin $\left(\mathrm{Chl}+\mathrm{Pheo} ; \mathrm{mg} \mathrm{m}^{-3}\right)$, from individual samples collected across the seven hydrographic transects completed during SKQ201712S. The white contour lines represent density distributions (see Figure 9). Note that the start of each transect is identified by a blue star in the map insert. The cross-section contour plots are based on binned downcast data collected at each CTD station indicated by dotted lines in each transect. The bubble plots showing $\mathrm{Chl}+$ Pheo concentrations are superimposed on the contour maps to identify the location of each individual sample.

Figure 11 illustrates the particle beam attenuation characteristics of the water columns across all seven SKQ201712S transects and shows superimposed SPM concentrations from individual water samples. As was the case for the previous cruise, virtually all surface to middepth waters $\left(23<\sigma_{\mathrm{t}}<25.5 \mathrm{~kg} \mathrm{~m}^{-3}\right)$ above or near the pycnocline in 2017 were characterized by very low $c_{\mathrm{p}}$ values $\left(<0.2 \mathrm{~m}^{-1}\right)$ and low SPM concentrations $\left(<3 \mathrm{~g} \mathrm{~m}^{-3}\right)$. The major exceptions were the inshore waters along the Barrow Canyon transects (transects 1 and 5) and the nearshore waters sampled along transects 6 and 7 following the upwelling wind event. In contrast, high-density $\left(\sigma_{\mathrm{t}}>25.5 \mathrm{~kg} \mathrm{~m}^{-3}\right)$ bottom waters displayed markedly elevated $c_{\mathrm{p}}$ values and SPM concentrations that ranged from 1 to $3 \mathrm{~m}^{-1}$ and 5-15 $\mathrm{g} \mathrm{m}^{-3}$, with the deep sample from the inshore station of transect 6 that had elevated POC $\left(>65 \mathrm{mmol} \mathrm{m}^{-3}\right)$, exhibiting very high values of $c_{\mathrm{p}}\left(\sim 7 \mathrm{~m}^{-1}\right)$ and 
Pre-Wind Event ---- Post Wind Event
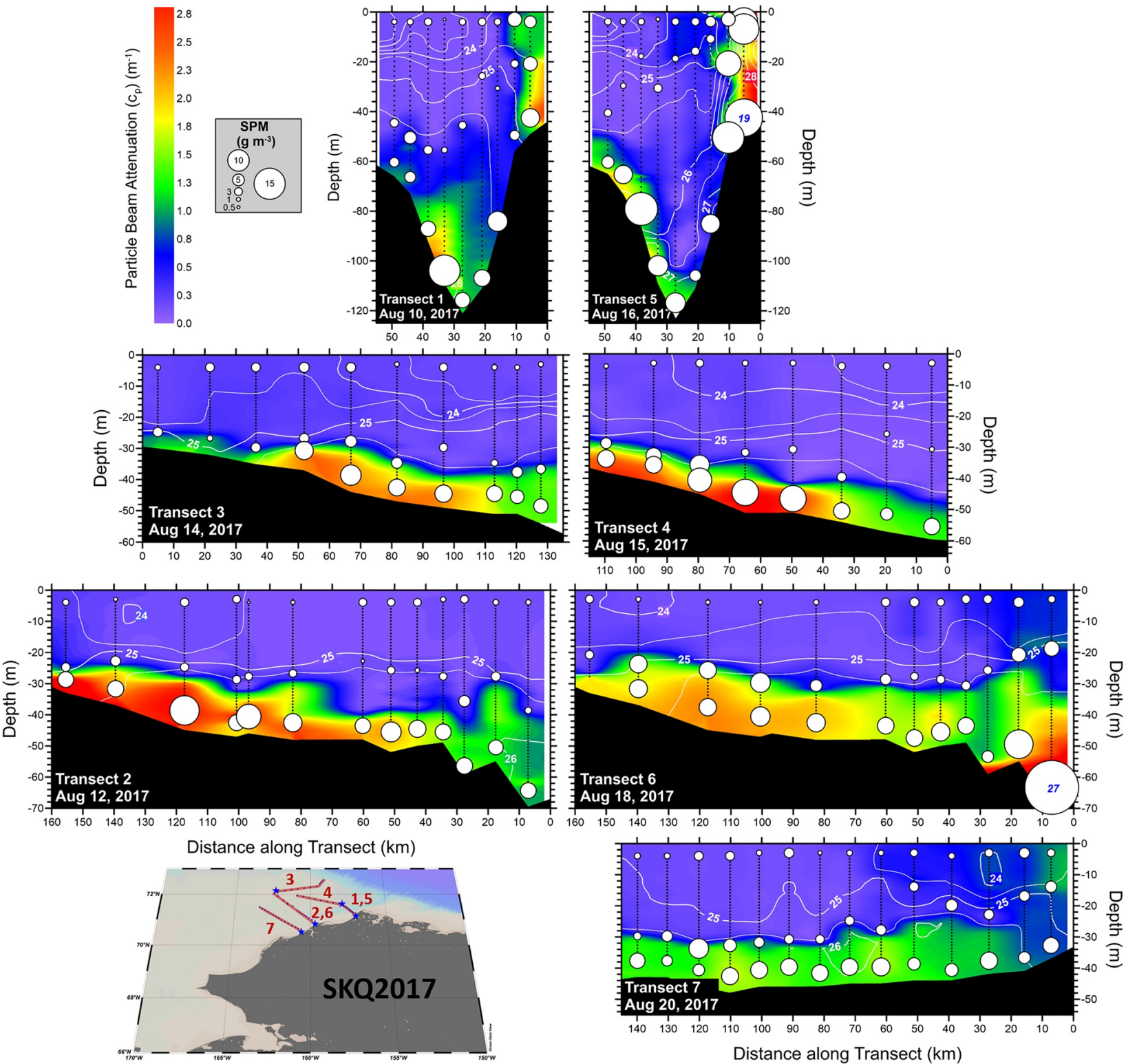

Figure 11. Distributions of particle beam attenuations sensor measurements $\left(c_{\mathrm{p}} ; \mathrm{m}^{-1}\right)$ throughout the water column and combined suspended particulate matter concentrations (SPM; $\mathrm{g} \mathrm{m}^{-3}$ ) from individual samples collected across the seven hydrographic transects completed during SKQ201712S. The white contour lines represent density distributions (see Figure 9). Note that the start of each transect is identified by a blue star in the map insert. The cross-section contour plots are based on binned downcast data collected at each CTD station indicated by dotted lines in each transect. The bubble plots showing SPM concentrations are superimposed on the contour maps to identify the location of each individual sample.

SPM $\left(27 \mathrm{~g} \mathrm{~m}^{-3}\right)$. While the overall extent and intensity of the particle-rich bottom waters differed between the two cruises (see Figures 7 and 11), they both highlight the predominance of turbid conditions in bottom waters throughout much of the Chukchi shelf during the open water period. The ranges and overall averages of $c_{\mathrm{p}}$ and SPM during SKQ201712S were generally higher to those during SKQ201612S, especially in samples from the middepth and deeper regions of the water column (Table 1), consistent with comparable contrasts in other variables.

As was the case for SKQ201612S, during SKQ201712S we completed several CTD casts close to local noon when surface PAR (500-1,000 $\mu$ Ein $\mathrm{cm}^{-2} \mathrm{~s}^{-1}$ ) was at a maximum (Figure 12). These plots show steep light 


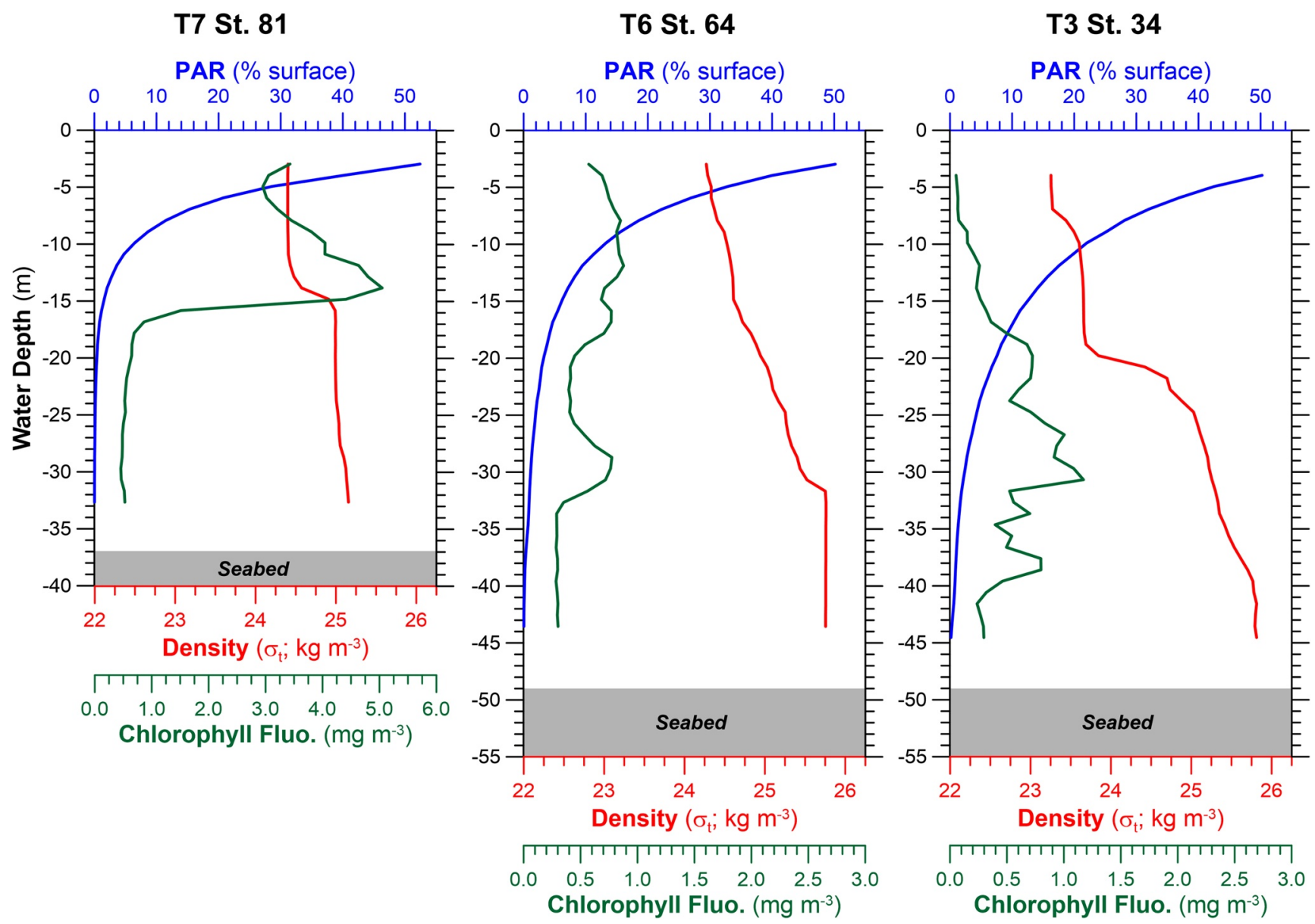

Figure 12. Profiles from selected hydrographic stations identified by transect (T\#) and CTD station (St.\#) numbers (see Figure 1) occupied near local mid-day during SKQ201712S. Local date/time occupation of these hydrographic stations is as follows: T3 St.34, August 14, 2017 at 12:25; T6 St.64, August 18, 2017 at 12:41; T7 St.81, August 20, 2017 at 11:19. The figures show depth profiles of density $\left(\sigma_{\dagger} ; \mathrm{kg} \mathrm{m}^{-3}\right)$, chlorophyll fluorescence $\left(\mathrm{mg} \mathrm{m}^{-3}\right)$ and photosynthetically active radiation (PAR; $\mu$ Ein $\mathrm{cm}^{-2} \mathrm{~s}^{-1}$ ) measurements calculated as a percent of surface PAR.

attenuation conditions were also prevalent during the August 2017 cruise, with some cases, such as stations 81 and 64 , where the 1\% PAR level corresponded to depths just below the pycnocline. Compared to the profiles obtained during September of 2016 (Figure 7), the profiles obtained during August of 2017 showed steeper light attenuation conditions, especially following the upwelling-favorable wind event.

\subsection{Comparison With Previous Observations}

The overall summaries of the different measurements carried out during SKQ201612S and SKQ201712S presented in Table 1 provide the opportunity to compare these data to those from previous studies of the same region. For example, temperature and salinity differences between the two cruises were especially notable in surface and middepth samples (Table 1), where warmer and saltier values characterized the late summer in 2017 relative to 2016. Similar compositional contrasts were measured throughout the Chukchi Shelf by S. L. Danielson et al. (2017) during two consecutive late seasons (August-September) in 2012 and 2013, highlighting the interannual variations in regional circulation and water mass distributions of this inflow shelf system. Depth-related density differences (e.g., Figures 4 and 9 ) summarized by the $\sigma_{t}$ averages in Table 1 were consistent with previous studies (e.g., S. L. Danielson et al., 2017; Martini et al., 2016; Weingartner et al., 2017), which highlighted the impacts of water column stratification on dissolved nutrients and phytoplankton biomass distributions. 
Our measurements of $\mathrm{Chl} \mathrm{Fl} \mathrm{distributions} \mathrm{during} \mathrm{the} 2016$ and 2017 cruises (Table 1) were comparable to those measured in 2012 and 2013 by S. L. Danielson et al. (2017), who showed chlorophyll concentrations in surface waters north of Pt. Hope ranged between 0.2 and $0.5 \mathrm{mg} \mathrm{m}^{-3}$ in the region around Hannah Shoal and 0.6-1.0 $\mathrm{mg} \mathrm{m}^{-3}$ in more inshore waters. Furthermore, both the overall ranges (Table 1) and depth distribution of $\mathrm{Chl} \mathrm{Fl} \mathrm{in} \mathrm{our} \mathrm{study} \mathrm{were} \mathrm{comparable} \mathrm{to} \mathrm{previous} \mathrm{measurements} \mathrm{by} \mathrm{Weingartner} \mathrm{et} \mathrm{al.} \mathrm{(2017),} \mathrm{who}$ showed transects near Hannah Shoal in 2012 with a well-defined SCM (2-10 mg m${ }^{-3}$ ) located immediately below pycnocline depths. Martini et al. (2016) showed similar ranges of chlorophyll concentrations at the SCM in the northeast region around Hannah Shoal during cruises in August-September 2013. As was the case for our study (e.g., Figures 7 and 12), these authors detected the SCM in a region of the water column that was below the mean pycnocline depth but above the mean euphotic depth as defined by the $1 \%$ PAR level. The overall agreement with previous measurements indicate the POM distributions and characteristics we measured during the 2016 and 2017 cruises are representative of late season conditions in this region of the Chukchi Shelf.

Our measurements of POC and photosynthetic pigment ( Chl + Pheo) concentrations during both SKQ201612S and SKQ201712S (Table 1) can be compared to previous studies investigating the seasonal evolution of phytoplankton productivity during the spring-summer period along the NE Chukchi Shelf. For example, studies conducted in June-July of 2010 showed markedly elevated chlorophyll ( $>30 \mathrm{mg}$ $\mathrm{m}^{-3}$ ) and POC (>60 $\mathrm{mmol} \mathrm{m}^{-3}$ ) concentrations in surface and subsurface waters from the central and NE Chukchi Sea that were much higher than those in this study (Table 1) and consistent with under-ice and ice-edge blooms in the spring (Arrigo et al., 2014; Brown et al., 2015; Lowry et al., 2015). Measurements conducted during the 2002 spring (May-June) and summer (July-August) open-water period along the NE Chukchi Sea (e.g., Hill \& Cota, 2005; Bates et al., 2005) showed POC concentrations that ranged from 2 to $40 \mathrm{mmol} \mathrm{m}^{-3}$ and chlorophyll concentrations that ranged from 0.2 to $6 \mathrm{mg} \mathrm{m}^{-3}$ along the regions around Hannah Shoal and Barrow Canyon. The highest values in both POC and chlorophyll were measured during the July-August period and were found in subsurface regions of the water column at or below the pycnocline. Our measurements during the August-September period generally agree with these trends and show moderately elevated photosynthetic pigment and POC concentrations at the middepths (Table 1). The fact that these features are present through the late summer-early fall suggest the importance of wind-driven mixing of nutrient-rich waters in maintaining subsurface productivity during the late open-water season (e.g., Ardyna \& Arrigo, 2020; Martini et al., 2016; Nishino et al., 2020; Stabeno et al., 2020).

Finally, our observations of elevated $c_{\mathrm{p}}$ values and high SPM concentrations in bottom-waters throughout the Chukchi Shelf were consistent with data from Martini et al. (2016), who measured high turbidity in denser waters below the pycnocline along shelf-transects near Hannah Shoal in September 2013. Mooring-based measurements along the Beaufort Sea margin by Forest et al. (2013, 2015) showed high turbidity waters off the Mackenzie Shelf during the open water season (July-August) that were not correlated with Chl Fl and were consistent with periods of energetic and downwelling-favorable wind conditions at the shelf-break. Cross-margin transects in this region during the summer period showed high density $\left(\sigma_{\mathrm{t}}>25.5 \mathrm{~kg} \mathrm{~m}^{-3}\right)$ bottom waters with low transmissivity (consistent with $c_{\mathrm{p}}>0.5 \mathrm{~m}^{-1}$ ) originated in shallower regions of the shelf (e.g., Forest et al., 2007). Several reports of SPM concentrations in Chukchi Sea waters include observations by Moran et al. (2005), who reported slightly elevated SPM values $\left(\sim 0.5-1.0 \mathrm{~g} \mathrm{~m}^{-3}\right)$ in bottom waters along the shelf-break east of Hannah Shoal and Barrow Canyon during Spring of 2002, a period of intermediate productivity (Hill \& Cota, 2005). Neukermans and coworkers (2014) measured $c_{\mathrm{p}}$ and SPM across the NE Chukchi shelf during the NASA ICESCAPE study in July 2011 and reported intermediate values $\left(c_{\mathrm{p}} \sim 0.5-1.0 \mathrm{~m}^{-1} ; \mathrm{SPM} \sim 2 \mathrm{~g} \mathrm{~m}^{-3}\right)$ in bottom waters near Hannah Shoal under open water conditions, and markedly higher values $\left(c_{\mathrm{p}} \sim 1-2 \mathrm{~m}^{-1} ; \mathrm{SPM} \sim 8 \mathrm{~g} \mathrm{~m}^{-3}\right)$ north of Hannah Shoal in under-ice conditions. There were distinct differences in the $\mathrm{Chl}$ and POC distributions associated with these samples which, along with further studies of optical characterization (e.g., particle backscatter), point toward contrasts among particle sources and compositions within the Pacific Arctic waters (e.g., Neukermans et al., 2016; Reynolds \& Stramski, 2019). 


\section{Discussion}

The spatial, temporal, and depth-related trends in POM distributions presented above and summarized in Table 1 cannot be fully understood without careful consideration of hydrographic conditions during the two cruise periods. In the following sections, we examine water mass distributions across the northeast Chukchi Shelf and relate the concentrations and compositions of POM to the distinct distribution patterns and wind forcings experienced during the two late-summer periods.

\subsection{Late Season Hydrographic Trends}

We can investigate the distributions of water masses across the Chukchi Shelf during the two late season cruises by plotting temperature and salinity compositions for the different stations and transects (Figure 13). In these graphs, we chose to highlight the compositions of distinct water masses based on the temperature and salinity signatures defined by S. L. Danielson et al. (2017), who conducted hydrographic surveys of this region during the late summer. For example, during SKQ201612S (Figures 13a and 13b), a large fraction of surface waters in this region of the Chukchi Shelf is made up of low-density $\left(22>\sigma_{\mathrm{t}}>24 \mathrm{~kg} \mathrm{~m}^{-3}\right)$ waters with salinity-temperature signatures consistent with a Melt Water (MW) source. Much of this MW is quite cold $\left(-1^{\circ} \mathrm{C}\right)$ and relative fresh (salinity $<28$ ), which is consistent with inputs from recently melted sea ice along offshore sections of transects 3, 4, 5, and 8 around Hannah Shoal, where we encountered the ice pack. In transects 2, 6, 7 further to the west, MW waters are warmer $\left(>0^{\circ} \mathrm{C}\right)$ and saltier $(>28)$ and likely influenced by mixing with other water masses. Intermediate density $\left(24>\sigma_{\mathrm{t}}>25.5 \mathrm{~kg} \mathrm{~m}^{-3}\right)$ Bering/Chukchi Summer Water (BCSW) and Bering/Chukchi Winter Water (BCWW) occupy the mid-depths across the study area and contribute to the strong pycnoclines observed during SKQ201612S. Relatively warm $\left(2{ }^{\circ} \mathrm{C}-5^{\circ} \mathrm{C}\right) \mathrm{BCSW}$ occupies mid-depths along transects 2, 6, 7, whereas low salinity (30-31.5) BCWW occupies the middepth sections of the water column further to the northeast along transects $3,4,8$ ). The deeper sections of the water column during SKQ201612S are occupied by high-density $\left(\sigma_{\mathrm{t}}>25.5 \mathrm{~kg} \mathrm{~m}^{-3}\right)$ waters that constitute the bottom mixed layer and are made up of BCWW and BCSW, with marked spatial differences among and within transects (Figures 13a and 13b).

The salinity-temperature plots for SKQ201712S (Figures 13c and 13d) illustrate quite different conditions from those of SKQ201612S, reflecting the occupation of stations inshore of the 30-mile distance and the diminished influence of sea-ice melt during the 2017 cruise. As shown in these graphs, BCSW is the major water mass throughout much of study area for SKQ201712S, with large swaths of all transects being occupied by these intermediate-density $\left(24>\sigma_{\mathrm{t}}>25.5 \mathrm{~kg} \mathrm{~m}^{-3}\right)$ modified summer waters. Lower-density $\left(22>\sigma_{\mathrm{t}}>24 \mathrm{~kg} \mathrm{~m}^{-3}\right) \mathrm{MW}$ is found in some sections of transects 1, 3, 4, whereas we find intermediate-density $\left(24>\sigma_{\mathrm{t}}>25 \mathrm{~kg} \mathrm{~m}^{-3}\right) \mathrm{ACW}$ with temperatures above $7^{\circ} \mathrm{C}$ in nearshore sections of transects $1,5,6,7$. The deeper sections of the water column are occupied primarily by high-density $\left(\sigma_{\mathrm{t}}>25.5 \mathrm{~kg} \mathrm{~m}^{-3}\right) \mathrm{BCSW}$ and BCWW, with the latter being found along transects $1,3,4,5$. The other major water mass observed during SKQ201712S is high-salinity ( $>33$ ) dense $\left(>26 \mathrm{~kg} \mathrm{~m}^{-3}\right)$ AtlW, which is found along the deeper part and southern sections of transect 5 following the upwelling event.

The spatial trends in water mass distributions, which are illustrated in Figures S2 and S3, reflect the regional circulation in this area of the Chukchi Shelf (e.g., Figure 1a, S. L. Danielson et al., 2017; Pacini et al., 2019; Okkonen et al., 2019; Weingartner et al., 2017) and highlight the contrasts between the two late-season cruises. For example, in SKQ201612S, most of the top $20 \mathrm{~m}$ of the water column through the study area is occupied by MW, which overlies denser BCWW and BCSW and results in the strong stratification conditions observed (Figure S2). Notably, MW overlies nutrient-rich remnant winter water (BCWW) in many of sections south and east of Hannah Shoal (e.g., transects 3, 4, 8), whereas nutrient-poor, modified water (BCSW) is found in regions west of Hannah Shoal (e.g., transects 2, 6 and 7). In contrast, during SKQ201712S, highly modified, nutrient-poor BCSW occupies much of the water column throughout the study area, including surface waters across transects to the south, west and directly over the Hannah Shoal region (Figure S3). The ubiquitous extent of BCSW combined with the restricted distribution of more buoyant water masses (e.g., MW and ACW) helps to explain the markedly lower degree of water column stratification that characterized SKQ201712S. Furthermore, unlike SKQ201612S, the distribution of nutrient-rich BCWW across the northeast Chukchi Shelf during SKQ201712S is restricted to the deepest regions of the water column 
a)

b)

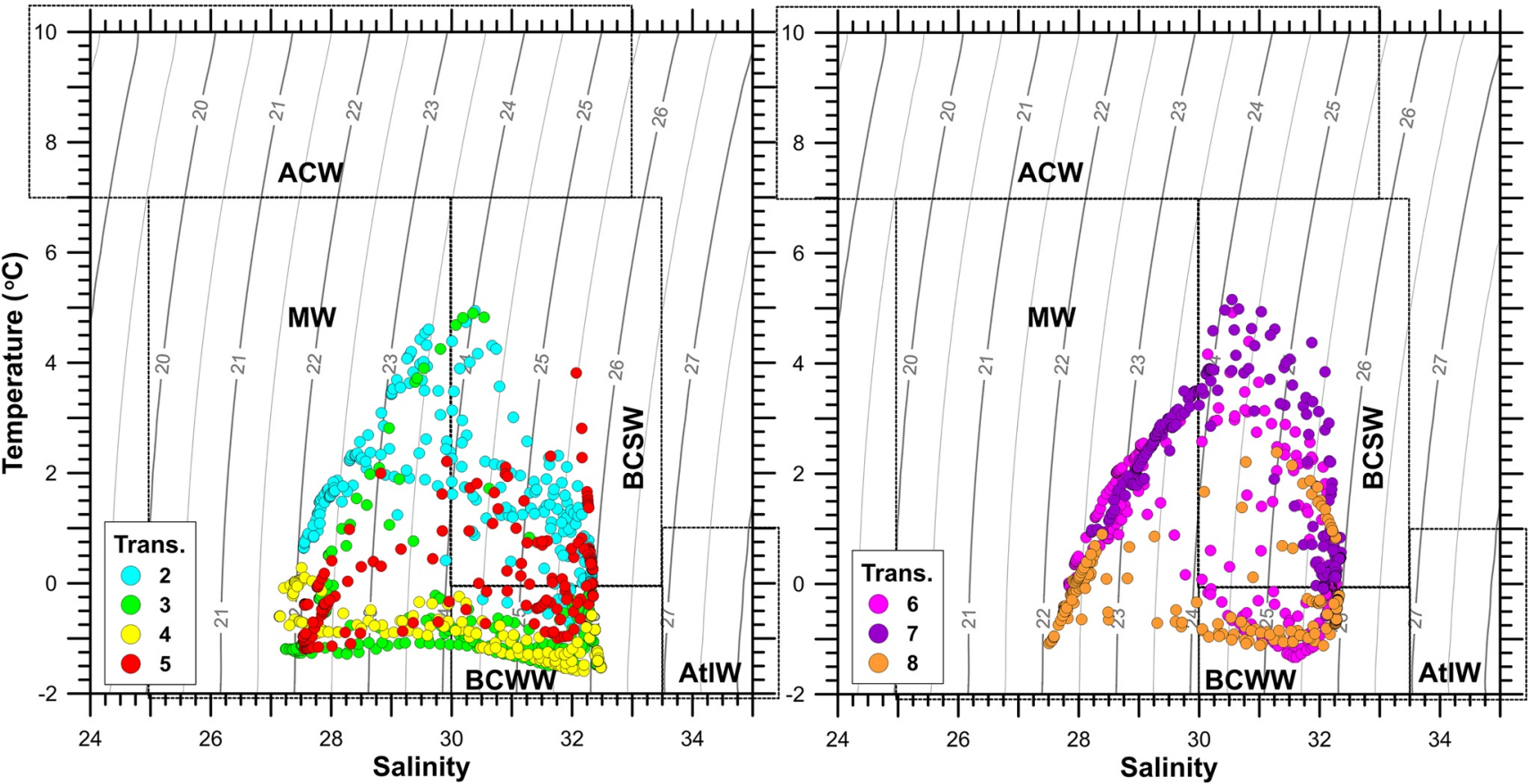

c)

d)

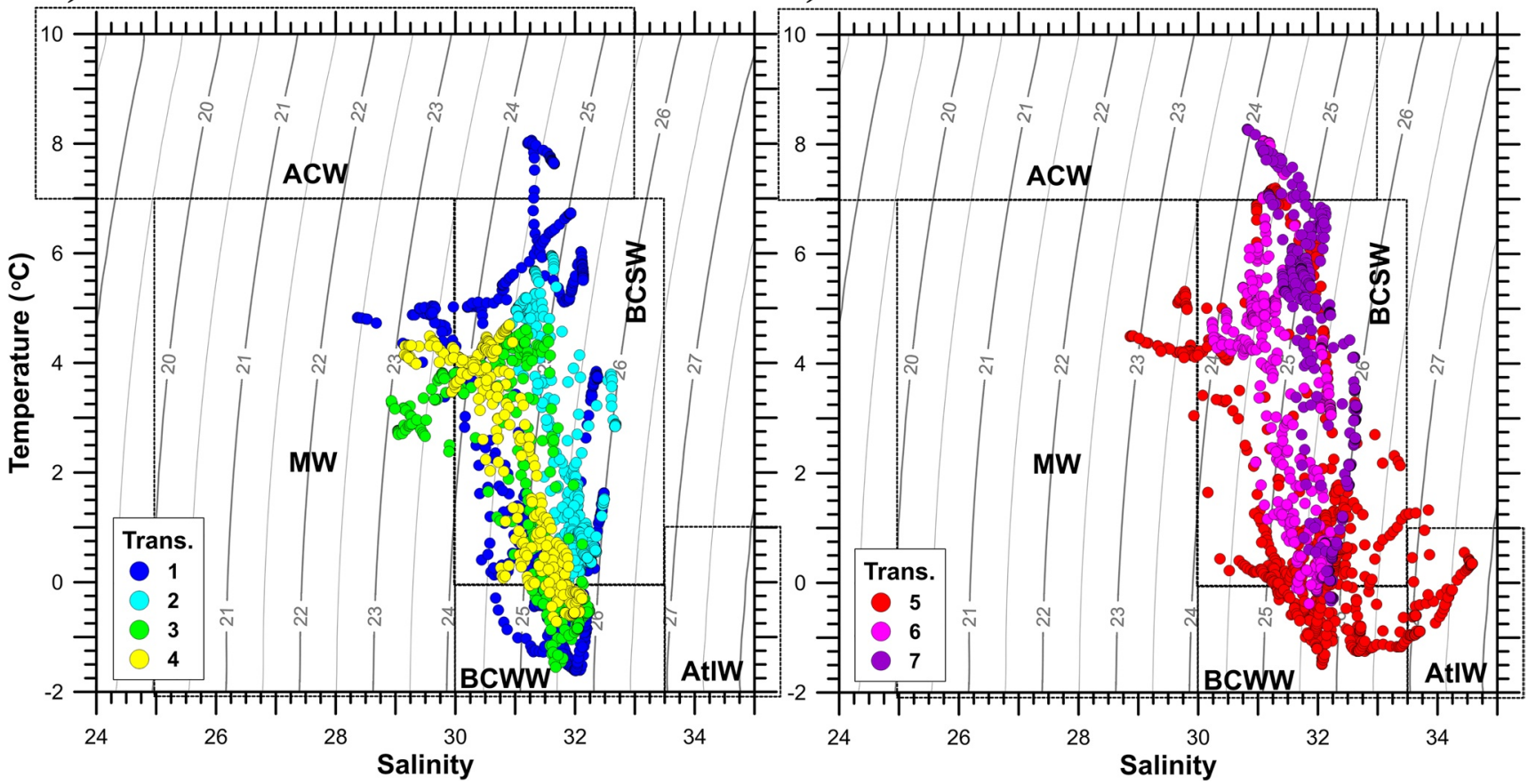

Figure 13. Temperature-Salinity plots summarizing hydrographic compositions measured during SKQ201612S before and after the Sep 17-20, 2016 downwelling-favorable wind event (a and b, respectively) and during SKQ201712S before and after the August 12-17, 2017 upwelling-favorable wind (c and $\mathrm{d}$, respectively). The transects occupied during each period are identified by the different colors. The plots also include the temperature-salinity ranges for different regional water masses based on the data from Danielson et al., 2017. The water masses shown include Alaska Coastal Water (ACW), Melt Water (MW), Bering-Chukchi Summer Water (BCSW), Bering-Chukchi Winter Water (BCWW), and Atlantic Water (AtlW). Also shown are lines of equal density ( $\sigma_{t}$; kg m ${ }^{-3}$ ) for the temperature and salinity ranges in each graph. 
east of Hannah Shoal and is overlain by modified BCSW. Figure S3 shows multiple water masses across Barrow Canyon, highlighting the more complex circulation associated with this feature and its response to wind-driven upwelling (e.g., Okkonen et al., 2019; Pickart et al., 2019).

As illustrated by Figures S2 and S3, the hydrographic responses to wind forcing on the shelf itself are more muted, but display patterns consistent with previous observations (e.g., Weingartner et al., 2017; Pickart et al., 2019). For example, after the downwelling-favorable wind-event in SKQ201612S we see changes that are consistent with an enhanced presence of BCWW in the offshore region west of Wainwright (see transect 6 vs. 2) and a deepening of the mixed layer across the southern flank of Hannah Shoal (offshore region of transect 8 vs. 3). Given the strong westerly winds measured in the period (September 16-21, 2016) between the repeated transects, we infer that enhanced advection and mixing likely contribute to the changes observed. In the case of SKQ201712S, the main effect of the strong easterly winds (August 12-15, 2017) is seen across Barrow Canyon, with the occurrence of AtlW across the southern flank of the Canyon and the offshore displacement of ACW across the surface (Figure S3), both consistent with the responsiveness of the canyon to upwelling-favorable wind forcing (e.g., Pickart et al., 2019; Pisareva et al., 2019). The offshore extension of ACW following the easterly wind-period is the main effect of upwelling across the shallow shelf regions to the west of Barrow Canyon (e.g., transect 6 vs. transect 2; transect 7).

Overall, the observed contrasts in water mass distributions reflect interannual differences in oceanographic conditions in the study area as well as contrasts in the spatial coverage of Chukchi Shelf afforded during each cruise. Furthermore, there are noticeable differences in the composition and structure of the water column across the northeast Chukchi Shelf in response to distinct wind forcings. The differences among transects occupied prior and following wind events reflect their distinct nature (i.e., downwelling vs. upwelling favorable) and variable magnitude. However, it is also clear that location (e.g., deeper Barrow Canyon vs. shallower Chukchi Shelf) relative to key geographical features (e.g., shoreline, Hannah Shoal) also influence the structure of the water column along any given transect. Understanding these contrasts and controls on water column POM is critical to evaluate the biogeochemical responses of this region of the Pacific Arctic during the prolonged open-water period.

\subsection{Water Mass-POM Distributions Along Chukchi Shelf}

In order to decipher the spatial and temporal patterns in POM distributions, we chose to evaluate compositional trends in the context of hydrographic conditions and water mass distributions. Hence, we use temperature-salinity class plots of $\mathrm{Chl} \mathrm{Fl}$ to investigate density-related trends in chlorophyll distributions among water masses (Figure 14). For example, during SKQ201612S, we generally find low to moderate Chl Fl values (0.8-1.4 $\mathrm{mg} \mathrm{m}^{-3}$ ) before the wind event of September 17-20, 2016 in all three water masses. In fact, prior to the wind event, the high $\mathrm{Chl} \mathrm{Fl} \mathrm{values}\left(>1.8 \mathrm{mg} \mathrm{m}^{-3}\right)$ that define the SCM are most predominant in higher-density BCSW (e.g., transect 2; Figure 5) rather than in BCWW (e.g., transect 3; Figure 5). Following the period of sustained downwelling winds, the high Chl Fl values shift to BCWW (Figure 14b), especially in the region west of Wainwright (i.e., transect 6; Figure 5). This trend, illustrated by the contrast between transects 2 and 6, indicates a deepening of the SCM due to mixing and advection of nutrient-rich BCWW in this region of the shelf (e.g., Figure 2s). The SKQ201712S data show that prior to the upwelling wind event in August 12-17 (2017), peaks in Chl Fl associated with the SCM occur in high density $\left(25>\sigma_{\mathrm{t}}>26 \mathrm{~kg} \mathrm{~m}^{-3}\right)$ waters in both BCWW and BCSW (Figure 14c). Following the period of upwelling winds, higher Chl Fl values are observed in lower density BCSW and ACW (Figure 14d), consistent with a phytoplankton productivity response due to nutrient mixing into upper parts of the water column along nearshore locations (Figure S3).

Similar temperature-salinity plots of $c_{\mathrm{p}}$ (Figure 15) reveal distinct trends in overall particle distributions that indicate chlorophyll-depleted particles are for the most part responsible for the elevated turbidity levels $\left(c_{\mathrm{p}}>1 \mathrm{~m}^{-1}\right)$ found in the densest $\left(\sigma_{\mathrm{t}} \sim 26 \mathrm{~kg} \mathrm{~m}^{-3}\right)$ waters, including BCSW, BCWW and AtlW. The fact that the high $c_{\mathrm{p}}$ and SPM values (Figures 6 and 11) coincide with dense bottom waters during both cruises (Figures 15a-15d) is a strong indication that interactions with the seabed through resuspension and/ or advection of pigment-depleted, mineral-rich particles contribute to the observed particle distributions along the NE Chukchi Shelf. The major exception are samples from the warm $\left(\sim 8^{\circ} \mathrm{C}\right)$, intermediate density $\left(24>\sigma_{\mathrm{t}}>25 \mathrm{~kg} \mathrm{~m}^{-3}\right)$ ACW that were measured in the nearshore section off Barrow Canyon (transect 
a)

b)

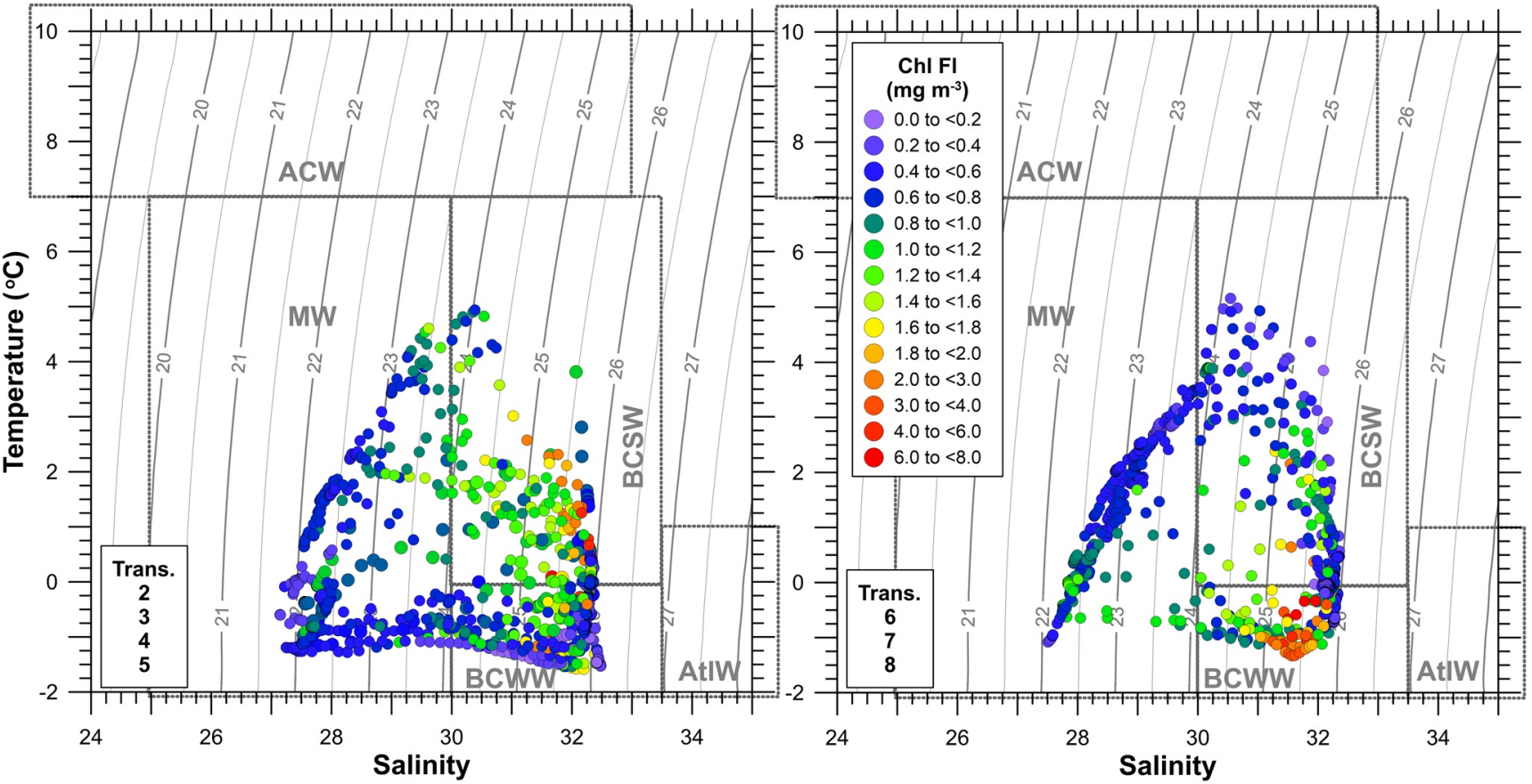

c)

d)

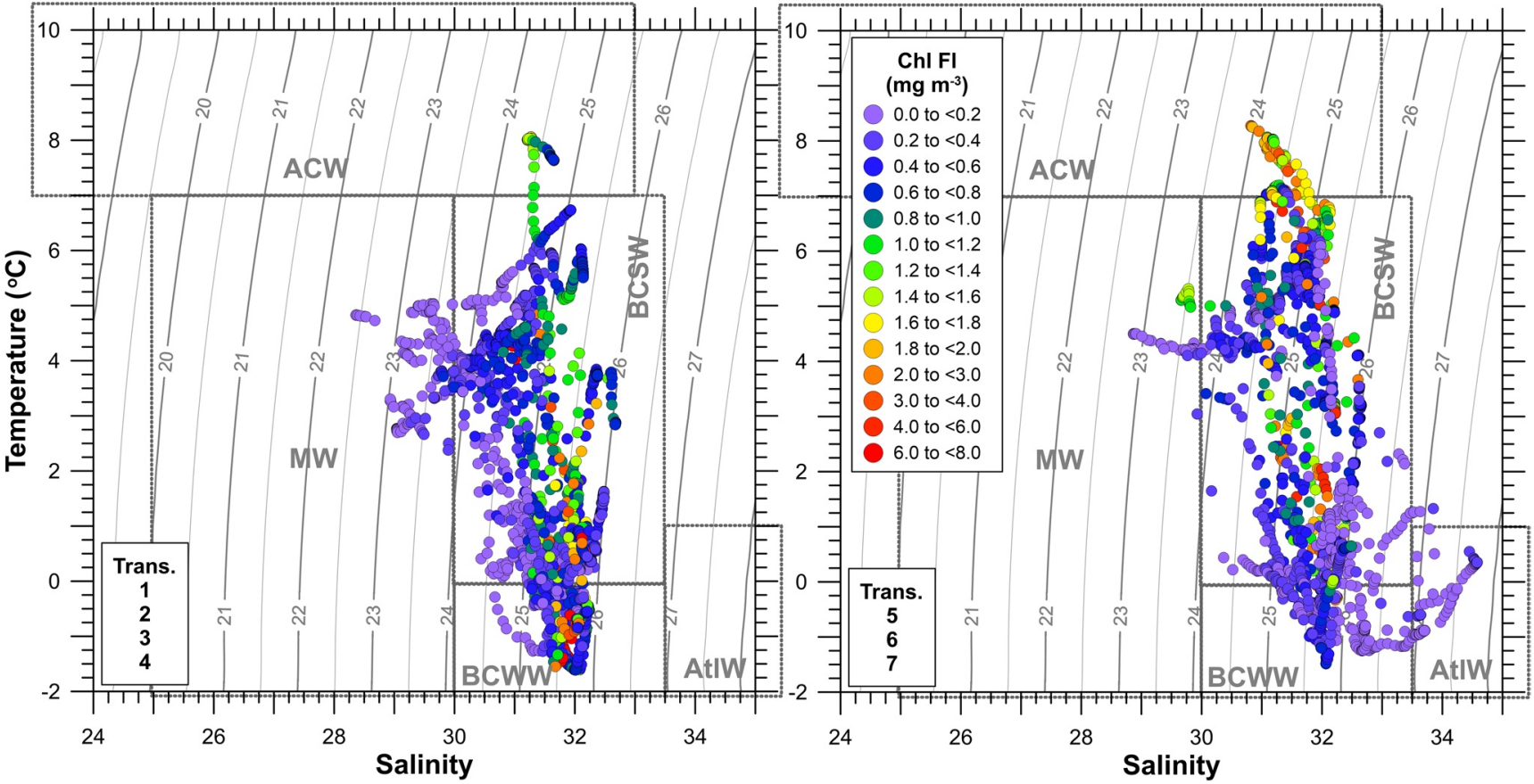

Figure 14. Chlorophyll fluorescence ( $\mathrm{Chl} \mathrm{Fl;} \mathrm{mg} \mathrm{m}^{-3}$ ) sensor data plotted in temperature-salinity graphs for stations occupied during SKQ201612S before and after the September 17-20, 2016 downwelling-favorable wind event ( $\mathrm{a}$ and b, respectively) and during SKQ201712S before and after the August 12-17, 2017 upwelling-favorable wind ( $\mathrm{c}$ and d, respectively). The plots include the temperature-salinity ranges for different regional water masses based on the data from Danielson et al. (2017). The water masses shown include Alaska Coastal Water (ACW), Melt Water (MW), Bering-Chukchi Summer Water (BCSW), BeringChukchi Winter Water (BCWW), and Atlantic Water (AtlW). Also shown are lines of equal density $\left(\sigma_{\mathrm{t}} ; \mathrm{kg} \mathrm{m}^{-3}\right)$ for the temperature and salinity ranges in each graph. 
a)

b)

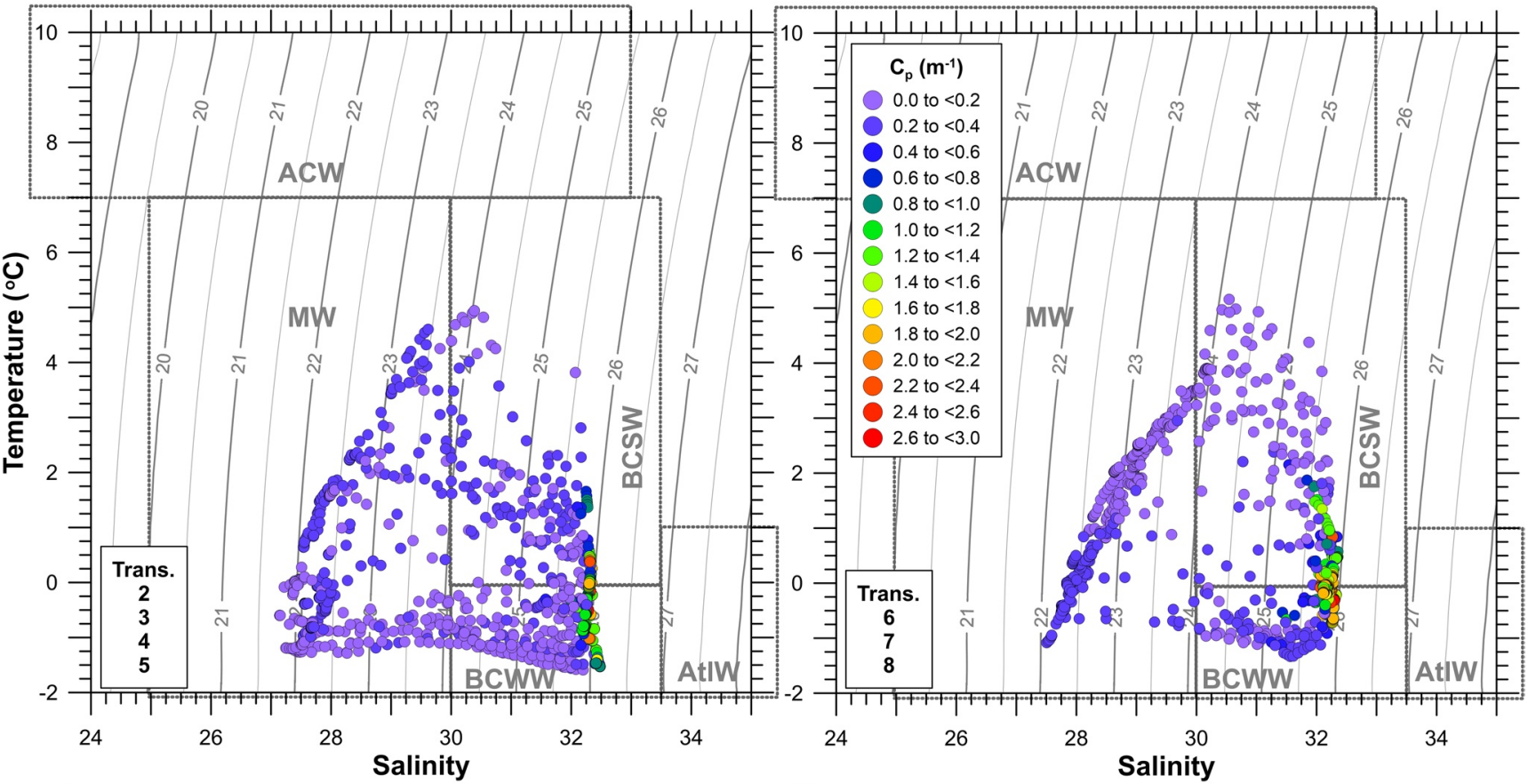

c)

d)

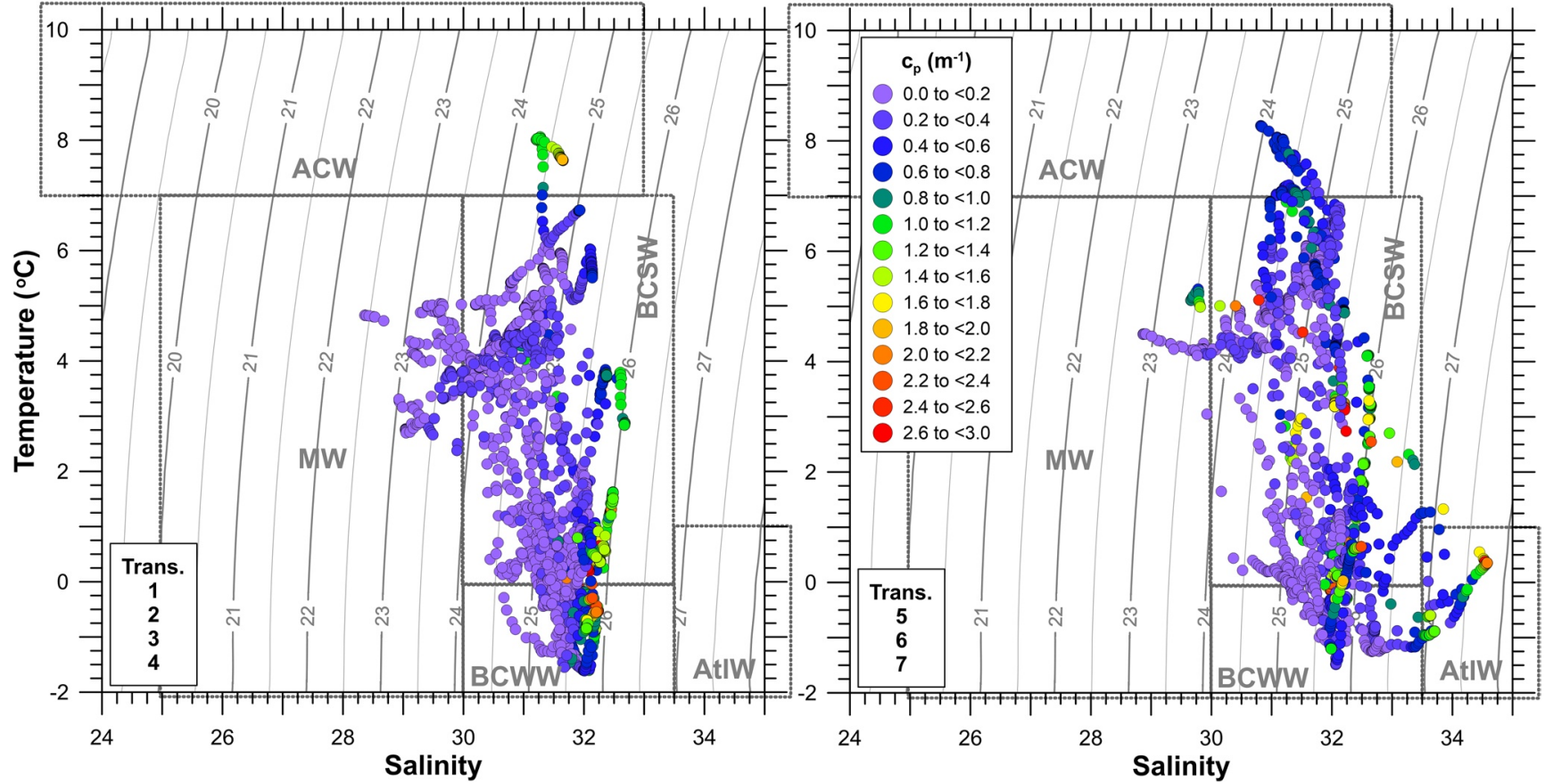

Figure 15. Particle beam attenuation $\left(c_{\mathrm{p}} ; \mathrm{m}^{-1}\right)$ sensor data plotted in temperature-salinity graphs for stations occupied during SKQ201612S before and after the September 17-20, 2016 downwelling-favorable wind event (a and b, respectively) and during SKQ201712S before and after the August 12-17, 2017 upwellingfavorable wind (c and d, respectively). The plots include the temperature-salinity ranges for different regional water masses based on the data from Danielson et al. (2017). The water masses shown include Alaska Coastal Water (ACW), Melt Water (MW), Bering-Chukchi Summer Water (BCSW), Bering-Chukchi Winter Water (BCWW), and Atlantic Water (AtlW). Also shown are lines of equal density $\left(\sigma_{\mathrm{t}} ; \mathrm{kg} \mathrm{m}^{-3}\right)$ for the temperature and salinity ranges in each graph. 
1; Figure 11) during SKQ201712S prior to the wind event (Figure 15c). It is likely that mineral-rich particles entrained within the ACW contribute to the elevated turbidity readings. In contrast, following the upwelling-wind event in 2017 (Figure S3), wind-induced phytoplankton production leads to elevated Chl Fl (Figure 14d) but relatively low $c_{\mathrm{p}}$ values (Figure 15d) in samples from ACW.

The compositions of individual samples can also be evaluated in the context of different water masses in the same way we assess the particle-related optical properties above (e.g., $\mathrm{Chl} \mathrm{Fl}$ and $c_{\mathrm{p}}$ ). For example, Figure 16 illustrates POC concentrations in temperature-salinity graphs and shows that despite the reduced number of individual samples, there are statistically significant differences among water masses measured in this study. Tables 2 and 3 provide summaries of the concentration data from individual samples for different water masses binned into density ranges and cruise periods prior/following the wind events. From both Figure 16 and Table 2, it is apparent that in SKQ201612S, moderate to elevated POC concentrations ( $\geq 8 \mathrm{mmol}$ $\mathrm{m}^{-3}$ ) coincide with cool, low density $\left(21>\sigma_{\mathrm{t}}>23 \mathrm{~kg} \mathrm{~m}^{-3}\right) \mathrm{MW}$ whereas the higher-salinity, higher density MW samples have lower POC concentrations (Figures 16a and 16b). All these samples are characterized by low Chl Fl signals, low $c_{\mathrm{p}}$ values, and low to moderate $\mathrm{Chl}+$ Pheo and SPM concentrations (Table 2). In contrast, the warmer and saltier MW samples measured during SKQ201712S are characterized by lower POC and lower Chl Fl values (Table 3). Overall, these trends suggest moderately elevated levels of phytoplankton biomass associated with surface waters affected by recently melted sea ice, which we encountered primarily in SKQ201612S (e.g., Figure 2s). The contrasting distributions between the two cruises likely reflect higher contributions from phytoplankton to suspended particles in recently formed, colder and fresher MW in SKQ201612S relative to the warmer MW encountered in SKQ201712S (Figure S3).

During SKQ201712S, moderate to high POC concentrations $\left(\geq 12 \mathrm{mmol} \mathrm{m}^{-3}\right)$ in surface waters are measured in samples from ACW, especially following the wind event (Figures 16c and 16d) when high Chl Fl and lowto moderate $c_{\mathrm{p}}$ values are also measured (Table 3). In contrast to MW, ACW samples in SKQ201712S have significantly elevated SPM and $\mathrm{Chl}+$ Pheo concentrations that coincide with the high POC concentrations and high $\mathrm{Chl} \mathrm{Fl}$ and $c_{\mathrm{p}}$ values. Unlike MW samples, there are significant differences in $\mathrm{Chl}+\mathrm{Pheo}$ and SPM concentrations (as well as Chl Fl and $c_{\mathrm{p}}$ signals) before and after the August 12-17, 2017 period (Table 3), that are consistent with an increase in phytoplankton biomass and a decrease in mineral-rich particles following the upwelling-favorable wind event. Overall, the statistically distinct compositions of ACW and MW samples reflect clear differences in both overall particle abundance and provenance between these two water masses that occupy surface sections of the northeast Chukchi Shelf during the late, open-water season (Figures S2 and S3).

Samples from BCSW and BCWW, which occupy the majority of the middepth and bottom regions of the water column across the northeast Chukchi Shelf, display variable compositions that are strongly related to density (Tables 2 and 3). For example, in both SKQ201612S and SQK201712S, samples from low- to intermediate-density $\left(\sigma_{\mathrm{t}}<25.5 \mathrm{~kg} \mathrm{~m}^{-3}\right)$ BCSW are characterized by low to moderate POC concentrations $\left(>8 \mathrm{mmol} \mathrm{m}^{-3}\right)$, whereas the higher-density $\left(\sigma_{\mathrm{t}}>25.5 \mathrm{~kg} \mathrm{~m}^{-3}\right)$ samples display higher POC concentrations $\left(>8 \mathrm{mmol} \mathrm{m}^{-3}\right)$ that in some cases exceed $20 \mathrm{mmol} \mathrm{m}^{-3}$ (Figure 16). Samples from low density $\left(23.5>\sigma_{\mathrm{t}}>24.5 \mathrm{~kg} \mathrm{~m}^{-3}\right)$ BCSW are characterized by low to intermediate $\mathrm{Chl} \mathrm{Fl}$ values $\left(0.3-1 \mathrm{mg} \mathrm{m}^{-3}\right)$, whereas those of intermediate density $\left(24.5>\sigma_{\mathrm{t}}>25.5 \mathrm{~kg} \mathrm{~m}^{-3}\right)$ associated with the top of the pycnocline

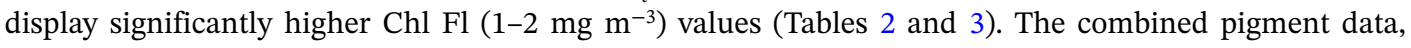
although sparse, show similar overall trends with moderately elevated Chl + Pheo concentrations that contribute to the SCM observed in transects from both cruises. Samples from both of these density ranges are characterized by relatively low $c_{\mathrm{p}}$ signals $\left(0.1-0.5 \mathrm{~m}^{-1}\right)$ and low SPM concentrations $\left(2-4 \mathrm{~g} \mathrm{~m}^{-3}\right)$, with samples from SKQ201712S (Table 3) displaying higher averages than samples from SKQ201612S (Table 2). Relative to their lower-density counterparts, higher-density $\left(25.5>\sigma_{\mathrm{t}}>26.0 \mathrm{~kg} \mathrm{~m}^{-3}\right)$ BCSW samples from both cruises (Tables 2 and 3) have higher POC concentrations (9-12 $\mathrm{mmol} \mathrm{m}^{-3}$ ) and are characterized by comparable Chl Fl values (1-2 $\left.\mathrm{mg} \mathrm{m}^{-3}\right)$ and $\mathrm{Chl}+$ Pheo concentrations (1-2.5 $\left.\mathrm{mg} \mathrm{m}^{-3}\right)$ but significantly higher $c_{\mathrm{p}}$ values $\left(\sim 1.4 \mathrm{~m}^{-1}\right)$ and SPM concentrations $\left(6-8 \mathrm{~g} \mathrm{~m}^{-3}\right)$. Notably, within this density range, BCSW samples with densities greater than $26.0 \mathrm{~kg} \mathrm{~m}^{-3}$ collected during SKQ201712S have lower Chl $\mathrm{Fl}$ and $\mathrm{Chl}+$ Pheo concentrations and higher POC, $c_{\mathrm{p}}$ and SPM values (Table 3 ).

In the case of BCWW, sample compositions from different density ranges display patterns that are similar to those from BCSW (Tables 2 and 3). For example, the few samples from low density $\left(24>\sigma_{\mathrm{t}}>25.5 \mathrm{~kg} \mathrm{~m}^{-3}\right)$ 
a)

b)

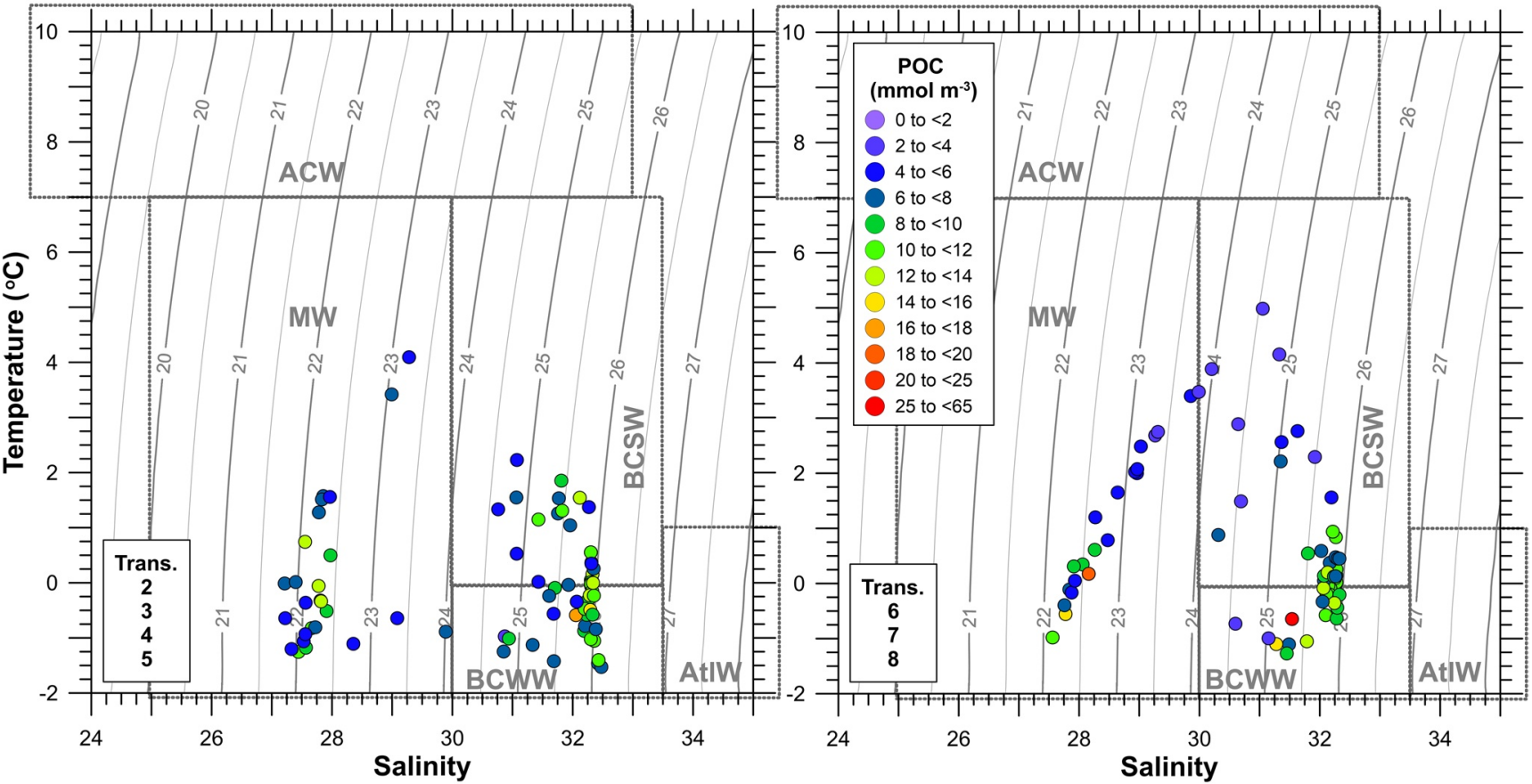

c)

d)

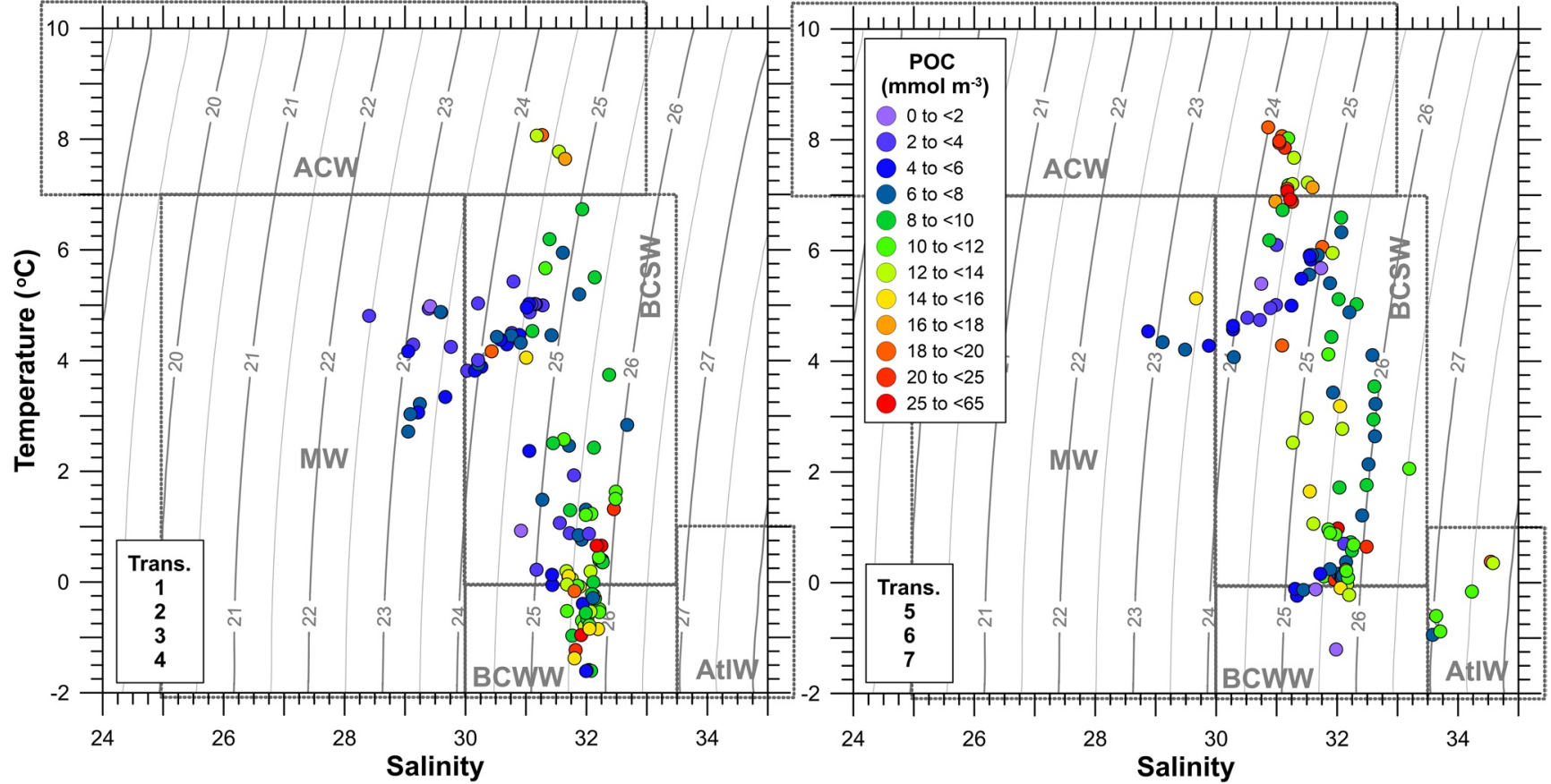

Figure 16. Particulate organic carbon (POC; $\mathrm{mmol} \mathrm{m}^{-3}$ ) concentrations from individual water samples plotted in temperature-salinity graphs for stations occupied during SKQ201612S before and after the September 17-20, 2016 downwelling-favorable wind event (a and b, respectively) and during SKQ201712S before and after the August 12-17, 2017 upwelling-favorable wind (c and d, respectively). The plots include the temperature-salinity ranges for different regional water masses based on the data from Danielson et al. (2017). The water masses shown include Alaska Coastal Water (ACW), Melt Water (MW), BeringChukchi Summer Water (BCSW), Bering-Chukchi Winter Water (BCWW), and Atlantic Water (AtlW). Also shown are lines of equal density $\left(\sigma_{\mathrm{t}} ; \mathrm{kg} \mathrm{m}^{-3}\right)$ for the temperature and salinity ranges in each graph. 
Table 2

Compositions (Average \pm Standard Deviation) of Density-Binned Niskin Bottle Samples From Different Water Masses During SKQ201612S

\begin{tabular}{lllll}
\hline Density bins $\sigma_{\mathrm{t}}\left(\mathrm{kg} \mathrm{m}^{-3}\right)$ & $\mathrm{Chl} \mathrm{Fl}\left(\mathrm{mg} \mathrm{m}^{-3}\right)$ & $c_{\mathrm{p}} \cdot\left(\mathrm{m}^{-1}\right)$ & $\mathrm{POC}\left(\mathrm{mmol} \mathrm{m}^{-3}\right)$ & $\left.\mathrm{Chl}+\mathrm{Pheo}_{(\mathrm{mg} \mathrm{m}}{ }^{-3}\right)$
\end{tabular}

Transects 2, 3, 4, 5 (September 12-17, 2016)

Melt Water (MW)

$\begin{array}{llllll}21.0-23.0 & 0.54 \pm 0.19 & 0.21 \pm 0.10 & 7.77 \pm 2.65 & 0.37 \pm 0.09 & 1.81 \pm 0.48 \\ 23.0-24.0 & 1.04 \pm 0.55 & 0.21 \pm 0.01 & 6.18 \pm 0.84 & 0.50 \pm 0.25 & 2.19 \pm 0.24\end{array}$

Alaska Coastal Water (ACW)

$$
\text { 24.0-25.0 }
$$

n.m.

n.m.

n.m.

n.m.

n.m.

Bering-Chukchi Summer Water (BCSW)

$23.5-24.0$

n.m.

n.m.

n.m.

n.m.

n.m.

25.5-27.0

$$
1.52 \pm 0.49
$$

$0.24 \pm 0.04$

$7.19 \pm 2.14$

$0.65 \pm 0.22$

$1.96 \pm 0.28$

$1.04 \pm 1.05$

$1.28 \pm 0.56$

$9.23 \pm 2.68$

$1.20 \pm 0.56$

$6.00 \pm 2.48$

Bering-Chukchi Winter Water (BCWW)
24.0-25.5
$1.45 \pm 1.04$
25.5-27.0
$0.65 \pm 0.53$

$0.16 \pm 0.07$

$6.76 \pm 1.54$

$0.87 \pm 0.58$

$2.34 \pm 0.31$

$1.46 \pm 0.59$

$10.0 \pm 2.79$

$0.87 \pm 0.51$

$5.85 \pm 2.51$

Atlantic Water (AtlW)

27.0-28.0

n.m.

n.m.

n.m.

n.m.

n.m.

Transects 6, 7, 8 (September 20-23, 2016)

Melt Water (MW)

21.0-23.0

23.0-24.0

Alaska Coastal Water (ACW)

24.0-25.0

n.m.

$0.70 \pm 0.23$

$0.25 \pm 0.06$

$0.11 \pm 0.04$

n.m.

$0.12 \pm 0.01$

$0.18 \pm 0.10$

$1.39 \pm 0.60$

$0.82 \pm 0.80$

25.5-27.0

$0.80 \pm 0.25$

Bering-Chukchi Winter Water (BCWW)
24.0-25.5
25.5-27.0
$2.93 \pm 2.87$
$0.75 \pm 0.71$

$0.32 \pm 0.21$

$1.79 \pm 0.68$

n.m.

n.m.
$8.37 \pm 4.43$

n.m.

$3.90 \pm$ n.a.

$4.61 \pm 1.66$

$9.12 \pm 2.02$

$12.2 \pm 11.8$

$10.8 \pm 1.76$ n.m.

n.m.

n.m.

n.m.

n.m.

n.m.

n.m.

n.m.

n.m.

n.m.

Note. Chl Fl, chlorophyll concentration based on fluorescence; $c_{\mathrm{p}}$, particle beam attenuation; POC, particulate organic carbon concentration; Chl+Pheo, chlorophyll plus pheophytin concentrations, SPM, suspended particulate matter.
BCWW measured in both SKQ201612S and SKQ201712S display low to intermediate POC concentrations (Figure 16) that coincide with high $\mathrm{Chl} \mathrm{Fl}$ and $\mathrm{Chl}+$ Pheo values and relatively low $c_{\mathrm{p}}$ and SPM concentrations (Tables 2 and 3). A major exception were samples collected following the upwelling wind event during SKQ201712S (Table 3), which display much lower POC $\left(\sim 4 \mathrm{mmol} \mathrm{m}^{-3}\right)$ and Chl Fl $\left(0.4 \mathrm{mg} \mathrm{m}^{-3}\right)$ values than the rest of the samples in this density category (see below). As was the case for BCSW, samples from the higher-density range $\left(24>\sigma_{\mathrm{t}}>25.5 \mathrm{~kg} \mathrm{~m}^{-3}\right)$ of BCWW in both cruises display higher POC concentrations (10-12 $\mathrm{mmol} \mathrm{m}^{-3}$ ) and Chl Fl values $\left(2-5 \mathrm{mg} \mathrm{m}^{-3}\right.$ ) and high $c_{\mathrm{p}}$ values and SPM concentrations (Table 2), all consistent with particle-rich, high turbidity deeper waters.

The marked contrasts among samples from BCSW and BCWW are clear evidence of fundamental density-related differences in POM composition and provenance within these water masses, which help explain the overall patterns observed during both cruises. Furthermore, by examining in more detail the trends as- 
Table 3

Compositions (Average \pm Standard Deviation) of Density-Binned Niskin Bottle Samples From Different Water Masses During SKQ201712S

\begin{tabular}{lllll}
\hline Density bins $\sigma_{\mathrm{t}}\left(\mathrm{kg} \mathrm{m}^{-3}\right)$ & $\mathrm{Chl} \mathrm{Fl}\left(\mathrm{mg} \mathrm{m}^{-3}\right)$ & $c_{\mathrm{p}}\left(\mathrm{m}^{-1}\right)$ & $\mathrm{POC}\left(\mathrm{mmol} \mathrm{m}^{-3}\right)$ & $\mathrm{Chl}+\mathrm{Pheo}_{\left(\mathrm{mg} \mathrm{m}^{-3}\right)}^{\mathrm{SPM}\left(\mathrm{g} \mathrm{m}^{-3}\right)}$ \\
\hline
\end{tabular}

Transects 1, 2, 3, 4 (August 10-16, 2017)

Melt Water (MW)

$\begin{array}{llllr}21.0-23.0 & 0.16 \pm \text { n.a. } & 0.14 \pm \text { n.a. } & 3.10 \pm \text { n.a. } & 1.48 \pm \text { n.a. } \\ 23.0-24.0 & 0.09 \pm 0.06 & 0.15 \pm 0.03 & 4.79 \pm 2.18 & 0.23 \pm \text { n.a. }\end{array}$

Alaska Coastal Water (ACW)

24.0-25.0

Bering-Chukchi Summer Water (BCSW)

$\begin{array}{ll}23.5-24.0 & 0.18 \pm 0.13 \\ 24.0-25.5 & 1.40 \pm 2.20 \\ 25.5-27.0 & 1.43 \pm 1.87\end{array}$

$$
3.78 \pm 2.60
$$

$1.65 \pm 1.94$

\begin{abstract}
$0.75 \pm 0.70$
$1.37 \pm 0.78$
\end{abstract}

$9.59 \pm 3.71$

$12.4 \pm 6.82$

$$
\begin{aligned}
& 3.80 \pm 1.98 \\
& 7.00 \pm 3.94 \\
& 11.4 \pm 5.99
\end{aligned}
$$

n.m.

n.m.

$1.03 \pm 0.47$

$6.51 \pm 1.43$

Atlantic Water (AtlW)

$$
\text { 27.0-28.0 }
$$

n.m.

.

Transects 5, 6, 7 (August 16-20, 2017)

Melt Water (MW)

$$
\text { 21.0-23.0 }
$$

$0.10 \pm$ n.a.

$0.14 \pm$ n.a.

$5.70 \pm$ n.a.

$0.77 \pm$ n.a.

$2.36 \pm$ n.a.

23.0-24.0

$0.30 \pm 0.42$

$0.34 \pm 0.34$

$8.07 \pm 4.72$

$0.54 \pm$ n.a.

$2.85 \pm 2.21$

Alaska Coastal Water (ACW)

$$
\text { 24.0-25.0 }
$$

$1.61 \pm 0.86$

$0.63 \pm 0.16$

$18.0 \pm 5.79$

$1.59 \pm 0.46$

$3.37 \pm 1.17$

Bering-Chukchi Summer Water (BCSW)
23.5-24.0
$0.33 \pm 0.07$
24.0-25.5
$1.16 \pm 1.43$
25.5-27.0
$1.92 \pm 2.82$

$0.19 \pm 0.01$

$4.56 \pm 0.49$

n.m.

$2.22 \pm 1.17$

$0.50 \pm 0.52$

$8.95 \pm 5.36$

$2.11 \pm 1.71$

$3.73 \pm 2.28$

$1.54 \pm 1.19$

$12.0 \pm 11.5$

$1.23 \pm 1.22$

$8.16 \pm 4.44$

Bering-Chukchi Winter Water (BCWW)

$$
24.0-25.5
$$

$$
0.44 \pm 0.33
$$

$0.12 \pm 0.03$

$3.98 \pm 2.61$

n.m.

$2.66 \pm 0.63$

$1.19 \pm 0.66$

$10.7 \pm 5.96$

$0.68 \pm$ n.a.

$5.83 \pm 2.38$

Atlantic Water (AtlW)

26.0-27.0

$0.21 \pm 0.08$

$1.55 \pm 0.67$

$11.9 \pm 4.09$

$0.86 \pm 0.20$

$10.9 \pm 4.95$

Abbreviations: Chl Fl, chlorophyll concentration based on fluorescence; $c_{\mathrm{p}}$, particle beam attenuation; POC, particulate organic carbon concentration; $\mathrm{Chl}+\mathrm{Pheo}$, chlorophyll plus pheophytin concentrations, SPM, suspended particulate matter.

sociated with the wind events in both SKQ201612S and SKQ201712S, we observe some significant contrasts among specific density ranges that suggest biogeochemical responses to the wind-forcing in subsurface waters (Tables 2 and 3). For example, in SKQ201612S there are significant increases in Chl Fl, $c_{\mathrm{p}}$, POC and SPM following the downwelling mixing event in samples from lower-density BCWW associated with pycnocline $\left(24>\sigma_{\mathrm{t}}>25.5 \mathrm{~kg} \mathrm{~m}^{-3}\right.$ ) waters (Table 2). A similar increase is not observed in the higher-density BCWW samples from deeper waters and, most significantly in samples from similar density-ranges of BCSW (Table 2). These observations suggest wind-driven mixing events of nutrient-rich, winter waters (BCWW) are likely to result in more noticeable biologic responses, that is, increases in POM production, than in the nutrient-poor, modified summer waters (BCSW). In terms of responses to the upwelling-favorable wind event in SKQ201712S, there are no major contrasts in intermediate- and high-density BCSW and BCWW 
that provide evidence of a region-wide response to the wind event. However, we do see increases of $\mathrm{Chl} \mathrm{Fl,}$ $\mathrm{Chl}+$ Pheo and POC in intermediate-density $\left(24.5>\sigma_{\mathrm{t}}>25.5 \mathrm{~kg} \mathrm{~m}^{-3}\right)$ BCSW samples from the Barrow Canyon transect following the wind event (e.g., transects 1 vs. 5; Figures 9 and 10) that contribute to the overall trends seen in Table 3. Note that the high variability within these samples leads to lower statistical significance in the difference between before and after compositions. Our results indicate the response of BCSW to upwelling differs regionally and is consistent with the sensitivity of Barrow Canyon to this forcing (Pickart et al., 2013, 2019).

In the case of the contrasts among lower-density $\left(24>\sigma_{\mathrm{t}}>25.5 \mathrm{~kg} \mathrm{~m}^{-3}\right)$ BCWW samples during SKQ201712S, it is likely that the observed decreases in $\mathrm{POC}$ and $\mathrm{Chl} \mathrm{Fl}$ are a result of our sampling of different locations before and after the wind event (Figure S3). Prior to the wind event, samples from this density range of BCWW originated primarily from the region north and east of Hannah Shoal (transects 3 and 4) and also from the offshore region of Barrow Canyon (transect 1; Figures 9 and 10), the latter of which included several samples with elevated POC and Chl Fl signals. Following the wind event, the only samples from this specific water mass density range were collected from the offshore region of Barrow Canyon (transect 5), which lacked the localized maxima seen in transect 1 . Hence, we conclude that the contrasts between BCWW samples evident in Table 3 are due to the fact that no samples of BCWW from the region around Hannah Shoal were collected during the period following the upwelling event (Figure S3) and that the high POM feature present in the north flank of Barrow Canyon in transect 1 was not found in transect 5.

It is clear that the elevated $\mathrm{Chl} \mathrm{Fl} \mathrm{values}\left(>1 \mathrm{mg} \mathrm{m}^{-3}\right)$ that define the SCM are observed in samples from a range of densities and water masses (Tables 2 and 3). Although sparse, the combined pigment (Chl $+\mathrm{Pheo})$ concentration data for the most part confirm the Chl Fl sample data and show that unlike POC, elevated photosynthetic pigment concentrations expand over a broader density range in both BCSW and BCWW. In contrast, $c_{\mathrm{p}}$ values, POC, and SPM concentrations peak in the samples from higher-density BCSW and BCWW that occupy the deeper regions above the seabed. These observations suggest that different types of particles are present in the subsurface regions of the water column during the late, open-water season in this region of the Chukchi Shelf. Particles in the intermediate density, middepth waters appear to be enriched in photosynthetic pigments and contain materials with relatively low light-attenuation properties. In contrast, particles in the denser, deeper regions of the water column, while still containing measurable pigments, include materials that have much greater light-attenuation capacity. The distinct distribution and variable concentrations of these particle types across density ranges in both BCSW and BCWW are responsible for the patterns we observe and directly influence the overall profiles of POM measured in Chukchi Shelf waters.

\subsection{Compositional Characteristics and Provenance of Late-Season POM in Chukchi Shelf}

The properties of water samples collected from different depths and locations reveal major contrasts in the compositions of suspended particles throughout the Chukchi Shelf during the late, open-water season. One way to evaluate such contrast is illustrated in plots of POC versus $\mathrm{Chl} \mathrm{Fl} \mathrm{for} \mathrm{samples} \mathrm{collected} \mathrm{during} \mathrm{the}$ two cruises (Figure 17). Among the trends evident in these graphs, we highlight samples from low- to intermediate-density waters $\left(\sigma_{\mathrm{t}}<26 \mathrm{~kg} \mathrm{~m}^{-3}\right)$ that exhibit high Chl Fl:POC ratios $\left(>10 \mathrm{mg} \mathrm{g}^{-1}\right)$ consistent with actively growing phytoplankton (e.g., Geider, 1987; Sathyendranath et al., 2020). In both cruises, the highest $\mathrm{Chl}$ :POC ratios $\left(>20 \mathrm{mg} \mathrm{g}^{-1}\right)$ are from samples within a narrower density range $\left(25<\sigma_{\mathrm{t}}<26 \mathrm{~kg} \mathrm{~m}^{-3}\right)$ from both BCSW and BCWW associated with pycnocline depths. These high pigment-to-carbon ratios likely reflect low-light acclimated phytoplankton that are most abundant at the depths associated with the SCM. Exceptions to these trends include some of the intermediate-density $\left(23<\sigma_{\mathrm{t}}<24.5 \mathrm{~kg} \mathrm{~m}^{-3}\right)$ samples collected during SKQ201712S, and especially those collected following the upwelling wind event, which are characterized by relatively low $\mathrm{Chl} \mathrm{Fl:POC} \mathrm{ratios} \mathrm{(5-10} \mathrm{mg} \mathrm{g}^{-1}$; Figures $17 \mathrm{c}$ and $17 \mathrm{~d}$ ). These samples correspond to warm BCSW and ACW samples from the surface, which have moderately elevated photosynthetic pigment concentrations (Table 3) and suggest the presence of phytoplankton acclimated to higher light intensities at these locations. The other major type of particles evident from this plot are samples from high-density $\left(\sigma_{\mathrm{t}}>25.5 \mathrm{~kg} \mathrm{~m}^{-3}\right)$ bottom waters that are characterized by low Chl Fl:POC $\left(\leq 5 \mathrm{mg} \mathrm{g}^{-1}\right)$ ratios (Figure 17), which are characterized by low overall chlorophyll concentrations and elevated $c_{\mathrm{p}}$ signals (Tables 2 and 3 ). 
a) SKQ2016 Transects 2, 3, 4, 5 (Sep 12-17, 2016)

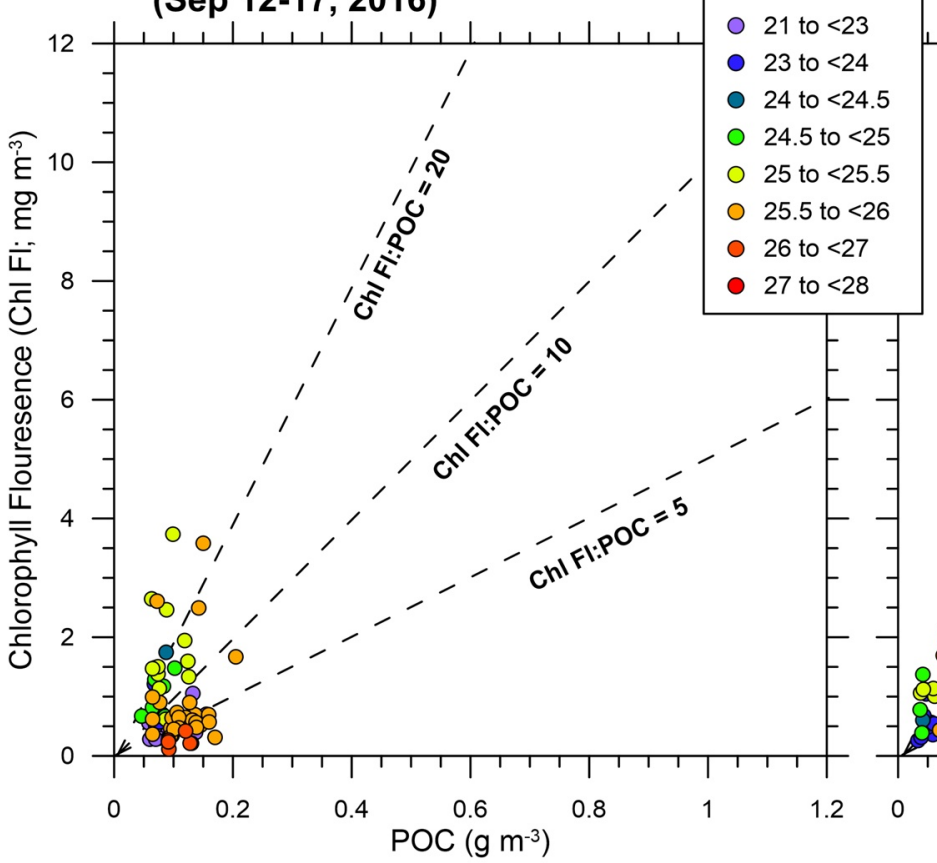

c) SKQ2017 Transects 1, 2, 3, 4 (Aug 10-16, 2017)

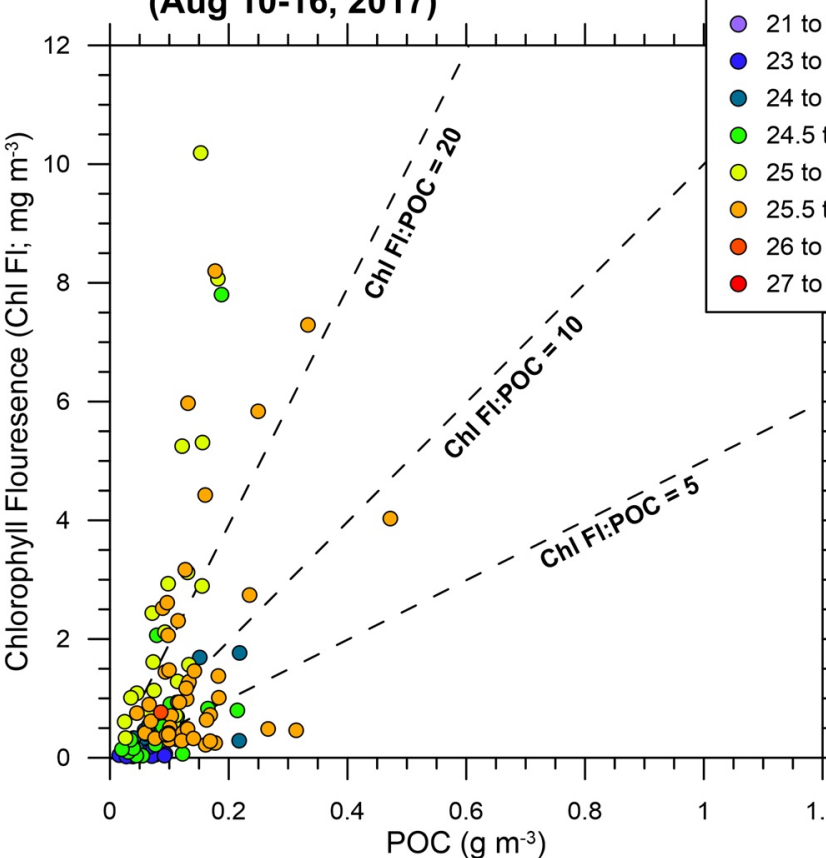

b) SKQ2016 Transects 6, 7, 8 (Sep 20-23, 2016)

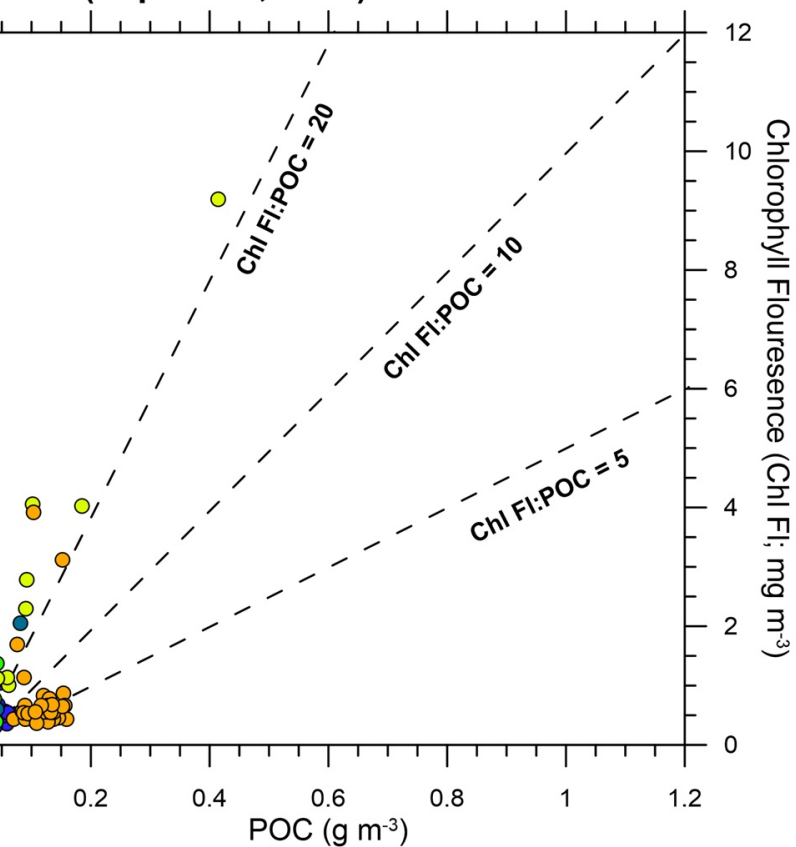

d) SKQ2017 Transects 5, 6, 7 (Aug 16-20, 2017)

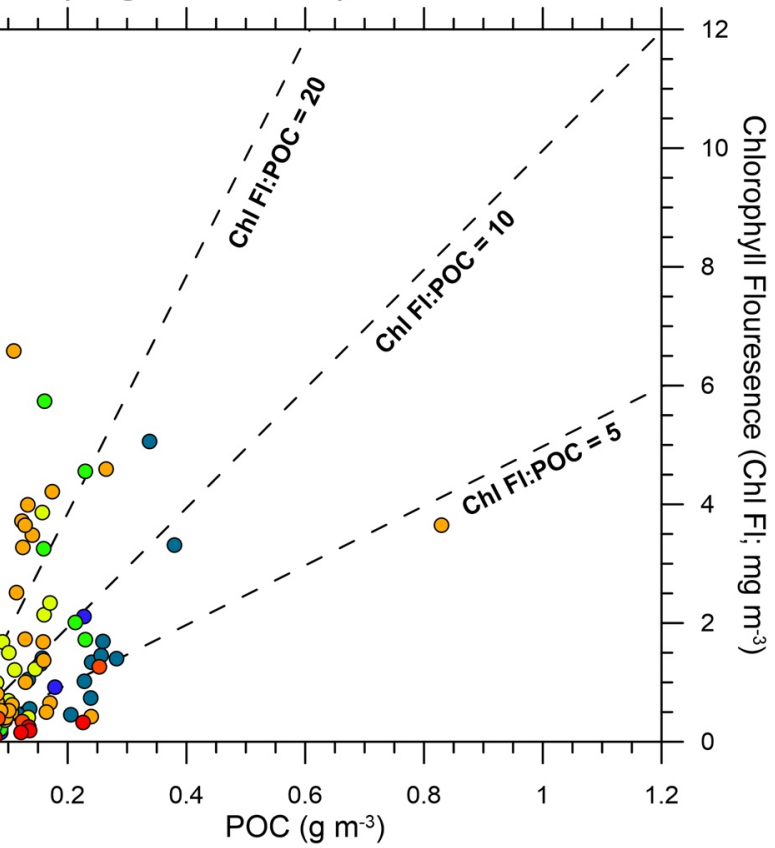

Figure 17. Plots of particulate organic carbon $\left(\mathrm{POC} ; \mathrm{g} \mathrm{m}^{-3}\right)$ concentrations versus chlorophyll fluorescence $\left(\mathrm{Chl} \mathrm{Fl} ; \mathrm{mg} \mathrm{m}^{-3}\right)$ sensor data for individual water samples from stations occupied during SKQ201612S before and after the September 17-20, 2016 downwelling-favorable wind event (a and b, respectively) and during SKQ201712S before and after the August 12-17, 2017 upwelling-favorable wind (c and d, respectively). Data are shown in different colors according to their density ranges (e.g., see Tables 2 and 3). Included in each graph are lines illustrating different Chl Fl:POC ratios $\left(\mathrm{mg} \mathrm{g}^{-1}\right)$ for reference. 
As described below, these compositions suggest significant contributions of mineral-rich particles that originate from the seabed.

Plots of $c_{\mathrm{p}}$ versus POC data for various density ranges (Figure 18) provide additional evidence for the presence of different particle pools throughout the water column of the NE Chukchi Shelf during the late, open-water season. The graphs for both SKQ201612S and SKQ201712S prior and after wind events highlight the stark contrasts between samples collected from high-density $\left(\sigma_{\mathrm{t}}>25.5 \mathrm{~kg} \mathrm{~m}^{-3}\right)$ bottom waters (both BCSW and BCWW), and samples from low- to intermediate-density ranges characteristic of surface and middepth waters (MW, ACW and BCSW). These latter samples are characterized by elevated POC: $c_{\mathrm{p}}$ ratios $\sim 30 \mathrm{mmol} \mathrm{m}^{-2}$, that are consistent with the global POC-beam attenuation relationships determined by Gardner et al. (2006) for plankton-dominated open ocean particles. In contrast, the markedly lower POC: $c_{\mathrm{p}}$ ratios $\left(<10 \mathrm{mmol} \mathrm{m}^{-2}\right)$ of high-density BCSW and BCWW indicate the high turbidity of the waters below the pycnocline contain particles with high mass-specific scattering coefficients that would be expected from mineral-rich detrital materials (e.g., Gardner et al., 2001; Goñi et al., 2021). These low POC:c ratios are consistent with contributions from sediment sources either through local resuspension from the seabed and/ or lateral advection from upstream regions. The fact that this particle pool is ubiquitous in both BCSW and BCWW bottom waters throughout the North East Chukchi shelf during both cruises is consistent with relatively high energy due to currents and/or waves in order to sustain these high levels of particle resuspension.

Table 4 summarizes the Chl Fl:POC and POC: $c_{\mathrm{p}}$ ratios of the different density ranges for the various water masses encountered during SKQ201612S and SKQ201712S and includes other parameters that help elucidate the composition and provenance of POM in samples from the NE Chukchi Shelf during late open-water season. For example, because pheophytin is a decay product of chlorophyll (e.g., Bianchi et al., 1988; Strom, 1993), we can examine the relative abundances of these two pigments to evaluate the freshness (and viability) of phytoplankton derived organic matter in our POM samples. Previous studies from the Chukchi Sea (McTigue et al., 2015) showed that surface sediments from sites across the shelf that received fresh input of phytoplankton exhibited low Pheo/(Chl + Pheo) $(<0.2)$ ratios whereas locations where degradation by microbial and herbivorous grazing was more significant displayed higher Pheo/(Chl $+\mathrm{Pheo})$ ratios $(>0.2)$. Although our suspended POM pigment analyses are somewhat sparse, the distributions of Pheo/ $(\mathrm{Chl}+\mathrm{Pheo})$ ratios tabulated in Table 4 clearly show that during both SKQ201612S and SKQ201712S, the vast majority of low- and intermediate-density $\left(\sigma_{\mathrm{t}}<\right.$ than $\left.25.5 \mathrm{~kg} \mathrm{~m}^{-3}\right)$ water masses throughout the top half of the water column across the Chukchi Shelf are characterized by pigment compositions indicative of relative fresh phytoplankton sources. In contrast, the high-density $\left(\sigma_{\mathrm{t}}>25.5 \mathrm{~kg} \mathrm{~m}^{-3}\right)$ water masses that occupy the lower half of the water column across the Chukchi Shelf during both cruises, and which correspond to BCSW and BCWW, are characterized by significantly elevated $\mathrm{Pheo} /(\mathrm{Chl}+\mathrm{Pheo})$ ratios consistent with contributions from degraded phytodetritus. The main exception to this trend are samples from high-density BCSW collected during SKQ201712S after the upwelling wind event (Table 3). These samples display low $\mathrm{Pheo} /(\mathrm{Chl}+\mathrm{Pheo})$ ratios that suggest inputs from fresh phytoplankton (Table 4).

Another parameter that displays trends consistent with distinct particle compositions is the POC:SPM ratio (Table 4), which similarly to the trends in POC: $c_{\mathrm{p}}$ ratios discussed above, tends to be higher $(\geq 4 \%)$ in samples from low-to intermediate-density waters and is lower (1\%-2\%) in high-density waters. The observed ranges in POC:SPM ratios (Table 4) are comparable to the compositional data from samples collected over a full season in 2016 by a bottom-moored sediment trap located at site offshore Wainwright (Chukchi Ecosystem Observatory; Lalande et al., 2020) that coincides with our transect locations (Figure 1). The materials collected in the sediment trap were characterized by Chl:POC ratios that ranged from $<0.5 \mathrm{mg} \mathrm{g}^{-1}$ during the winter months, to $\sim 5 \mathrm{mg} \mathrm{g}^{-1}$ in the early open water season (June and July). In addition, these same samples exhibited POC:SPM mass ratios that ranged from $2 \%$ in the winter to $>4 \%$ in the mid-summer periods of high productivity (data from Lalande et al., 2020). Notably, data from the ICESCAPE project in June-July of 2011 (Neukermans et al., 2014) showed that samples from surface waters exhibiting under-ice phytoplankton blooms showed lower Chl:POC ratios $\left(10 \mathrm{mg} \mathrm{g}^{-1}\right)$ and much higher POC:SPM (40\%) ratios than those collected from the SCM regions during the two late-season open water cruises. In contrast, the compositions of samples from bottom waters with high turbidity collected during ICESCAPE displayed moderate Chl:POC $\left(4 \mathrm{mg} \mathrm{g}^{-1}\right)$ and POC:SPM (1.4\%) ratios that were similar to the ones collected from high density BCSW and BCWW in this study. Thus, it appears that the particles present in the water column of 
a) SKQ2016 Transects 2, 3, 4, 5 (Sep 12-17, 2016)

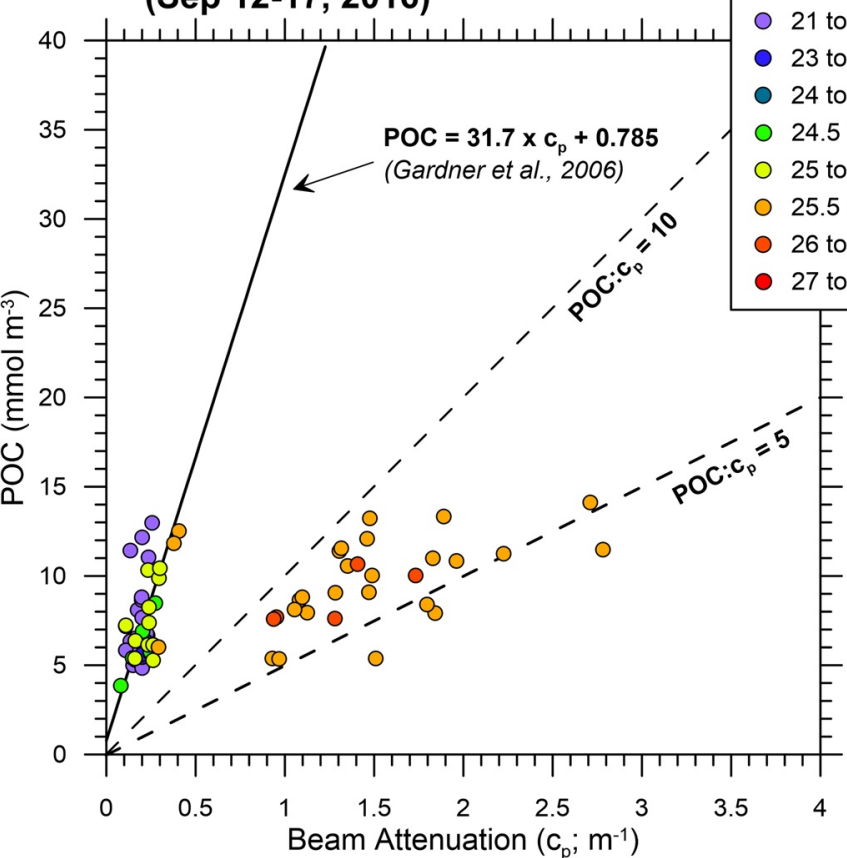

c) SKQ2017 Transects 1, 2, 3, 4 (Aug 10-16, 2017)

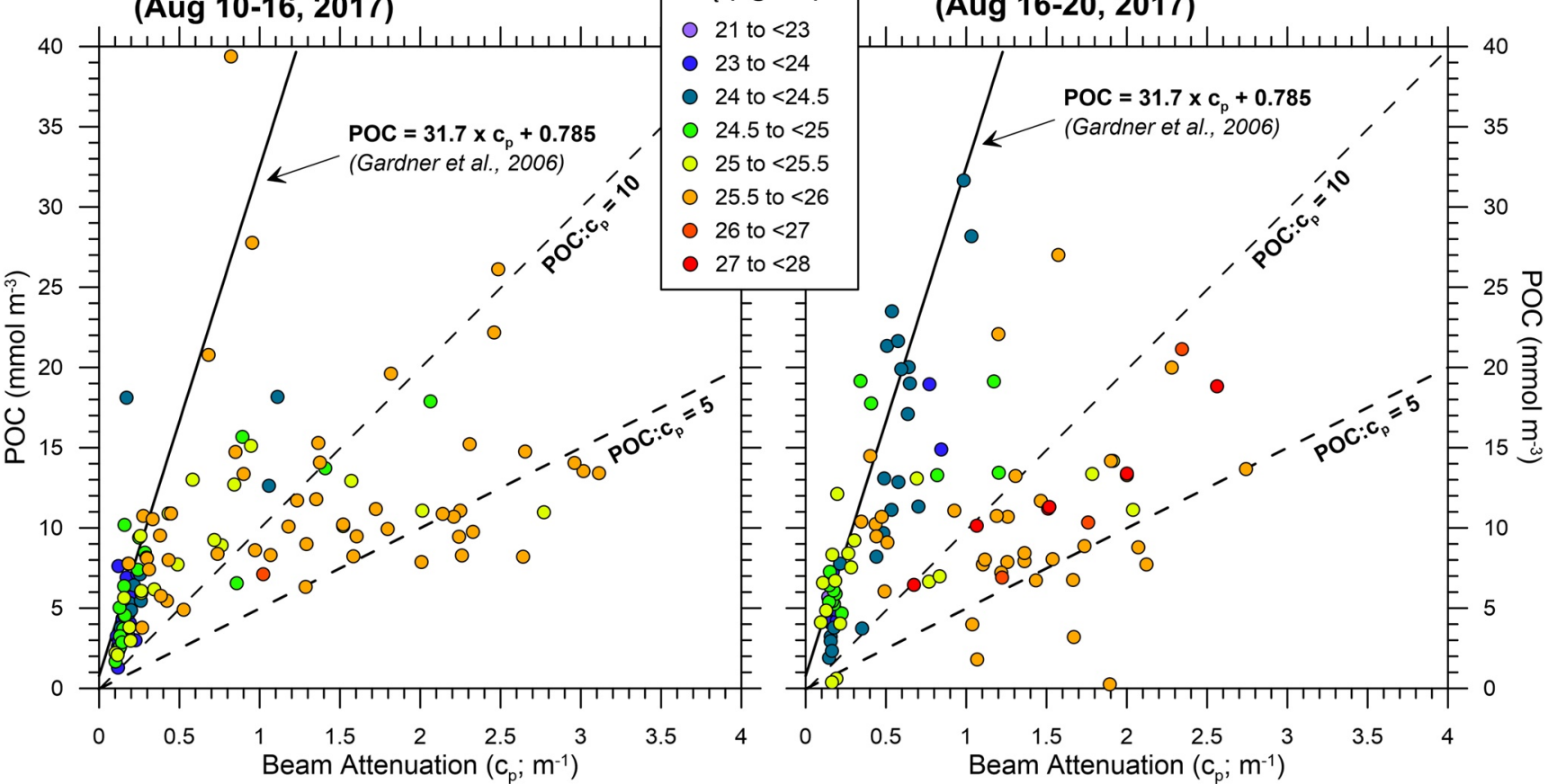

Figure 18. Plots of particulate beam attenuation sensor data $\left(c_{\mathrm{p}} ; \mathrm{m}^{-1}\right)$ versus particulate organic carbon (POC; $\left.\mathrm{mmol} \mathrm{m}^{-3}\right)$ concentrations for individual water samples from stations occupied during SKQ201612S before and after the September 17-20, 2016 downwelling-favorable wind event (a and b, respectively) and during SKQ201712S before and after the August 12-17, 2017 upwelling-favorable wind (c and d, respectively). Data are shown in different colors according to their density ranges (e.g., see Tables 2 and 3). Included in each graph are lines illustrating different POC: $c_{\mathrm{p}}$ ratios $\left(\mathrm{mmol} \mathrm{m}^{-2}\right)$ for reference, including the global average relationship measured by Gardner et al. (2006). Note the deep inshore sample from transect 6 in SKQ201712S (see Figures 10 and 11) characterized by highly elevated POC $\left(69 \mathrm{mmol} \mathrm{m}^{-3}\right), c_{\mathrm{p}}\left(7.4 \mathrm{~m}^{-1}\right)$, and SPM $\left(27 \mathrm{~g} \mathrm{~m}^{-3}\right)$ values plots outside the area in Figure $18 \mathrm{~d}$ but displays a POC: $c_{\mathrm{p}}$ ratio of $9.4 \mathrm{mmol} \mathrm{m}^{-2}$. 
Table 4

Particulate Organic Matter Compositions of Density-Binned Niskin Bottle Samples From Different Water Masses During SKQ201612S and SKQ21712S

\begin{tabular}{|c|c|c|c|c|c|}
\hline Water Mass cruise period & Density bins $\sigma_{\mathrm{t}}\left(\mathrm{kg} \mathrm{m}^{-3}\right)$ & Chl Fl:POC $\left(\mathrm{mg} \mathrm{g}^{-1}\right)$ & POC: $c_{\mathrm{p}}\left(\mathrm{mmol} \mathrm{m}^{-2}\right)$ & Pheo/(Chl + Pheo $)$ & POC:SPM (mass \%) \\
\hline \multicolumn{6}{|l|}{ Melt Water (MW) } \\
\hline SKQ2016 September 12-17, 2016 & $21.0-23.0$ & $6.3 \pm 3.1$ & $40.6 \pm 24.1$ & $0.10 \pm 0.06$ & $6.0 \pm 2.6$ \\
\hline SKQ2016 September 20-23, 2016 & $21.0-23.0$ & $8.1 \pm 5.1$ & $30.5 \pm 18.0$ & n.m. & $3.8 \pm 2.3$ \\
\hline SKQ2017 August 10-16, 2017 & $21.0-23.0$ & $4.3 \pm$ n.a. & $21.7 \pm$ n.a. & $0.18 \pm$ n.a. & $2.4 \pm$ n.a. \\
\hline SKQ2017 August 16-20, 2017 & $21.0-23.0$ & $1.4 \pm$ n.a. & $40.6 \pm$ n.a. & n.m. & $2.9 \pm$ n.a. \\
\hline SKQ2016 September 12-17, 2016 & $23.0-24.0$ & $13.8 \pm 7.5$ & $28.2 \pm 4.2$ & $0.17 \pm 0.20$ & $3.5 \pm 0.6$ \\
\hline SKQ2016 September 20-23, 2016 & $23.0-24.0$ & $9.5 \pm 3.5$ & $37.6 \pm 12.4$ & n.m. & $2.1 \pm 0.5$ \\
\hline SKQ2017 August 10-16, 2017 & $23.0-24.0$ & $1.9 \pm 1.5$ & $31.7 \pm 16.0$ & $0.30 \pm$ n.a. & $3.7 \pm 2.2$ \\
\hline SKQ2017 August 16-20, 2017 & $23.0-24.0$ & $2.2 \pm 3.3$ & $30.5 \pm 35.7$ & $0.16 \pm$ n.a. & $3.8 \pm 3.7$ \\
\hline \multicolumn{6}{|l|}{ Alaska Coastal Water (ACW) } \\
\hline SKQ2016 September 12-17, 2016 & $24.0-25.0$ & n.m. & n.m. & n.m. & n.m. \\
\hline SKQ2016 September 20-23, 2016 & $24.0-25.0$ & n.m. & n.m. & n.m. & n.m. \\
\hline SKQ2017 August 10-16, 2017 & $24.0-25.0$ & $7.0 \pm 3.2$ & $11.7 \pm 4.4$ & $0.22 \pm 0.22$ & $2.9 \pm 0.8$ \\
\hline SKQ2017 August 16-20, 2017 & $24.0-25.0$ & $7.8 \pm 4.8$ & $29.4 \pm 11.9$ & $0.06 \pm 0.02$ & $7.2 \pm 3.4$ \\
\hline \multicolumn{6}{|c|}{ Bering-Chukchi Summer Water (BCSW) } \\
\hline SKQ2016 September 12-17, 2016 & $23.5-24.0$ & n.m. & n.m. & n.m. & n.m. \\
\hline SKQ2016 September 20-23, 2016 & $23.5-24.0$ & $22.3 \pm$ n.a. & $32.9 \pm$ n.a. & n.m. & $2.3 \pm$ n.a. \\
\hline SKQ2017 August 10-16, 2017 & $23.5-24.0$ & $3.6 \pm 3.3$ & $20.8 \pm 12.6$ & $0.15 \pm$ n.a. & $1.9 \pm 1.2$ \\
\hline SKQ2017 August 16-20, 2017 & $23.5-24.0$ & $6.0 \pm 1.5$ & $24.3 \pm 2.8$ & n.m. & $2.8 \pm 1.5$ \\
\hline SKQ2016 September 12-17, 2016 & $24.0-25.5$ & $18.8 \pm 8.3$ & $30.0 \pm 10.5$ & $0.13 \pm 0.05$ & $4.4 \pm 1.5$ \\
\hline SKQ2016 September 20-23, 2016 & $24.0-25.5$ & $21.7 \pm 15.2$ & $30.5 \pm 21.0$ & n.m. & $2.1 \pm 0.8$ \\
\hline SKQ2017 August 10-16, 2017 & $24.0-25.5$ & $13.9 \pm 23.2$ & $25.1 \pm 34.7$ & $0.08 \pm 0.09$ & $3.6 \pm 3.0$ \\
\hline SKQ2017 August 16-20, 2017 & $24.0-25.5$ & $10.1 \pm 13.9$ & $25.5 \pm 30.6$ & $0.25 \pm 0.44$ & $3.3 \pm 2.8$ \\
\hline SKQ2016 September 12-17, 2016 & $25.5-27.0$ & $10.0 \pm 10.1$ & $9.9 \pm 1.6$ & $0.34 \pm 0.0 .16$ & $2.1 \pm 0.3$ \\
\hline SKQ2016 September 20-23, 2016 & $25.5-27.0$ & $8.0 \pm 8.0$ & $9.4 \pm 4.6$ & n.m. & $1.7 \pm 0.8$ \\
\hline SKQ2017 August 10-16, 2017 & $25.5-27.0$ & $11.2 \pm 15.7$ & $13.3 \pm 11.3$ & $0.28 \pm 0.29$ & $2.4 \pm 1.7$ \\
\hline SKQ2017 August 16-20, 2017 & $25.5-27.0$ & $15.3 \pm 26.9$ & $9.5 \pm 11.7$ & $0.09 \pm 0.14$ & $1.8 \pm 2.0$ \\
\hline
\end{tabular}

Cruise period Density bins $\sigma_{\mathrm{t}}\left(\mathrm{kg} \mathrm{m}^{-3}\right) \quad \mathrm{Chl} \mathrm{Fl:POC}\left(\mathrm{mg} \mathrm{g}^{-1}\right) \quad$ POC: $c_{\mathrm{p}}\left(\mathrm{mmol} \mathrm{m}^{-2}\right)$

Pheo/(Chl + Pheo $)$

POC:SPM (mass \%)

Bering-Chukchi Winter Water (BCWW)

SKQ2016 September 12-17, 2016

SKQ2016 September 20-23, 2016

SKQ2017 August 10-16, 2017

SKQ2017 August 16-20, 2017

SKQ2016 September 12-17, 2016

SKQ2016 September 20-23, 2016

SKQ2017 August 10-16, 2017

SKQ2017 August 16-20, 2017

$\begin{array}{ccc}24.0-25.5 & 18.4 \pm 14.0 & 43.7 \pm 21.2 \\ 24.0-25.5 & 26.9 \pm 37.0 & 28.0 \pm 33.0 \\ 24.0-25.5 & 29.6 \pm 23.3 & 21.8 \pm 21.9 \\ 24.0-25.5 & 53.0 \pm 52.6 & 36.3 \pm 25.4 \\ & & \\ 25.5-27.0 & 5.6 \pm 4.8 & 8.0 \pm 3.9 \\ 25.5-27.0 & 5.8 \pm 5.6 & 8.7 \pm 3.6 \\ 25.5-27.0 & 10.5 \pm 13.6 & 12.8 \pm 10.2 \\ 25.5-27.0 & 18.6 \pm 17.8 & 13.6 \pm 10.7\end{array}$

$\begin{array}{cc}0.20 \pm 0.18 & 3.4 \pm 0.9 \\ \text { n.m. } & 2.7 \pm 3.0 \\ \text { n.m. } & 3.0 \pm 2.5 \\ \text { n.m. } & 1.9 \pm 1.3\end{array}$

$0.41 \pm 0.39$

$2.5 \pm 1.3$

n.m.

$1.6 \pm 0.5$

$0.30 \pm 0.35$

$2.7 \pm 2.0$

$0.26 \pm$ n.a.

$2.7 \pm 1.9$ 
Table 4

Continued

\begin{tabular}{|c|c|c|c|c|c|}
\hline Cruise period & Density bins $\sigma_{\mathrm{t}}\left(\mathrm{kg} \mathrm{m}^{-3}\right)$ & Chl Fl:POC (mg g $\left.{ }^{-1}\right)$ & POC: $c_{\mathrm{p}}\left(\mathrm{mmol} \mathrm{m}^{-2}\right)$ & Pheo/(Chl + Pheo) & POC:SPM (mass \%) \\
\hline \multicolumn{6}{|l|}{ Atlantic Water (AtlW) } \\
\hline SKQ2016 September 12-17, 2016 & $27.0-28.0$ & n.m. & n.m. & n.m. & n.m. \\
\hline SKQ2016 September 20-23, 2016 & $27.0-28.0$ & n.m. & n.m. & n.m. & n.m. \\
\hline SKQ2017 August 10-16, 2017 & $27.0-28.0$ & n.m. & n.m. & n.m. & n.m. \\
\hline SKQ2017 August 16-20, 2017 & $27.0-28.0$ & $1.4 \pm 0.7$ & $8.3 \pm 4.5$ & $0.68 \pm 0.21$ & $1.4 \pm 0.8$ \\
\hline
\end{tabular}

Note. Compositions were determined by averaging the ratios of individual samples from the different density ranges and calculating their variability by applying propagation of error calculations to the standard deviations of the parameters ratioed. Chl Fl:POC, chlorophyll fluorescence-particulate organic carbon ratio $\left(\mathrm{mg} \mathrm{g}^{-1}\right)$; POC: $c_{\mathrm{p}}$, particulate organic carbon-particle beam attenuation ratio $\left(\mathrm{mmol} \mathrm{m}^{-2}\right)$; Pheo/(Chl + Pheo), pheophytin-combined chlorophyll plus pheophytin ratio $\left(\mathrm{mg} \mathrm{mg}^{-1}\right)$; POC:SPM, particulate organic carbon-suspended particulate matter mass ratio $\left(\mathrm{g} \mathrm{g}^{-1}\right) \times 100(\%)$.

the northeast Chukchi Shelf during the late summer display compositions that are consistent with a heterogeneous mixture of POM sources that are distinct from those present during the early summer.

\section{Summary and Future Work}

The hydrographic characteristics across the water column of the Northeast Chukchi Sea during the late summer are consistent with previous studies (e.g., S. L. Danielson et al., 2017; Weingartner et al., 2017) and show the highly stratified water column has a fundamental impact on the distribution and composition of POM in the region. Contrasts in POM compositional ratios (e.g., Chl:POC, POC:SPM, POC: $c_{\mathrm{p}}$ ) indicate the presence of different types of particles in distinct regions and depths of the study area, including the nutrient depleted surface layers, the middepths with characteristic SCM, and the highly turbid deeper waters. We conclude that the spatial and temporal contrasts in water mass distributions and the impacts of distinct wind forcings lead to different biogeochemical responses. For example, changes consistent with enhanced phytoplankton production (increases in $\mathrm{Chl}$ and $\mathrm{POC}$ ) occur in surface waters across Barrow Canyon and in nearshore regions associated with ACW in response to upwelling. Furthermore, similar biological responses are also observed in middepth regions of the water column at the interface between MW and BCWW around Hannah Shoal in response to downwelling-favorable winds. These findings are consistent with our previous work (e.g., Beaird et al., 2020; Goñi et al., 2019; Juranek et al., 2019) and suggest the productivity responses are primarily related to the mixing of nutrients across the steep pycnocline that characterizes the region during the late open-water season. At this point, we do not have enough observations to evaluate the specific mechanisms, magnitude and extent of these processes under distinct wind forcings (i.e., upwelling vs. downwelling favorable). However, the large temporal and spatial variability in particulate compositions illustrates the highly dynamic nature of POM in the northeast Chukchi Shelf and reflects the complex productivity and provenance regimes that characterize this region of the Arctic Ocean. Our results suggest the extent of phytoplankton productivity in the surface and subsurface regions of the Chukchi Sea during the late open-water season varies as a function of water mass distributions, wind forcing, and location relative to bathymetric and topographic features such as canyons, shoals, and capes.

Work to evaluate other biogeochemical tracers of primary productivity, including dissolved oxygen and nutrients, across the Northeast Chukchi Sea during the open water season is ongoing. Examination of the distribution and dynamics of these productivity tracers along with incubation-based measurements of primary production will help us further understand the controls on the biological response to climate change of this and other Arctic marginal seas and start addressing the underlying mechanisms that may be responsible for the "greening" of the Arctic Ocean (e.g., Ardyna \& Arrigo, 2020). To fully evaluate the impacts of climate change on Arctic Ocean ecology and biogeochemistry, future studies should focus on enhancing the spatial and temporal coverage across complex hydrographic regions such as the Chukchi Sea throughout the polar seasons. 


\section{Data Availability Statement}

All the data, including CTD profiles and individual sample compositions from Niskin bottles are archived in the Arctic Data Center (Goni, 2021; doi:10.18739/A2T14TQ6Q.). All the CTD profile data are available at the Rolling Deck to Repository (R2R) data repository for R/V Sikuliaq's cruises SKQ201612S and SKQ210712S (https://www.rvdata.us/search/cruise/SKQ201612S12S Cruise DOI 10.7284/907439 and https://www.rvdata.us/search/cruise/SKQ201712S12S Cruise DOI: 10.7284/907787, respectively. All remaining filter samples are stored in M. Goñi's laboratory.

\section{References}

Acknowledgments

The authors thank the captains and crew of the R/V Sikuliaq who facilitated the completion of this work during the two cruises. Emmanuel Alegria, Sydney Clark, Elizabeth Corvi, Kimberly Craig, Erin Guillory, and Quinn Roberts provided valuable help in the collection and analyses of water samples. The science crews of SKQ201612S and SKQ201712S were critical in helping complete the CTD surveys during both cruises. Funding for this work was provided by U.S. National Science Foundation (NSF) Arctic Natural Sciences through grants 1504394 and 1949593 for M. Goñi and L. Juranek and through grant 1504307 for R. Sipler.
Allen, M. R., Dube, O. P., Solecki, W., Aragón-Durand, F., Cramer, W., Humphreys, S., et al. (2018). Framing and context. In V. Masson-Delmotte, P. Zhai, H.-O. Pörtner, et al. (Eds.), Global Warming of $1.5^{\circ} \mathrm{C}$. An IPCC Special Report on the impacts of global warming of $1.5^{\circ} \mathrm{C}$ above pre-industrial levels and related global greenhouse gas emission pathways, in the context of strengthening the global response to the threat of climate change, sustainable development, and efforts to eradicate poverty. Washington, DC: In Press. E. Arar,and B. Collins (Eds.), Method 445.0 in vitro determination of chlorophyll a and pheophytin in marine and freshwater algae by fluorescence.

Arar, E. J., \& Collins, G. B. (1997). Method 445.0 in vitro determination of chlorophyll a and pheophytin ain marine and freshwater algae by fluorescence revision 1.2 (p. 22). Washington, DC: U.S. Environmental Protection Agency.

Ardyna, M., \& Arrigo, K. R. (2020). Phytoplankton dynamics in a changing Arctic Ocean. Nature Climate Change, 10, 892-903. https://doi. org/10.1038/s41558-020-0905-y

Ardyna, M., Babin, M., Gosselin, M., Devred, E., Belanger, S., Matsuoka, A., \& Tremblay, J.-E. (2013). Parameterization of vertical chlorophyll a in the Arctic Ocean: Impact of the subsurface chlorophyll maximum on regional, seasonal, and annual primary production estimates. Biogeosciences, 10, 4383-4404. https://doi.org/10.5194/bg-10-4383-2013

Ardyna, M., Mundy, C. J., Mills, M. M., Oziel, L., Grondin, P.-L., Lacour, L., et al. (2020). Environmental drivers of under-ice phytoplankton bloom dynamics in the Arctic Ocean. Elementa: Science of the Anthropocene, 8, 30. https://doi.org/10.1525/elementa.430

Arrigo, K. R., Perovich, D. K., Pickart, R. S., Brown, Z. W., van Dijken, G. L., Lowry, K. E., et al. (2012). Massive phytoplankton blooms under Arctic sea ice. Science, 336, 1408-1408. https://doi.org/10.1126/science.1215065

Arrigo, K. R., Perovich, D. K., Pickart, R. S., Brown, Z. W., van Dijken, G. L., Lowry, K. E., et al. (2014). Phytoplankton blooms beneath the sea ice in the Chukchi Sea. Deep-Sea Research Part II, 105, 1-16. https://doi.org/10.1016/j.dsr2.2014.03.018

Arrigo, K. R., \& van Dijken, G. L. (2015). Continued increases in Arctic Ocean primary production. Progress in Oceanography, 136, 60-70. https://doi.org/10.1016/j.pocean.2015.05.002

Bates, N. R., Hansell, D. A., Moran, S. B., \& Codispoti, L. A. (2005). Seasonal and spatial distribution of particulate organic matter (POM) in the Chukchi and Beaufort Seas. Deep-Sea Research II: Topical Studies in Oceanography, 52, 3324-3343. https://doi.org/10.1016/j. dsr2.2005.10.003

Beaird, N. L., Shroyer, E. L., Juranek, L. W., Hales, B., \& Goñi, M. A. (2020). Nutrient-rich gravity current formed by upwelling in Barrow Canyon: High-resolution observations. Journal of Geophysical Research: Oceans, 125, e2020JC016160. https://doi.org/10.1029/2020jc016160

Bianchi, T. S., Dawson, R., \& Sawangwong, P. (1988). The effects of macrobenthic deposit-feeding on the degradation of chloropigments in sandy sediments. Journal of Experimental Marine Biology and Ecology, 122, 243-255. https://doi.org/10.1016/0022-0981(88)90126-8

Bröder, L., Andersson, A., Tesi, T., Semiletov, I., \& Gustafsson, Ö. (2019). Quantifying degradative loss of terrigenous organic carbon in surface sediments across the Laptev and East Siberian Sea. Global Biogeochemical Cycles, 33, 85-99. https://doi.org/10.1029/2018GB005967

Brown, Z. W., Lowry, K. E., Palmer, M. A., van Dijken, G. L., Mills, M. M., Pickart, R. S., \& Arrigo, K. R. (2015). Characterizing the subsurface chlorophyll a maximum in the Chukchi Sea and Canada Basin. Deep-Sea Research II: Topical Studies in Oceanography, 118, 88-104. https://doi.org/10.1016/j.dsr2.2015.02.010

Chaves, J. E., Cetinić, I., Dall'Olmo, G., Estapa, M., Gardner, W., Goñi, M., et al. (2021). Particulate organic matter sampling and measurement protocols: consensus towards future ocean color missions. NASA ocean ecology lab field support group and hosted at NASA Goddard Space Flight Center.

Coachman, L. K., Aagaard, K., \& Tripp, R. B. (1975). Bering Strait: The regional physical oceanography (p. 172). Seattle, WA: University of Washington Press.

Danielson, S., Hedstrom, K., Hennon, T., Mordy, C., Stabeno, P., Stockwell, D., \& Woodgate, R. (2021). Recent volume, heat, and nutrient fluxes on the Pacific Arctic Continental Shelf. In Abstract in 2021 Alaskan marine science symposium (p. 160).

Danielson, S. L., Eisner, L., Ladd, C., Mordy, C., Sousa, L., \& Weingartner, T. J. (2017). A comparison between late summer 2012 and 2013 water masses, macronutrients, and phytoplankton standing crops in the northern Bering and Chukchi Seas. Deep-Sea Research II: Topical Studies in Oceanography, 135, 7-26. https://doi.org/10.1016/j.dsr2.2016.05.024

Danielson, S. L., Weingartner, T. J., Hedstrom, K. S., Aagaard, K., Woodgate, R., Curchitser, E., \& Stabeno, P. J. (2014). Coupled windforced controls of the Bering-Chukchi shelf circulation and the Bering Strait throughflow: Ekman transport, continental shelf waves, and variations of the Pacific-Arctic sea surface height gradient. Progress in Oceanography, 125, 40-61. https://doi.org/10.1016/j. pocean.2014.04.006

Fetterer, F., Knowles, K., Meier, W., Savoie, M., \& Windnagel, A. K. (2017). Sea ice index, version 3. Sea ice extent and concentration. Boulder, CO: NSIDC: National Snow and Ice Data Center. https://doi.org/10.7265/N5K072F8

Forest, A., Babin, M., Stemmann, L., Picheral, M., Sampei, M., Fortier, L., et al. (2013). Ecosystem function and particle flux dynamics across the Mackenzie Shelf (Beaufort Sea, Arctic Ocean): An integrative analysis of spatial variability and biophysical forcings. Biogeosciences, 10, 2833-2866. https://doi.org/10.5194/bg-10-2833-2013

Forest, A., Osborne, P. D., Fortier, L., Sampei, M., \& Lowings, M. G. (2015). Physical forcings and intense shelf-slope fluxes of particulate matter in the halocline waters of the Canadian Beaufort Sea during winter. Continental Shelf Research, 101, 1-21. https://doi. org/10.1016/j.csr.2015.03.009

Forest, A., Sampei, M., Hattori, H., Makabe, R., Sasaki, H., Fukuchi, M., et al. (2007). Particulate organic carbon fluxes on the slope of the Mackenzie Shelf (Beaufort Sea): Physical and biological forcing of shelf-basin exchanges. Journal of Marine Systems, 68, 39-54. https:// doi.org/10.1016/j.jmarsys.2006.10.008 
Foukal, N. P., Pickart, R. S., Moore, G. W. K., \& Lin, P. (2019). Shelf break downwelling in the Alaskan Beaufort Sea. Journal of Geophysical Research: Oceans, 124, 7201-7225. https://doi.org/10.1029/2019JC015520

Gardner, W. D., Blakey, J. C., Walsh, I. D., Richardson, M. J., Pegau, S., Zaneveld, J. R. V., et al. (2001). Optics, particles, stratification, and storms on the New England continental shelf. Journal of Geophysical Research, 106, 9473-9497. https://doi.org/10.1029/2000jc900161

Gardner, W. D., Mishonov, A. V., \& Richardson, M. J. (2006). Global POC concentrations from in-situ and satellite data. Deep-Sea Research II: Topical Studies in Oceanography, 53, 718-740. https://doi.org/10.1016/j.dsr2.2006.01.029

Geider, R. J. (1987). Light and temperature dependence of the carbon to chlorophyll a ratio in microalgae and cyanobacteria: Implications for physiology and growth of phytoplankton. New Phytologist, 106, 1-34. https://doi.org/10.1111/j.1469-8137.1987.tb04788.x

Goni, M. (2021). Sikuliaq cruises (SKQ201612S, SKQ201712S) conductivity temperature depth (CTD) bottle data, northeastern Chukchi Sea. Arctic Data Center. https://doi.org/10.18739/A2T14TQ6Q

Goñi, M. A., Corvi, E. R., Welch, K. A., Alegria, E., Watkins-Brandt, K., \& White, A. E. (2021). Wintertime particulate organic matter distributions in surface waters of the northern California current system. Continental Shelf Research, 213. https://doi.org/10.1016/j. csr.2020.104312

Goñi, M. A., Corvi, E. R., Welch, K. A., Buktenica, M., Lebon, K., Alleau, Y., \& Juranek, L. W. (2019). Particulate organic matter distributions in surface waters of the Pacific Arctic shelf during the late summer and fall season. Marine Chemistry, 211. https://doi.org/10.1016/j.marchem.2019.03.010

Grebmeier, J. M., Bluhm, B. A., Cooper, L. W., Danielson, S. L., Arrigo, K. R., Blanchard, A. L., et al. (2015). Ecosystem characteristics and processes facilitating persistent macrobenthic biomass hotspots and associated benthivory in the Pacific Arctic. Progress in Oceanography, 136, 92-114. https://doi.org/10.1016/j.pocean.2015.05.006

Grebmeier, J. M., Moore, S. E., Cooper, L. W., \& Frey, K. E. (2019). The Distributed Biological Observatory: A change detection array in the Pacific Arctic - An introduction. Deep-Sea Research Part II, 162, 1-7. https://doi.org/10.1016/j.dsr2.2019.05.005

Hill, V., \& Cota, G. (2005). Spatial patterns of primary production on the shelf, slope and basin of the Western Arctic in 2002. Deep Sea Research Part II: Topical Studies in Oceanography, 52(24-26), 3344-3354. https://doi.org/10.1016/j.dsr2.2005.10.001

Huntington, H. P., Danielson, S. L., Wiese, F. K., Baker, M., Boveng, P., Citta, J. J., et al. (2020). Evidence suggests potential transformation of the Pacific Arctic ecosystem is underway. Nature Climate Change, 10, 342-348. https://doi.org/10.1038/s41558-020-0695-2

Jackson, J. M., Allen, S. E., McLaughlin, F. A., Woodgate, R. A., \& Carmack, E. C. (2011). Changes to the near-surface waters in the Canada Basin, Arctic Ocean from 1993-2009: A basin in transition. Journal of Geophysical Research, 116(C10), C10008. https://doi. org/10.1029/2011jc007069

Juranek, L., Takahashi, T., Mathis, J., \& Pickart, R. (2019). Significant biologically mediated $\mathrm{CO}_{2}$ uptake in the Pacific Arctic during the late open water season. Journal of Geophysical Research: Oceans, 124, 821-843. https://doi.org/10.1029/2018JC014568

Konar, B., Frisch, L., \& Moran, S. B. (2017). Development of best practices for scientific research vessel operations in a changing Arctic: A case study for R/V Sikuliaq. Marine Policy, 86, 182-189. https://doi.org/10.1016/j.marpol.2017.09.021

Lalande, C., Grebmeier, J. M., Hopcroft, R. R., \& Danielson, S. L. (2020). Annual cycle of export fluxes of biogenic matter near Hanna Shoal in the northeast Chukchi Sea. Deep Sea Research II, 177. https://doi.org/10.1016/j.dsr2.2020.104730

Lewis, K. M., van Dijken, G. L., \& Arrigo, K. R. (2020). Changes in phytoplankton concentration now drive increased Arctic Ocean primary production. Science, 369, 198-202. https://doi.org/10.1126/science.aay8380

Lin, P., Pickart, R. S., Moore, G. W. K., Spall, M. A., \& Hu, J. (2019). Characteristics and dynamics of wind-driven upwelling in the Alaskan Beaufort Sea based on six years of mooring data. Deep-Sea Research Part II Topical Studies in Oceanography, 162, 79-92. https://doi. org $/ 10.1016 /$ j.dsr2.2018.01.002

Lowry, K., Pickart, R., Mills, M., Brown, Z., van Dijken, G., Bates, N., \& Arrigo, K. (2015). Influence of winter water on phytoplankton blooms in the Chukchi Sea. Deep Sea Research II: Topical Studies in Oceanography, 118, 53-72. https://doi.org/10.1016/j.dsr2.2015.06.006

Martini, K. I., Stabeno, P. J., Ladd, C., Winsor, P., Weingartner, T. J., Mordy, C. W., \& Eisner, L. B. (2016). Dependence of subsurface chlorophyll on seasonal water masses in the Chukchi Sea. Journal of Geophysical Research: Oceans, 121, 1755-1770. https://doi. org/10.1002/2015JC011359

McLaughlin, F. A., \& Carmack, E. C. (2010). Deepening of the nutricline and chlorophyll maximum in the Canada Basin interior, 20032009. Geophysical Research Letters, 37, L24602. https://doi.org/10.1029/2010GL045459

McTigue, N. D., Bucolo, P., Liu, Z., \& Dunton, K. H. (2015). Pelagic-benthic coupling, food webs, and organic matter degradation in the Chukchi Sea: Insights from sedimentary pigments and stable carbon isotopes. Limnology \& Oceanography, 60, 429-445. https://doi. org $/ 10.1002 / \operatorname{lno} .10038$

Moran, S. B., Kelly, R. P., Hagstrom, K., Smith, J. N., Grebmeier, J. M., Cooper, L. W., et al. (2005). Seasonal changes in POC export flux in the Chukchi Sea and implications for water column-benthic coupling in Arctic shelves. Deep-Sea Research II: Topical Studies in Oceanography, 52, 3427-3451. https://doi.org/10.1016/j.dsr2.2005.09.011

Neukermans, G., Reynolds, R. A., \& Stramski, D. (2014). Contrasting inherent optical properties and particle characteristics between an under-ice phytoplankton bloom and open water in the Chukchi Sea. Deep-Sea Research, Part II, 105, 59-73. https://doi.org/10.1016/j. dsr2.2014.03.014

Neukermans, G., Reynolds, R. A., \& Stramski, D. (2016). Optical classification and characterization of marine particle assemblages within the western Arctic Ocean. Limnology \& Oceanography, 61, 1472-1494. https://doi.org/10.1002/lno.10316

Nguyen, A. T., Woodgate, R. A., \& Heimbach, P. (2020). Elucidating large-scale atmospheric controls on Bering Strait throughflow variability using a data-constrained ocean model and its adjoint. Journal of Geophysical Research: Oceans, 125, e2020JC016213. https://doi. org/10.1029/2020JC016213

Nishino, S., Kawaguchi, Y., Inoue, J., Yamamoto-Kawai, M., Aoyama, M., Harada, N., \& Kikuchi, T. (2020). Do strong winds impact water mass, nutrient, and phytoplankton distributions in the ice-free Canada Basin in the fall? Journal of Geophysical Research: Oceans, 125, e2019JC015428. https://doi.org/10.1029/2019JC015428

Okkonen, S., Ashjian, C., Campbell, R. G., \& Alatalo, P. (2019). The encoding of wind forcing into the Pacific-Arctic pressure head, Chukchi Sea ice retreat and late-summer Barrow Canyon water masses. Deep-Sea Research Part II, 162, 22-31. https://doi.org/10.1016/j. dsr2.2018.05.009

Pacini, A., Moore, G. W. K., Pickart, R. S., Nobre, C., Bahr, F., Våge, K., \& Arrigo, K. R. (2019). Characteristics and transformation of Pacific winter water on the Chukchi Sea shelf in late-spring. Journal of Geophysical Research: Oceans, 124, 7153-7177. https://doi. org/10.1029/2019JC015261

Parsons, T. R., Maita, Y., \& Lalli, C. M. (1984). A manual of chemical \& biological methods for seawater analysis. Elsevier. Retrieved from https://linkinghub.elsevier.com/retrieve/pii/C20090077745 
Pickart, R. S., Nobre, C., Lin, P., Arrigo, K. R., Ashjian, C. J., Berchok, C., et al. (2019). Seasonal to mesoscale variability of water masses and atmospheric conditions in Barrow Canyon, Chukchi Sea. Deep-Sea Research Part II Topical Studies in Oceanography, 162, 32-49. https://doi.org/10.1016/j.dsr2.2019.02.003

Pickart, R. S., Schulze, L. M., Moore, G. W. K., Charette, M. A., Arrigo, K. R., van Dijken, G., \& Danielson, S. L. (2013). Long-term trends of upwelling and impacts on primary productivity in the Alaskan Beaufort Sea. Deep-Sea Research Part I Oceanographic Research Papers, 79, 106-121. https://doi.org/10.1016/j.dsr.2013.05.003

Pisareva, M. N., Pickart, R. S., Lin, P., Fratantoni, P. S., \& Weingartner, T. J. (2019). On the nature of wind-forced upwelling in Barrow Canyon. Deep-Sea Research Part II, 162, 63-78. https://doi.org/10.1016/j.dsr2.2019.02.002

Reynolds, R. A., \& Stramski, D. (2019). Optical characterization of marine phytoplankton assemblages within surface waters of the western Arctic Ocean. Limnology \& Oceanography, 64, 2478-2496. https://doi.org/10.1002/lno.11199

Sathyendranath, S., Platt, T., Kovac, Z., DingleJackson, J. T., Brewin, R. J. W., Franks, P., et al. (2020). Reconciling models of primary production and photoacclimation. Applied Optics, 59. https://doi.org/10.1364/AO.386252

Shroyer, E. L., \& Pickart, R. S. (2019). Pathways, timing, and evolution of Pacific Winter Water through Barrow Canyon. Deep-Sea Research Part II, 162, 50-62. https://doi.org/10.1016/j.dsr2.2018.05.004

Slagstad, D., Wassmann, P. F. J., \& Ellingsen, I. (2015). Physical constrains and productivity in the future Arctic Ocean. Frontiers in Marine Science, 2, 85. https://doi.org/10.3389/fmars.2015.00085

Stabeno, P. J., Mordy, C. W., \& Sigler, M. F. (2020). Seasonal patterns of near-bottom chlorophyll fluorescence in the eastern Chukchi Sea: 2010-2019. Deep-Sea Research Part II, 177, 104842. https://doi.org/10.1016/j.dsr2.2020.104842

Stavn, R. H., Rick, H. J., \& Falster, A. V. (2009). Correcting the errors from variable sea salt retention and water of hydration in loss on ignition analysis: Implications for studies of estuarine and coastal waters. Estuarine, Coastal and Shelf Science, 81, 575-582. https://doi. org/10.1016/j.ecss.2008.12.017

Stramski, D., Babin, M., \& Wozniak, S. B. (2007). Variations in the optical properties of terrigenous mineral-rich particulate matter suspended in seawater. Limnology \& Oceanography, 52(6), 2418-2433. https://doi.org/10.4319/lo.2007.52.6.2418

Stroeve, J., \& Notz, D. (2018). Changing state of Arctic sea ice across all seasons. Environmental Research Letters, 13, 103001. https://doi. org/10.1088/1748-9326/aade56

Strom, S. L. (1993). Production of pheopigments by marine protozoa: Results of laboratory experiments analyzed by HPLC. Deep-Sea Research I, 40, 57-80. https://doi.org/10.1016/0967-0637(93)90053-6

Vonk, J. E., Tank, S. E., Bowden, W. B., Laurion, I., Vincent, W. F., Alekseychik, P., et al. (2015). Reviews and syntheses: Effects of permafrost thaw on Arctic aquatic ecosystems. Biogeosciences, 12, 7129-7167. https://doi.org/10.5194/bg-12-7129-2015

Weingartner, T., Aagaard, K., Woodgate, K., Danielson, R., Sasaki, S., \& Cavalieri, D. Y. (2005). Circulation on the north central Chukchi Sea shelf. Deep-Sea Research Part II, 52, 3150-3174. https://doi.org/10.1016/j.dsr2.2005.10.015

Weingartner, T., Fang, Y.-C., Winsor, P., Dobbins, E., Potter, R., Statscewich, H., et al. (2017). The summer hydrographic structure of the Hanna Shoal region on the northeastern Chukchi Sea shelf: 2011-2013. Deep-Sea Research Part II, 144, 6-20. https://doi.org/10.1016/j. dsr2.2017.08.006

Woodgate, R. A. (2018). Increases in the Pacific inflow to the Arctic from 1990 to 2015, and insights into seasonal trends and driving mechanisms from year-round Bering Strait mooring data. Progress in Oceanography, 160,124-154. https://doi.org/10.1016/j.pocean.2017.12.007

Woodgate, R. A., Stafford, K. M., \& Prahl, F. G. (2015). A synthesis of year-round interdisciplinary mooring measurements in the Bering Strait (1990-2014) and the RUSALCA years (2004-2011). Oceanography, 28(3), 46-67. https://doi.org/10.5670/oceanog.2015.57

Wood, K. R., Bond, N. A., Danielson, S. L., Overland, J. E., Salo, S. A., Stabeno, P. J., \& Whitefield, J. (2015). A decade of environmental change in the Pacific Arctic region. Progress in Oceanography, 136, 12-31. https://doi.org/10.1016/j.pocean.2015.05.005

Yamamoto-Kawai, M., McLaughlin, F. A., Carmack, E. C., Nishino, S., Shimada, K., \& Kurita, N. (2009). Surface freshening of the Canada Basin, 2003-2007: River runoff versus sea ice meltwater. Journal of Geophysical Research: Oceans, 114. https://doi. org/10.1029/2008JC005000

Zhang, J., Spitz, Y. H., Steele, M., Ashjian, C., Campbell, R., Berline, L., \& Matrai, P. (2010). Modeling the impact of declining sea ice on the Arctic marine planktonic ecosystem. Journal of Geophysical Research, 115, C10015. https://doi.org/10.1029/2009JC005387 